\title{
Magnesium-Based Materials for Hydrogen Storage-A Scope Review
}

\author{
Agata Baran (D) and Marek Polański *(D) \\ Department of Functional Materials and Hydrogen Technology, Military University of Technology, \\ Kaliskiego 2 Street, 00-908 Warsaw, Poland; agata.baran@wat.edu.pl \\ * Correspondence: marek.polanski@wat.edu.pl
}

Received: 4 July 2020; Accepted: 5 September 2020; Published: 9 September 2020

check for updates

\begin{abstract}
Magnesium hydride and selected magnesium-based ternary hydride $\left(\mathrm{Mg}_{2} \mathrm{FeH}_{6}, \mathrm{Mg}_{2} \mathrm{NiH}_{4}\right.$, and $\mathrm{Mg}_{2} \mathrm{CoH}_{5}$ ) syntheses and modification methods, as well as the properties of the obtained materials, which are modified mostly by mechanical synthesis or milling, are reviewed in this work. The roles of selected additives (oxides, halides, and intermetallics), nanostructurization, polymorphic transformations, and cyclic stability are described. Despite the many years of investigations related to these hydrides and the significant number of different additives used, there are still many unknown factors that affect their hydrogen storage properties, reaction yield, and stability. The described compounds seem to be extremely interesting from a theoretical point of view. However, their practical application still remains debatable.
\end{abstract}

Keywords: hydrogen storage; solid-state hydrogen storage; mechanochemical synthesis; ball milling; mechanical alloying; reactive ball milling; magnesium hydride; magnesium-based hydrides; magnesium ternary hydrides; $\mathrm{Mg}_{2} \mathrm{FeH}_{6} ; \mathrm{Mg}_{2} \mathrm{NiH}_{4} ; \mathrm{Mg}_{2} \mathrm{CoH}_{5}$

\section{Introduction}

In recent decades, the need for new energy carriers has increased [1]. High and still growing worldwide energy consumption [2] (mainly based on fossil fuels) has greatly influenced irreversible global climate change [3]. Thus, the need to expand to new, efficient, and reliable sources of energy has become essential. The greatest challenge is to transform our carbon-based economy to a carbon-free economy [4]. Renewable energy sources are candidates to replace fossil fuels. Unfortunately, they are, to an extent, limited and unevenly distributed. The full exploitation of these energy sources requires an efficient energy carrier and storage system. Hydrogen has been considered for a long time to solve the problems mentioned above and has influenced broad technological investigations involving issues associated with its production, storage, and application [5]. Hydrogen is an almost ideal energy carrier that is considered to be a clean fuel and has the largest gravimetric density of all known chemical substances ( $~ 3$ times higher than that of gasoline) [6]. Moreover, hydrogen is the most abundant element ( $15 \mathrm{~mol} \%$ ) on the surface of the Earth (found in water, biomass and fossil fuels) [7]. The European Commission describes hydrogen as a new energy carrier with "a great potential for clean, efficient power in stationary, portable, and transport applications" [8]. Hydrogen is an important element of the energy chain of alternative energy sources (such as solar, wind, ocean, and geothermal) because of its environmental compatibility and efficiency and because it is thought to be adequate for mobile applications [9]. Hydrogen-fueled transportation started with the Apollo 11 mission to the moon and has continued until today, with hydrogen fuel cell vehicles, trains, and ferries [8]. A hydrogen economy has been developed over the last decades, but despite the billions of dollars spent, the storage problem is still a challenge. Therefore, it is necessary to find a reliable and effective method for hydrogen storage because all of the known solutions have advantages and disadvantages $[10,11]$. 
Solid-state hydrogen storage is a promising option when considering some of its unique features (such as heat evolution during loading and low-pressure filling). This solution is characterized by having the highest volumetric density (higher than that of liquid hydrogen) and, when properly used, is relatively safe [12]. On the other hand, solid-state hydrogen storage is characterized by a rather low energy density per mass unit temperature even without considering the material itself instead of the mass of the system [13]. Solid-state vessels usually do not need to work under high pressure, and hydrogen is released in an endothermic reaction, which, depending on the conditions, material and vessel size, may take from minutes to days [14] due to the extremely low heat conductivity of hydrides, which in real systems remains in the effective range of insulators $(<1 \mathrm{~W} / \mathrm{m} / \mathrm{K})$, even those that are metallic alloys [15]. Not considering low-temperature adsorption on porous materials, solid-state hydrogen storage is based on metal hydrides, intermetallic hydrides, and complex hydrides [16]. These materials are believed to be a safe, risk-free solution and have recently become an alternative to conventional methods [17]. However, many safety issues still have to be solved, as dealing with kilograms of usually very pyrophoric powders can be an issue from a legal point of view in addition to causing engineering problems. There is an abundance of solid-state hydrogen storage materials, but currently, only some are of great importance, e.g., intermetallic $\mathrm{AB}_{5^{-}}, \mathrm{AB}_{2^{-}}$, and $\mathrm{AB}$-type alloys, which are practically used and commercially sold. However, none of the above materials stores more than $2 \%$ hydrogen by weight, which is a very serious drawback in potential mobile applications [18]. On the other hand, most solid-state hydrogen storage materials offer a higher volumetric hydrogen density than liquid hydrogen (at least when lattice density is considered).

One of the most investigated types of materials (mainly due to their relatively high gravimetric capacity) is a group of magnesium-based hydrides, including pure magnesium. Magnesium is a low-density, relatively inexpensive and highly abundant (in the form of different compounds in Earth's crust) metal [19]. In its pure form, magnesium can absorb hydrogen (preferably at $>400{ }^{\circ} \mathrm{C}$ ) at up to $7.6 \mathrm{wt} . \%$, but it has low stability (readily reacting with oxygen, for example) and low hydrogen absorption/desorption kinetics [16]. To date, substantial efforts have been made to examine the optimum desorption pressure and temperature for reactions to take place [20], to improve (or at least better understand) poor cycle life and slow kinetics by doping with catalysts [21,22], and to investigate destabilization [23-26], crystallite size reduction [27-29] and even heavy-ion irradiation effects [30]. Some known compounds $\left(\mathrm{Mg}_{2} \mathrm{NiH}_{4}, \mathrm{Mg}_{2} \mathrm{CoH}_{5}\right.$, and $\left.\mathrm{Mg}_{2} \mathrm{FeH}_{6}\right)$ appear to be interesting alternatives to pure magnesium hydride, creating a compromise between hydrogen capacity by volume or mass and different equilibrium pressures, stability, and costs. The largest hydrogen capacities (by volume) have been observed with compounds of the form $\mathrm{Mg}_{2} \mathrm{TMH}_{\mathrm{x}}(\mathrm{TM}=\mathrm{Ni}, \mathrm{Co}, \mathrm{Fe})$, which also have very high gravimetric capacities (3.6-5.6\%) [31-45]. Among the different methods of energy storage, metal hydride-based materials are also ideal candidates for the future storage of thermal energy due to their capability to store and release substantial amounts of heat at high temperatures. This process can be driven only by slight pressure changes [46]. The successful attempts to synthesize such materials from magnesium and steel (even stainless) waste (scrap) [47-50] suggest that there is a real chance of implementing them as a low-cost storage solution.

A mechanochemical synthesis method that utilizes ball-milled magnesium hydride (with and without additives) and alloying metals has been employed to produce potential hydrogen storage materials with high efficiency. This method of synthesis allows not only the introduction of defects to the material and an increase in hydrogen diffusion but also the direct synthesis of compounds and doping of the materials with catalysts. The number of scientific papers related to magnesium hydride and related compounds since 1951, when magnesium hydride synthesis from pure elements [51] was presented, can easily be counted in the thousands. Recently, several review papers were published in this field, which summarized the issues related to hydrogen storage in this material group. Due to the ongoing investigation of a large number of issues related to these materials, from synthesis method efficiency, reaction mechanisms, and structural characterization to the improvement of reaction kinetics, destabilization, sintering problems, safety issues, scaling up and heat exchange, it would 
be nearly impossible to prepare one review to cover all such subjects. For example, Jain et al. [52] briefly presented magnesium as a hydrogen storage medium. However, they provided only a brief overview and some kinetic problems, while the formation of ternary hydrides was presented as alloying with transition elements only. Additionally, Huot et al. [18], in their very successful work, described the basic properties of $\mathrm{Mg}$ as well as $\mathrm{Mg}_{2} \mathrm{NiH}_{4}, \mathrm{Mg}_{2} \mathrm{FeH}_{6}$, and $\mathrm{Mg}_{2} \mathrm{CoH}_{5}$. However, because this work had a very broad scope and was focused on mechanochemistry, the authors did not provide many details about reaction pathways or other modifications. A very detailed work was provided by Webb [21], who focused mainly on magnesium hydride and additives. However, ternary hydrides were not described. Crivello et al. [53] reviewed the problems related to $\mathrm{MgH}_{2}$, including theoretical explanations and DFT modeling of structure and phase diagrams, methods of $\mathrm{MgH}_{2}$ processing, including not only ball milling (BM), but also more unique techniques (such as severe plastic deformation and plasma-enhanced synthesis), and the behavior of magnesium pellets. In their second review paper [54], they focused mostly on the destabilization reactions and use of alloying elements leading to drastic changes in reaction enthalpy. The effects of both catalytic and destabilizing additives on magnesium hydride were summarized in the review by Wang and Wang [55]. Despite the compactness of the paper, the authors managed to present different types of additives, including organometallic additives. The review of Zhang et al. [56] covered a similar scope but emphasized the nanostructured nature of both additives and substrates. Problems related to nanoconfinement and nanocatalysts were described in detail in their work. A significant number of magnesium-based materials were presented and described in work by Yartys et al. [16], together with their modification, their cycling stability, and a historical overview. An important summary of the recent progress in the field of $\mathrm{Mg}-\mathrm{Fe}-\mathrm{H}$ and $\mathrm{Mg}-\mathrm{Co}-\mathrm{H}$ systems was given by Puszkiel et al. [57], but neither pure magnesium-based materials nor $\mathrm{Mg}$-Ni systems were described in their book chapter.

Each of the recently published reviews addressed magnesium-related problems with great care, putting stress on different aspects. In this scope review, we have chosen magnesium, $\mathrm{Mg}_{2} \mathrm{NiH}_{4}$, $\mathrm{Mg}_{2} \mathrm{FeH}_{6}$ and $\mathrm{Mg}_{2} \mathrm{CoH}_{5}$ (which can sometimes be treated as $\mathrm{MgH}_{2}$ derivatives) since in many cases, these materials coexist or can successfully replace each other in chosen applications due only slight differences in properties. They are also characterized by similar thermodynamics and mechanisms of formation despite having significant differences in behavior and stability. Furthermore, successful replacement of certain elements $(\mathrm{Fe} / \mathrm{Ni} / \mathrm{Co})$ has been performed, resulting in materials with mixed properties $[50,58]$. The real problem is that the large amount of available data "on the market", despite the apparent simplicity of the systems, makes it difficult to distinguish reliable research that expresses new ideas from research that unwittingly replicates old ideas that have already been forgotten. Some of the new papers present physically impossible results that, despite having been published, should be forgotten and not mentioned anymore. In this work, we have focused on the material group with which we have personal experience. On the basis of this experience, we sometimes narratively present some of the issues related to magnesium hydride and the mentioned ternary hydrides, putting stress on the results and issues of great importance while in some cases omitting data that have been published but seem to be redundant with the chosen papers. The main aim of publishing this paper is to help researchers starting work in this field to gain basic knowledge about magnesium-based hydrogen storage materials and to present results that provide a basic overview of the current state of the art in this field. However, it must be strongly stressed that several other important subjects are outside of the scope of this work.

\section{Magnesium Hydride}

Magnesium hydride has several known polymorphs that are thermodynamically stable at different temperatures and pressures, which was experimentally verified by Bastide et al. [59] and later shown by modeling work. Figure 1 shows pressure-temperature phase diagrams for magnesium hydride (and its isotopic analogs) calculated by Moser et al. [60]. Knowledge about the stability of $\mathrm{MgH}_{2}$ phases is crucial in understanding the formation of its polymorphs and may be important in the interpretation of 
experimental data, especially for ball-milled samples. Magnesium hydride exists as an $\alpha-\mathrm{MgH}_{2}$ (with a rutile structure) phase under ambient conditions [61]. Changing the temperature and pressure leads to a phase transformation. High pressure is needed to change $\alpha-\mathrm{MgH}_{2}\left(\mathrm{TiO}_{2}\right)$ to $\beta$ - and $\gamma-\mathrm{MgH}_{2}$ at low temperatures. The transformation of the $\beta-\mathrm{MgH}_{2}$ phase (with a modified $\mathrm{CaF}_{2}$ structure) is possible only at temperatures below $700^{\circ} \mathrm{C}$. Above that temperature, direct transformation from $\alpha-\mathrm{MgH}_{2}$ to $\gamma-\mathrm{MgH}_{2}$ (with an orthorhombic structure similar to that of $\alpha-\mathrm{PbO}_{2}$ ) occurs. From a practical point of view, in hydrogen storage research, only two polymorphs are important. One polymorph (the $\mathrm{TiO}_{2}$ structure) is stable under ambient conditions, and the second, which is metastable (the $\mathrm{PbO}_{2}$-type structure), appears in magnesium hydride processed by BM for a long time [62] due to the high pressure generated by the collisions of balls with the milled material and cylinder walls. The $\gamma$ phase $\left(\gamma-\mathrm{MgH}_{2}\right)$ is a high-pressure polymorphic form of the $\beta-\mathrm{MgH}_{2}$ phase [59]. It is important to note that, over time, and for unknown reasons, the phase names originally given by Bastide et al. [59] changed, which may cause significant confusion to readers. What was originally named the $\alpha$ phase $\left(\mathrm{TiO}_{2}\right.$-type structure) is currently called the $\beta$ phase in most current papers. Fortunately, the $\gamma$ phase still describes the originally named $\gamma$ phase.

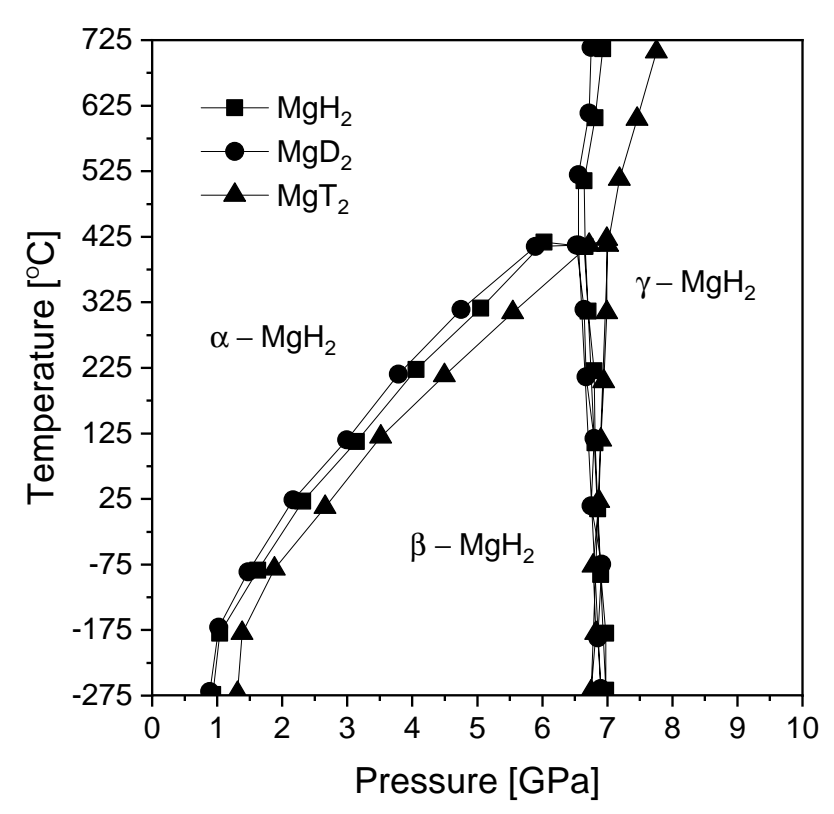

Figure 1. Pressure-temperature $(\mathrm{P}-\mathrm{T})$ phase diagrams for three studied isotopic analogs of magnesium dihydride: $\mathrm{MgH}_{2}, \mathrm{MgD}_{2}$, and $\mathrm{MgT}_{2}$. The graph was prepared based on [56,59].

Magnesium hydride $\left(\mathrm{MgH}_{2}\right)$ is widely investigated due to its relatively high gravimetric and volumetric densities ( $\rho_{\mathrm{m}}=7.6 \mathrm{wt} . \% \mathrm{H}$ and $\rho_{\mathrm{V}}=0.11 \mathrm{~kg} \mathrm{H} / \mathrm{dm}^{3}$, respectively). Its dissociation enthalpy was first measured by Stampfer et al. [20] based on decomposition pressure measurements between 314 and $576{ }^{\circ} \mathrm{C}$. Due to its high enthalpy of formation, $\mathrm{MgH}_{2}$ is considered a stable hydride. Figure 2 presents the dependence of the decomposition plateau pressure on temperature for magnesium hydride. The graph was prepared based on data obtained from Stampfer's measurements [20]. From this graph, a temperature of $285^{\circ} \mathrm{C}$ was estimated to be required to desorb hydrogen at a pressure of one bar $(0.1 \mathrm{MPa})$ (usually, desorption at that temperature is very difficult to achieve in noncatalyzed systems due to very slow kinetics). 


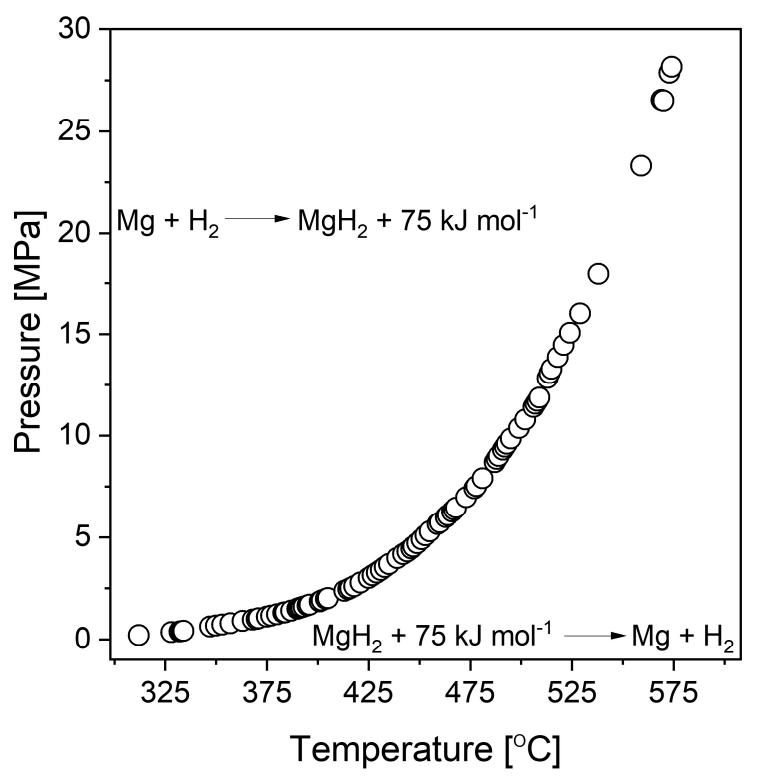

Figure 2. Temperature dependence of the $\mathrm{MgH}_{2}$ dissociation pressure. The graph was prepared based on data from Stampfer et al. [20].

The high thermodynamic stability of $\mathrm{MgH}_{2}$ is a serious drawback, but technological and practical issues also make studies on this material difficult. Even now, tens of years after the first synthesis was achieved in 1951 by Wiberg et al. [51], it is difficult to find commercial magnesium hydride with a purity of more than $90 \%$ (despite the official specifications given by manufacturers). Instead, magnesium hydride is usually a mixture of magnesium hydride, magnesium metal, and magnesium hydroxide contamination. Moreover, the hydroxide is usually present in the form of an amorphous layer on the surface of the particles, making it very difficult to observe (for example, by X-ray diffraction (XRD)), while magnesium is present in the core of the particles. These observations result in the measured amount of unreacted metal being low due to the weak diffraction obtained from the "hidden" magnesium. Figure 3a shows a cross-section of commercially available magnesium hydride particles. The proper choice of scanning electron microscopy (SEM) parameters and ion milling allows the differences in the atomic mass densities of $\mathrm{MgH}_{2}$ and $\mathrm{Mg}$ to be observed, which are usually not easy to observe. Notably, magnesium metal in its pure form (which likely does not react with hydrogen during the synthesis process) can be found inside larger particles, and thus its amount can hardly be called negligible, despite the fact that the analyzed sample was a commercial product (Alfa Aesar, Haverhill, MA, USA). The presence of hydroxide, on the other hand, can usually be observed only with the use of thermogravimetric analysis (TGA). An investigative analysis performed in our laboratory on a commercially available material showed that the significant mass losses $(\sim 0.2 \%)$ that were observed were related to the release of -OH groups from hydroxides, while almost no noticeable heat effect could be seen from the differential scanning calorimetry (DSC) curve obtained at the same time (Figure $3 b$ ). Also the maximum capacity is far from the theoretical one, and the show example is one of the best results obtained for commercially available $\mathrm{MgH}_{2}$. In practice, it is very difficult to convert magnesium to magnesium hydride below $350{ }^{\circ} \mathrm{C}$, even when the magnesium is in the form of very fine powder (again, due to slow kinetics). In the case of coarser particles (a coarse powder or turnings), such conversion is almost impossible, even at a much higher temperature and pressure, due to the formation of a hydride layer on the outside, preventing the reaction from occurring throughout the whole volume of the particle $[63,64]$. Thus, a two-step synthesis was developed to transform the remaining sample volume into the metal hydride. The main scientific goal was to decrease the practical absorption and desorption temperatures while maintaining the same volumetric and gravimetric densities. 


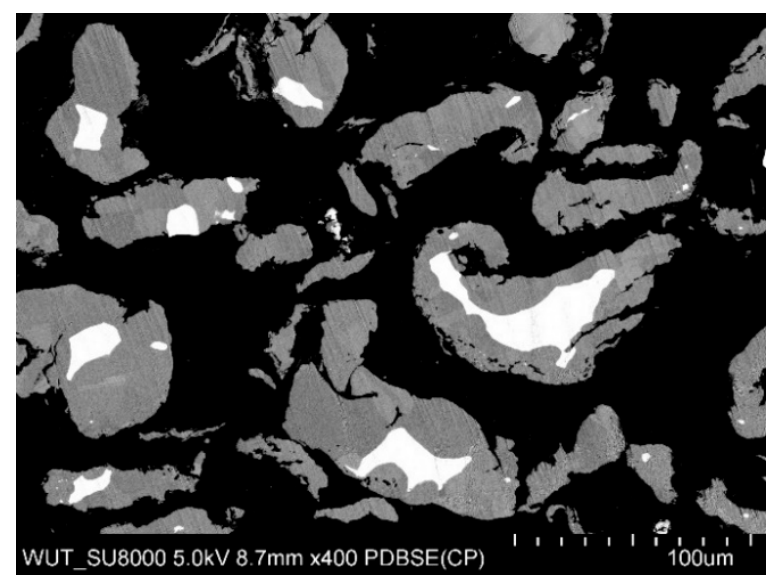

(a)

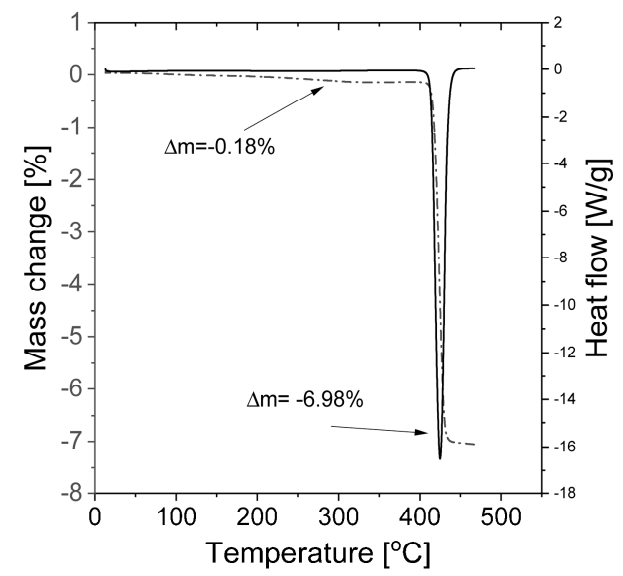

(b)

Figure 3. (a) Cross-section of commercially available magnesium hydride particles with visible white magnesium cores; $\mathrm{MgH}_{2}$ supplied by Alfa Aesar (photo taken at Warsaw University of Technology by dr Tomasz Płociński). (b) TGA/DSC curve for commercial $\mathrm{MgH}_{2}$.

Much effort has been made to overcome problems associated with synthesis outcomes, which are related to the previously discussed poor reaction kinetics of hydrides. The main approach for changing the sorption behavior of a hydride without decreasing its hydrogen capacity involves decreasing the grain or crystallite size. The grain size effect and the role of surface modifications (surface activity, oxide layer penetration, diffusion rate of hydrogen, and mobility of metal-hydride interfaces) on the sorption characteristics of hydrides were shown for the first time by Zaluska et al. [28]. The conducted research was inspired by previous attempts related to powder absorption $[64,65]$. The fabricated magnesium powders had a similar particle size, but the grain size (or better, crystallite size) inside the particles was different. Thus, a nanocrystalline structure combined with surface modification was shown to greatly improve the hydrogenation and dehydrogenation rates. Over time, more research has been devoted to this issue $[27,29,62,66]$. Following the idea of lowering the size of crystallites and particles, Nielsen et al. investigated $\mathrm{MgH}_{2}$ nanocluster confinement within nanoporous aerogel scaffolds [67]. Additionally, a broad review was written to organize the knowledge about nanoconfined hydrides for energy storage [68]. Later, Kim et al., in their theoretical work [69] based on the Wulff construction, predicted the influence of nanoparticle size on the thermodynamics of hydrogen release. Their research suggested that destabilization of the hydride phase was possible with a decrease in particle size. In most of the considered cases, the desorption temperature should decrease slightly upon reducing the particle size, but these changes were relatively small in comparison with the properties of the bulk material. Practical attempts were presented by Paskevicius et al. [70] and Zhao-Karger [71]. A decrease in particle size (down to the nanometer scale) led to a decrease in the hydrogenation/dehydrogenation energy (lower values of enthalpy and entropy) for the nanoconfined system compared with that of the bulk material. As a result of thermodynamic destabilization, the $0.1 \mathrm{MPa}$ hydrogen equilibrium temperature decreased by $\sim 6^{\circ} \mathrm{C}$ or even $11^{\circ} \mathrm{C}$. Thus, the thermodynamics of smaller nanoparticles were dominated by changes in the enthalpy of the reaction. Hence, the temperature reduction was smaller than theoretically predicted [70]. This decrease in hydrogen desorption energy has been predicted to work only for relatively small clusters $\left(\mathrm{MgH}_{2}\right.$ crystallite sizes of $\left.\sim 1.3 \mathrm{~nm}\right)$ [72]. It is worth mentioning that for particles, only the crystallite size, not the grain size, should be small. The thermodynamic stability of $\mathrm{MgH}_{2}$ with respect to that of $\mathrm{Mg}+\mathrm{H}_{2}$ as a function of crystal grain size was investigated by Wagemans et al. [72]. Their calculations showed that $\mathrm{MgH}_{2}$ became less stable than $\mathrm{Mg}$ as the cluster size decreased. Small clusters needed less desorption energy, which led to a low hydrogen desorption temperature. Quantum Monte Carlo simulations were performed by Wu et al. [73] to verify experimental data and estimate the nanoparticle size with the most beneficial desorption temperature. Unfortunately, it turned out that explaining the experimentally observed 
nanoscale effects in metal hydrides required more information than just the cluster size. Therefore, the authors suggested that the specific chemical environment of the nanoparticles played a crucial role in terms of hydride destabilization. Recently, some experimental works confirmed this theoretical prediction after successful syntheses of $\mathrm{MgH}_{2}$ nanoclusters, e.g., by using an immiscible system (Mg-Ti) as a precursor [74]. Magnesium nanoclusters were also synthesized by Huang. However, the authors did not show a difference in the decomposition enthalpy (what should be expected), but rather focused on the decomposition kinetics [75].

\section{1. $\mathrm{MgH}_{2}$ Synthesis/Mechanical Modifications}

Mechanochemical synthesis or milling allows the production of magnesium hydride with or without additives $[18,76]$ by reactive ball milling (RBM), which is basically BM in a hydrogen atmosphere, or by simply BM in an inert atmosphere, respectively. These are the most common techniques used for the production of many metal hydrides. In the case of RBM, the balls (the most commonly used balls are made of steel or tungsten carbide) are placed together with metallic particles in a pressurized vial of hydrogen, and their high-energy impact results in the fracture and cold-welding of the metallic particles while also reacting to hydrogen. BM in an inert atmosphere is conducted without pressurizing the vial with hydrogen. Thus, chemically produced magnesium hydride must be used for modification by BM. Both techniques help to reduce the particle and crystallite size and to induce $\gamma$ phase (high-pressure polymorph) formation. BM requires the use of a proper combination of parameters, namely the type of ball mill, ball-to-powder ratio, milling time, speed, temperature, and hydrogen pressure $[18,29,77]$. Slight modification of even one parameter results in a material with different properties. All of these factors make a comparison of all published research complicated since, in most cases, there may not be even a single common parameter among different experiments. In many cases, the experiments are not described extensively enough to be replicated, but BM in general leads to an improvement in hydride properties (mainly a decrease in sorption temperature). This improvement is the reason why this method is still an attractive way of producing $\mathrm{MgH}_{2}$.

\subsection{Ball Milling}

The dissociation of hydrogen molecules occurs on the surface of the metal. For this reason, in the first stages, absorption is determined by the hydrogen dissociation activity [78]. It is known that pure $\mathrm{Mg}$ chemisorption is rather slow [79]. Moreover, as the reaction progresses, a hydride layer grows on the metal surface, and the ability to diffuse through this layer becomes limited [64,78]. $\mathrm{BM}$ helps to improve the reaction. The surface area increases because micro- or even nanostructures form, and defects are introduced. A high number of defects provides different hydriding properties and behaviors [28]. Therefore, changing the alloy composition, surface features, or technological parameters during BM helps to control the material properties, such as the reaction kinetics and storage capacity [80]. The first attempt of pure $\mathrm{MgH}_{2}$ synthesis by BM was conducted by Strom-Olsen with Zaluski and Zaluska [81]. The research was inspired by previous synthesis attempts (mostly involving the synthesis of $\mathrm{Mg}_{2} \mathrm{Ni}$, but also $\mathrm{MgH}_{2}$, by RBM) [82-84]. This synthesis was a two-step method: first, magnesium powder was ball milled in argon, and then, the material was hydrogenated in a gas titration system at a hydrogen pressure of $1 \mathrm{MPa}$ and $310^{\circ} \mathrm{C}$. Improvements in powder morphology and surface activity were noticed during hydrogenation. Moreover, no traces of unreacted magnesium were found. The enhanced kinetics (the first dehydrogenation occurred between 270 and $280{ }^{\circ} \mathrm{C}$, and a hydrogen capacity of almost $7 \mathrm{wt}$ \% was reached during the subsequent hydrogenation) remained unaltered even after 15 cycles. The results showed that with changes in milling time, the onset temperatures of desorption significantly decreased. The onset of desorption from the hydride can be seen in the DSC graphs of measurements obtained at a heating rate of $40^{\circ} \mathrm{C} / \mathrm{min}$ (Figure 4). Significant differences are evident even for such high heating rates. Upon reducing the average crystallite size (indicated by Bragg peak broadening in XRD plots), the desorption energy decreased, and the desorption temperature dropped by as much as $100{ }^{\circ} \mathrm{C}$. Moreover, the desorption peak shifted by approximately $30-50{ }^{\circ} \mathrm{C}$. 


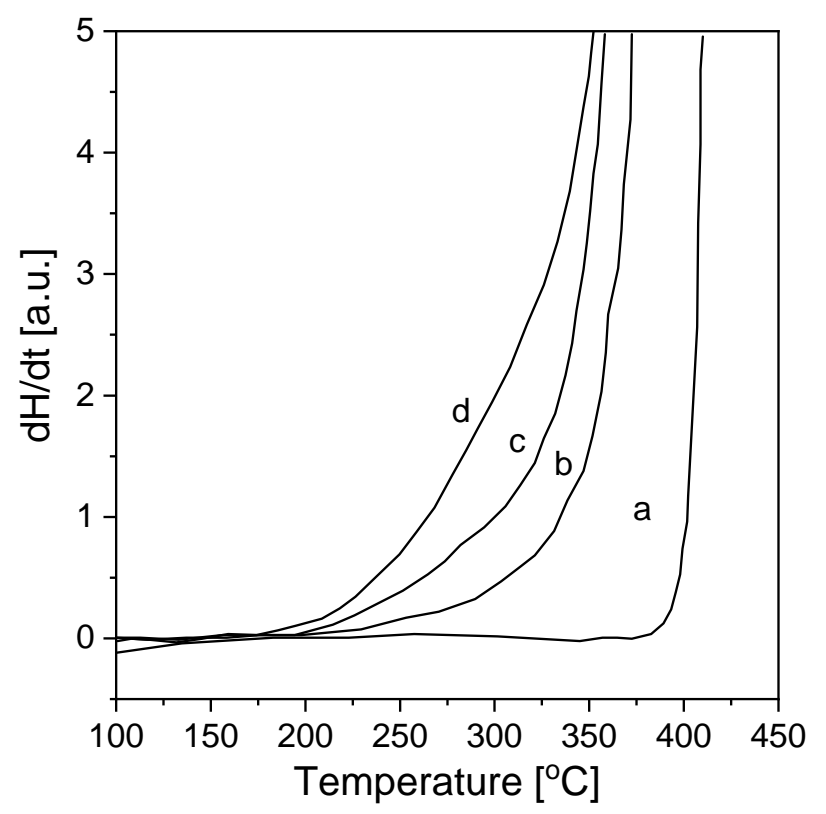

Figure 4. Onset sections of the DSC curves of $\mathrm{MgH}_{2}$ desorption after BM for different periods of time: (a) initial magnesium hydride, (b) after BM for 2 min, (c) after BM for $7 \mathrm{~min}$, and (d) after BM for 9 min. The graph was prepared based on data from [81]. The DSC plots were obtained with a heating rate of $40^{\circ} \mathrm{C} / \mathrm{min}$.

Using pure $\mathrm{Mg}$ for hydrogen storage has drawbacks-the material needs to be activated. To perform initial hydrogenation, the Mg must be exposed to hydrogen at a higher temperature and pressure than is required for subsequent normal operation. Nevertheless, the absorption and desorption kinetics can still be rather slow. Since modifying the magnesium hydride decomposition enthalpy is nearly impossible (except in the case of so-called destabilization, which will be described later), the main goal is to improve the decomposition and formation kinetics of $\mathrm{MgH}_{2}$. Fast hydrogenation kinetics directly lead to the possibility of a short refilling time for hydrogen storage tanks (if proper heat exchange conditions are fulfilled). Therefore, some research has concentrated on metal additives, and several attempts have been made to study the influence of metal oxides or additives on hydrides. Studies have shown the effects of using both metal oxides and additives. Table 1 presents selected research results and the basic sorption properties of BM-synthesized Mg-based hydrides. From the studies presented below, it is clear that the reaction kinetics have improved as a result of using different catalysts. Hence, the desorption temperatures have decreased. What is even more clear from the table is that the experimental conditions used in the literature are very different from each other. This variation makes it very difficult to compare reported values, practically making a comparison impossible other than just qualitatively. The observed maximum hydrogen capacities should also be treated very carefully, given that the maximum capacities range from $3.5 \%$ to $7 \%$ for no real physical reason, assuming that the amount of catalyst was not $50 \%$ by weight in some cases. A deeper look at the experimental conditions used in the selected research will reveal further differences in sample mass, gas purities, etc. 
Table 1. Catalytic effect of different additives on the properties of some BM-synthesized Mg-based hydrides.

\begin{tabular}{|c|c|c|c|c|c|c|c|}
\hline Material & $\begin{array}{l}\text { Temperature } \\
\left({ }^{\circ} \mathrm{C}\right)\end{array}$ & $\begin{array}{l}\text { Pressure } \\
\text { (MPa) }\end{array}$ & $\underset{\text { (wt. } \%)}{\operatorname{Max} . \mathrm{H}_{2}}$ & $\begin{array}{l}\text { Approx. Absorption } \\
\text { Time (s) }\end{array}$ & $\begin{array}{l}\text { Approx. Desorption } \\
\text { Time (s) }\end{array}$ & Reference & Remarks \\
\hline $\mathrm{MgH}_{2}$ & $\begin{array}{l}\mathrm{T}_{\mathrm{abs}}=200 \\
\mathrm{~T}_{\text {des }}=300\end{array}$ & $\begin{array}{c}\mathrm{p}_{\mathrm{abs}}=1 \\
\mathrm{p}_{\mathrm{des}}=0.015\end{array}$ & 4.7 & 1000 & 1000 & \multirow{6}{*}{ [85] } & \multirow{6}{*}{$\begin{array}{l}\text { Kinetics curves of the samples measured on the } \\
\text { third cycle }\end{array}$} \\
\hline $\mathrm{MgH}_{2}-5$ at. $\% \mathrm{Ti}$ & $\begin{array}{l}\mathrm{T}_{\mathrm{abs}}=200 \\
\mathrm{~T}_{\text {des }}=300\end{array}$ & $\begin{array}{c}\mathrm{p}_{\mathrm{abs}}=1 \\
\mathrm{p}_{\mathrm{des}}=0.015\end{array}$ & 5.0 & 50 & 200 & & \\
\hline $\mathrm{MgH}_{2}-5$ at. $\% \mathrm{~V}$ & $\begin{array}{l}\mathrm{T}_{\text {abs }}=200 \\
\mathrm{~T}_{\text {des }}=300\end{array}$ & $\begin{aligned} p_{\mathrm{abs}} & =1 \\
\mathrm{p}_{\mathrm{des}} & =0.015\end{aligned}$ & 5.5 & 50 & 300 & & \\
\hline $\mathrm{MgH}_{2}-5$ at. $\% \mathrm{Mn}$ & $\begin{array}{l}\mathrm{T}_{\mathrm{abs}}=200 \\
\mathrm{~T}_{\text {des }}=300\end{array}$ & $\begin{array}{c}\mathrm{p}_{\mathrm{abs}}=1 \\
\mathrm{p}_{\mathrm{des}}=0.015\end{array}$ & 6.0 & 200 & 500 & & \\
\hline $\mathrm{MgH}_{2}-5$ at. $\% \mathrm{Fe}$ & $\begin{array}{l}\mathrm{T}_{\text {abs }}=200 \\
\mathrm{~T}_{\text {des }}=300\end{array}$ & $\begin{aligned} p_{\text {abs }} & =1 \\
p_{\text {des }} & =0.015\end{aligned}$ & 4.3 & 200 & 300 & & \\
\hline $\mathrm{MgH}_{2}-5$ at. $\% \mathrm{Ni}$ & $\begin{array}{l}\mathrm{T}_{\mathrm{abs}}=200 \\
\mathrm{~T}_{\text {des }}=300\end{array}$ & $\begin{array}{c}\mathrm{p}_{\mathrm{abs}}=1 \\
\mathrm{p}_{\mathrm{des}}=0.015\end{array}$ & 4.7 & 1000 & 400 & & \\
\hline $\mathrm{MgH}_{2}+\left(\mathrm{Cr}_{2} \mathrm{O}_{3}\right)_{0.05}$ & $\mathrm{~T}_{\mathrm{abs}}=300$ & $\mathrm{p}_{\mathrm{abs}}=1.5$ & 4.02 & 600 & \multirow{4}{*}{$\begin{array}{c}\text { Only absorption } \\
\text { kinetics was } \\
\text { measured }\end{array}$} & \multirow{4}{*}{ [86] } & \multirow{4}{*}{ High-energy BM } \\
\hline $\mathrm{MgH}_{2}+\left(\mathrm{V}_{2} \mathrm{O}_{5}\right)_{0.05}$ & $\mathrm{~T}_{\mathrm{abs}}=250$ & $\mathrm{p}_{\mathrm{abs}}=1.5$ & 3.2 & 600 & & & \\
\hline $\mathrm{MgH}_{2}+\left(\mathrm{Al}_{2} \mathrm{O}_{3}\right)_{0.05}$ & $\mathrm{~T}_{\mathrm{abs}}=300$ & $\mathrm{p}_{\mathrm{abs}}=1.5$ & $\begin{array}{l}4.09 \\
4.49 \\
\end{array}$ & $\begin{array}{c}600 \\
4000 \\
\end{array}$ & & & \\
\hline $\mathrm{MgH}_{2}+\left(\mathrm{Fe}_{2} \mathrm{O}_{3}\right)_{0.05}$ & $\mathrm{~T}_{\mathrm{abs}}=300$ & $\mathrm{p}_{\mathrm{abs}}=1.5$ & $\begin{array}{l}1.37 \\
3.53\end{array}$ & $\begin{array}{c}600 \\
5000\end{array}$ & & & \\
\hline Nano $-\mathrm{MgH}_{2}$ & $\mathrm{~T}_{\mathrm{abs}}=300$ & $\mathrm{p}_{\mathrm{abs}}=0.8$ & 5.97 & 178 & \multirow{4}{*}{$\begin{array}{c}\text { Only absorption } \\
\text { kinetics was } \\
\text { modeled }\end{array}$} & \multirow{4}{*}{ [87] } & \multirow{4}{*}{$\begin{array}{l}\text { Modeling of the hydriding kinetic properties of } \\
\text { a nanocomposite }\end{array}$} \\
\hline $\mathrm{MgH}_{2}+\left(\mathrm{Cr}_{2} \mathrm{O}_{3}\right)_{0.05}$ & $\mathrm{~T}_{\mathrm{abs}}=300$ & $\mathrm{p}_{\mathrm{abs}}=0.8$ & 4.64 & 32 & & & \\
\hline $\mathrm{MgH}_{2}+\left(\mathrm{V}_{2} \mathrm{O}_{5}\right)_{0.05}$ & $\mathrm{~T}_{\mathrm{abs}}=300$ & $\mathrm{p}_{\mathrm{abs}}=0.8$ & 4.07 & 39 & & & \\
\hline $\mathrm{MgH}_{2}+\left(\mathrm{Fe}_{2} \mathrm{O}_{3}\right)_{0.05}$ & $\mathrm{~T}_{\mathrm{abs}}=300$ & $\mathrm{p}_{\mathrm{abs}}=0.8$ & 4.31 & 35 & & & \\
\hline $\mathrm{MgH}_{2}+0.5$ mol. $\% \mathrm{Nb}_{2} \mathrm{O}_{5}$ & $\begin{array}{l}\mathrm{T}_{\text {abs }}=250 \\
\mathrm{~T}_{\text {des }}=300\end{array}$ & $\begin{array}{l}\mathrm{p}_{\text {abs }}=0.84 \\
\mathrm{p}_{\text {des }}=0.84\end{array}$ & 7.0 & 60 & 90 & [88] & $\begin{array}{l}\mathrm{MgH}_{2} \text { ball milled for } 20 \mathrm{~h} \text { and later combined } \\
\text { with } \mathrm{Nb}_{2} \mathrm{O}_{5}\end{array}$ \\
\hline $\mathrm{MgH}_{2}+1$ mol. $\% \mathrm{Nb}_{2} \mathrm{O}_{5}$ & $\begin{array}{l}\mathrm{T}_{\text {abs }}=150 \\
\mathrm{~T}_{\text {des }}=160\end{array}$ & $\begin{array}{l}\mathrm{p}_{\mathrm{abs}}=0.1 \\
\mathrm{p}_{\mathrm{des}}=0.1\end{array}$ & 6 & 30 & 60,000 & [89] & $\begin{array}{l}\text { Desorption in a purified helium flow } \\
\text { atmosphere with zero hydrogen partial pressure }\end{array}$ \\
\hline $\mathrm{MgH}_{2}+1$ mol. $\% \mathrm{La}_{2} \mathrm{O}_{3}$ & $\begin{array}{l}\mathrm{T}_{\text {abs }}=300 \\
\mathrm{~T}_{\text {des }}=300\end{array}$ & $\begin{array}{r}\mathrm{p}_{\mathrm{abs}}=0.3 \\
\mathrm{p}_{\mathrm{des}}=0.03\end{array}$ & 6.0 & 100 & 430 & [90] & Samples annealed at different temperatures \\
\hline
\end{tabular}




\subsubsection{Nanostructurization}

It was shown in [91] that milling brittle $\mathrm{MgH}_{2}$ was more effective than milling pure magnesium powder (which is relatively ductile) due to combining a nanocrystalline structure with a high surface area. It was observed that mechanical deformation produced similar structural transformations to those obtained with high static pressure (in the range of $8 \mathrm{GPa}$ ). The hydrogen absorption rate of $\mathrm{Mg}$-based alloys also increased with milling time. The examined material absorbed $7 \mathrm{wt} . \% \mathrm{H}_{2}$ at $300^{\circ} \mathrm{C}$, and the same amount was desorbed at $350{ }^{\circ} \mathrm{C}$ (within 400 and $600 \mathrm{~s}$, respectively).

In terms of nanostructurization conducted by mechanochemical methods, the influence of milling equipment on hydrogen sorption properties is crucial. It was proven in [92] that there was no significant difference between $\mathrm{MgH}_{2}$ samples milled in commonly used ball mills but that planetary mills appeared to be more productive than other types of mills (Figure 5). BM led to an improvement in the absorption and desorption kinetics, with only a small difference observed in the maximum hydrogen capacity when comparing different mills. It was suggested that high-energy BM had a great impact on hydriding/dehydriding properties due to the effect of reducing the particle and crystallite size (increasing the specific surface area), even when BM was performed in an argon atmosphere.

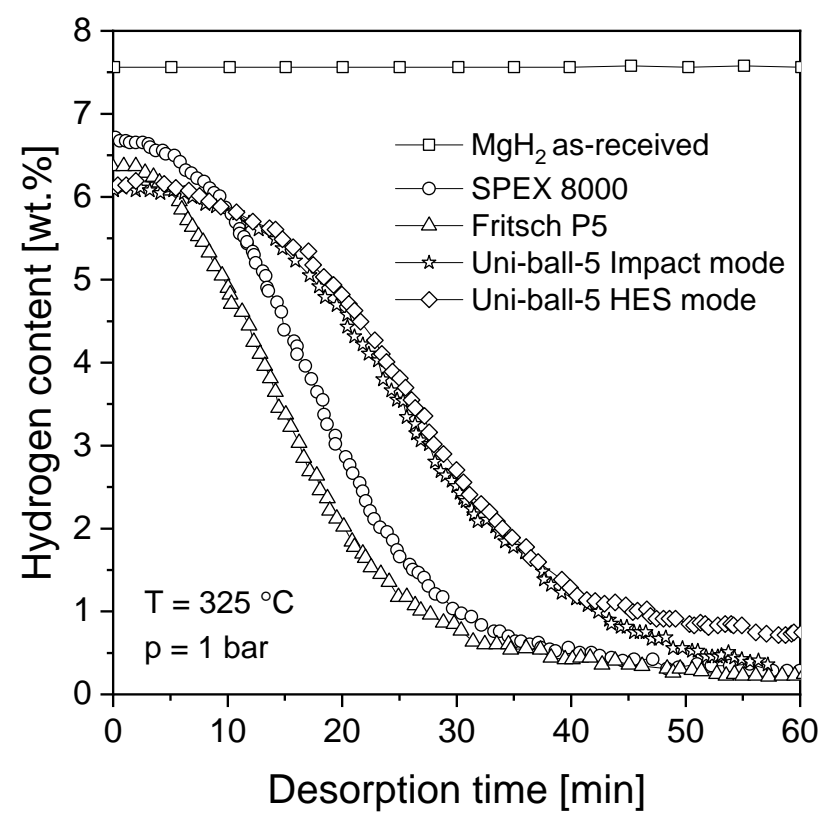

Figure 5. Desorption kinetics of nanocrystalline $\mathrm{MgH}_{2}$ ball milled for $20 \mathrm{~h}$ in different types of ball mills. The graph is based on [92].

Comparisons between milled and unmilled $\mathrm{MgH}_{2}$ were provided by Huot et al. [80] (Figure 6) and by Vitorri Antisari et al. [93]. The sorption kinetics were found to be much faster for milled samples than unmilled samples. Milled hydride had better reaction kinetics and a lower activation energy. The ball-milled $\mathrm{MgH}_{2}$ desorption temperature was $64^{\circ} \mathrm{C}$ lower than that measured for the unmilled sample [80]. Both the absorption and desorption of ball-milled magnesium hydride occurred at low temperatures and were much more rapid than those of unmilled magnesium hydride. Additionally, a 10-fold increase in specific surface area was observed after the BM technique was introduced, which was related to the results obtained by Schulz et al. [92]. The BM sample fully absorbed hydrogen at $300^{\circ} \mathrm{C}$ and desorbed hydrogen at $350^{\circ} \mathrm{C}$ at a relatively high rate. On the other hand, no significant change in storage capacity and no influence of $\mathrm{BM}$ on the thermodynamic properties of the obtained hydride were noticed. Therefore, improved kinetics are connected with the introduction of defects, a small particle size, and an increased specific surface area. These results prove that BM has advantages over other techniques in terms of kinetics, but fortunately does not significantly change the storage capacity of the material. 


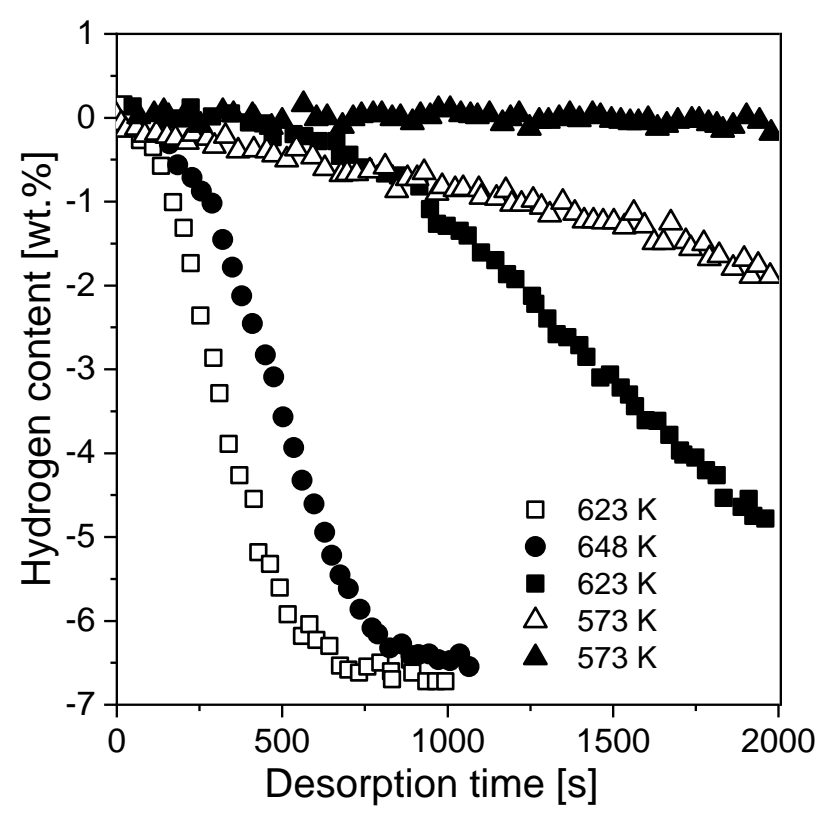

Figure 6. Hydrogen desorption curves of unmilled (solid symbols) and ball-milled (open symbols) $\mathrm{MgH}_{2}$ at $0.015 \mathrm{MPa}$ hydrogen pressure. The graph was plotted using data from [80].

\subsubsection{Metal Additives}

It is well known that the introduction of even a small amount of metal additives can significantly improve the hydrogen absorption and desorption kinetics of magnesium. The most popular metal catalysts are transition metals, e.g., $\mathrm{Al}, \mathrm{Fe}, \mathrm{Cu}, \mathrm{Pd}, \mathrm{Ni}, \mathrm{V}, \mathrm{Nb}, \mathrm{Ti}, \mathrm{Mn}$, and $\mathrm{Cr}$ (synthesized together with Mg by BM and RBM techniques) [85,94-104]. However, recently, some alkali metals have also been used [105]. Vitorri Antisari et al. [93] showed a correlation between experimental results and a model describing the role of Fe catalyst particles in the nucleation step in the $\mathrm{MgH}_{2}$ reaction. The addition of Fe through the use of BM caused a significant increase in particle density with nucleation at the metal particles and in the bulk material. The newly formed structural defects acted as nucleation sites, exhibiting increased nucleation rates with increasing defect density. Hence, the reaction mechanism remained unaffected, but the rate of hydrogen desorption changed, thus proving that a surface catalyst could accelerate the reaction process. The cycle stability of hydrogen absorption/desorption and the hydrogen desorption activation energy were proven to be influenced by a vanadium additive $[97,106]$. Liang et al. [85] synthesized $\mathrm{MgH}_{2}-5 \mathrm{~mol} \% \mathrm{TM}(\mathrm{TM}=\mathrm{Ti}, \mathrm{V}, \mathrm{Mn}, \mathrm{Fe}, \mathrm{Ni})$ and showed that $\mathrm{MgH}_{2}$ ball milled with these five transition metals possessed superior hydrogen storage properties in terms of reaction kinetics. The addition of $\mathrm{Ti}$ increased the hydrogen absorption rate. $\mathrm{V}, \mathrm{Fe}, \mathrm{Mn}$, and Ni were also beneficial in terms of desorption properties. Thus, different elements were profitable in different temperature ranges (e.g., the $\mathrm{MgH}_{2}$ - $\mathrm{Ti}$ composite exhibited good properties in the $250-300{ }^{\circ} \mathrm{C}$ range, and the range for $\mathrm{MgH}_{2}-\mathrm{V}$ extended up to $200^{\circ} \mathrm{C}$ ). Later, Liang et al. [107] proved that the superior hydrogen desorption properties were caused by vanadium particles and their strong affiliation with hydrogen. Pelletier et al. [108] found that during $\mathrm{BM}$ of a $\mathrm{MgH}_{2}-\mathrm{Nb}$ composite, the $\mathrm{NbH}_{0.6}$ phase (solid solution of a metallic hydride) was formed, and the niobium atoms created a structure with vacancies, thereby providing "channels" for hydrogen to flow into the sample.

Kinetic analysis together with practical BM was also conducted by Antisari et al. [93]. Pure $\mathrm{MgH}_{2}$ powder was ball milled for $10 \mathrm{~h}$ at $0.6 \mathrm{MPa}$ argon pressure. Metallographic observations proved that structural defects enhanced the reaction of $\mathrm{Mg}$ with $\mathrm{H}_{2}$. Although the authors stated that the $\mathrm{MgH}_{2}$ particle density increased with the density of structural defects caused by BM, this result is quite unlikely even from a physical point of view (unless the defects are only interstitial atoms, which is usually not the case). The same research studied the influence of a Fe additive on the hydride, which resulted in a further increase in particle density. Thus, defects were proven to behave like 
nucleation sites and speed up the phase transformation rate. The paper showed the role of a catalyst on hydrogen absorption and desorption kinetics and suggested that surface catalysis can speed up hydrogen absorption and desorption.

Likely inspired by Reilly and Wiswall [31], whose research suggested the possibility of using $\mathrm{Mg}_{2} \mathrm{Ni}$ as a catalyst for $\mathrm{MgH}_{2}$ formation, Huot et al. [82] performed $\mathrm{MgH}_{2}$ synthesis with a nickel catalyst. Both hydrogen and argon atmospheres were used during the experiment (the RBM process in that paper is broadly described in the following chapters). When milling a $2 \mathrm{Mg}+\mathrm{Ni}$ mixture in an argon atmosphere, the presence of intermetallic $\mathrm{Mg}_{2} \mathrm{Ni}$ was noted. This phase had an influence on the decomposition temperature (which increased by approximately $40{ }^{\circ} \mathrm{C}$ ) and on the decomposition rate. The abovementioned examples should only suggest to the reader the possible effects of the tested metal additives in terms of improving the kinetics of $\mathrm{MgH}_{2}$ synthesis and decomposition. However, it must be noted that almost all existing metallic metals have been tried in this context, and describing those trials is far beyond the scope of this work.

\subsubsection{Intermetallic Additives}

A high hydrogen sorption capacity, low desorption temperature, and better kinetics are general effects of the addition of intermetallic compounds, mainly in La-Ni, ZrNi, ZrMn, and Mg-Ni systems [109-114]. Zhou and Ren et al. performed an experiment to examine the effect of Ti and V intermetallic compounds on hydrogen storage properties $[115,116]$. The lowest desorption temperature was noted for magnesium with added $\mathrm{TiMn}_{2}$, but the system had improved absorption kinetics at room temperature while also retaining a high hydrogen storage capacity. $\mathrm{A} \mathrm{MgH}_{2}-50 \% \mathrm{ZrNi}$ compound showed $2.6 \mathrm{wt}$. $\%$ hydrogen desorption at $\sim 275{ }^{\circ} \mathrm{C}$ [113]. The authors proposed that a cooperative dehydriding mechanism took place due to elastic interactions at the $\mathrm{MgH}_{2} / \mathrm{ZrMn}_{2} \mathrm{H}_{\mathrm{x}}$ interface.

Liang et al. [117] mechanically alloyed pure $\mathrm{Mg}$ with $\mathrm{LaNi}_{5}$ in an argon atmosphere. It was shown that the nanocomposite was not stable during hydrogenation. Thus, it transformed into a mixture of $\mathrm{Mg}+\mathrm{LaH}_{\mathrm{x}}+\mathrm{Mg}_{2} \mathrm{Ni}$ and influenced the kinetics of the reaction. As a consequence, even $4.1 \mathrm{wt} . \%$ hydrogen was absorbed at an elevated temperature for $250 \mathrm{~s}$, while $2.5 \mathrm{wt} . \%$ hydrogen was absorbed at room temperature for $500 \mathrm{~s}$ (with Mg-50 wt.\% Ni hydride). Hence, even at room temperature, good absorption kinetics were recorded. The absorption curves of the composite for different pressure values are presented in Figure 7. According to the authors, the fast absorption kinetics at room temperature could be a result of the hydrogen pressure (but only up to $1.5 \mathrm{MPa}$; nothing changed above that pressure) and temperature. Moreover, the absorption kinetics were highly sensitive to both phases, i.e., $\mathrm{Mg}_{2} \mathrm{Ni}$ and lanthanum hydride, which acted as catalysts for magnesium hydrogenation. The fast diffusion of hydrogen through phase boundaries and nanocrystalline $\mathrm{Mg}_{2} \mathrm{Ni}$ was beneficial to the absorption kinetics. The hydrogen storage properties were influenced by the $\mathrm{Mg}$ to $\mathrm{Mg}_{2} \mathrm{Ni}$ and lanthanum hydride ratio. An optimum $\mathrm{Mg}$ to $\mathrm{Mg}_{2} \mathrm{Ni}$ and lanthanum hydride ratio was crucial in the context of hydrogen storage properties. Therefore, it was proven that ternary $\mathrm{Mg}-\mathrm{Ni}-\mathrm{La}$ alloys had better sorption kinetics than Mg-La and Mg-Ni binary alloys [118]. Lanthanum hydride had a poor effect on hydrogen desorption but significantly improved absorption. Other studies [119] were carried out with compounds produced by the mechanical milling of $\mathrm{La}_{2} \mathrm{Mg}_{17}$ together with $\mathrm{LaNi}_{5}$ as an additive. It was proven that the composite kinetics were improved due to the complex porous agglomeration of the $\mathrm{Mg}_{2} \mathrm{Ni}, \mathrm{La}$, and $\mathrm{Mg}$ phases. 


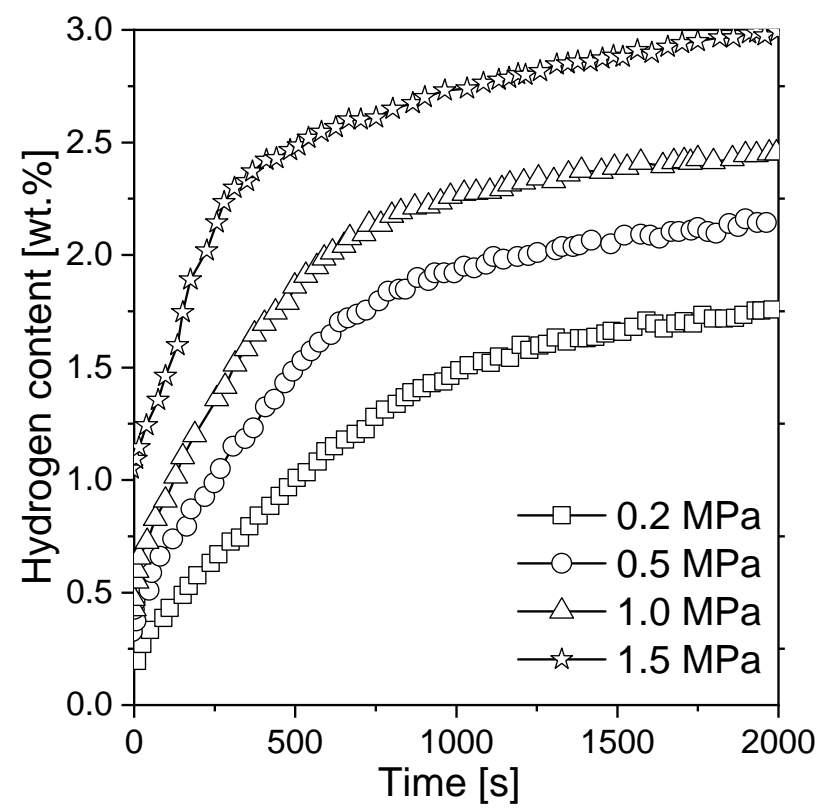

Figure 7. Absorption curves of $\mathrm{Mg}-50$ wt. $\% \mathrm{LaNi}_{5}$ at $28{ }^{\circ} \mathrm{C}$ at different pressures. The graph is based on [117].

Composites of magnesium hydride with AB-type compounds (FeTi in this case) were also studied [120]. It was found that the addition of FeTi lowered the desorption temperature (measured as the position of the DSC peak), and the improvement was correlated with the ratio of intermetallics added.

Based on the literature, it can be said that intermetallics generally improve decomposition kinetics. If intermetallics absorb hydrogen, they can actively influence absorption and desorption. If intermetallics do not have an affinity for hydrogen, they can at least act as grinding agents to improve the mechanical milling process and thus provide a passive influence.

\subsubsection{Metal Halide/Oxide Additives}

Metal halides and metal oxides influence the hydrogen desorption temperature and the kinetics of both desorption and adsorption of magnesium-based hydrides. Metal oxides can act as agents to refine particles during BM. There is also believed to be an affinity between metal oxides and hydrogen molecules, which enables easy absorption of hydrogen on the surface [21,121-127].

The catalytic effects of mischmetals and mischmetal oxides on improving the dehydrogenation and rehydrogenation behavior of magnesium hydride $\left(\mathrm{MgH}_{2}\right)$ were reported [128]. Mischmetals (mixtures of rare-earth metals, mostly Ce and La) and their oxides exhibited an influential catalytic effect on improving the hydrogen sorption kinetics and lowering the desorption/absorption temperature of $\mathrm{MgH}_{2}$. The best catalyst concentration was approximately $5 \mathrm{wt} . \%$ for both catalysts, which mostly affected the hydrogenation kinetics and temperature (in comparison to those of ball-milled $\mathrm{MgH}_{2}$ under the same pressure and temperature conditions). The onset desorption temperature decreased by approximately 80 and $60^{\circ} \mathrm{C}$ as a result of the catalytic effect of added mischmetal oxide and mischmetal, respectively (compared with that of ball-milled $\mathrm{MgH}_{2}$ ). During the first $10 \mathrm{~min}$, dehydrogenated $\mathrm{Mg}$ catalyzed with a mischmetal oxide absorbed $4.75 \mathrm{wt} . \%$ hydrogen at $315{ }^{\circ} \mathrm{C}$ and $1.5 \mathrm{MPa}$ hydrogen pressure, and the value increased to $5.5 \mathrm{wt} . \%$ over $40 \mathrm{~min}$ of rehydrogenation. The same conditions were applied to ball-milled $\mathrm{Mg}$ and $\mathrm{Mg}$ catalyzed with a mischmetal and mischmetal oxide, and as a result, over $40 \mathrm{~min}$, the samples reabsorbed $4.15,4.62$, and $5.43 \mathrm{wt} . \% \mathrm{H}_{2}$, respectively [128].

The effect of mechanical milling with the use of inorganic salts as magnesium additives on hydriding properties was investigated [129]. The examined halides— $\mathrm{NaF}, \mathrm{NaCl}, \mathrm{MgF}_{2}$, and $\mathrm{CrCl}_{3}$ —seemed to have different influences on the surface properties and reaction kinetics. The lowest hydrogen capacity was noted for the $\mathrm{Mg}-5 \% \mathrm{MgF}_{2}$ mixture ( 4.5 wt.\%), while an absorption range of 5.5-6 wt. $\% \mathrm{H}_{2}$ 
was achieved for other additives with hydrogenation conditions of $350{ }^{\circ} \mathrm{C}$ and $1.5 \mathrm{MPa}$ hydrogen pressure. Thus, it was obvious that $\mathrm{MgF}_{2}$ did not act as a catalyst. Additionally, a significant effect on the dehydrogenation kinetics of $\mathrm{MgH}_{2}$ was noted. However, the specific surface area increased with an increase in salt content and milling time. Additionally, the influence of various halide additives on magnesium hydride was studied [130]. Some compounds caused a significant change in the hydrogenation kinetics and $\mathrm{MgH}_{2}$ decomposition temperature. The strongest catalytic influence was noted for the fluorides $\mathrm{NbF}_{5}$ and $\mathrm{TiF}_{3}$. All fluorides, except $\mathrm{Cu}$ and $\mathrm{Y}$, significantly decreased the decomposition temperature. A possible reason for this behavior was that $\mathrm{Cu}$ and $\mathrm{Y}$ halides formed stable compounds with $\mathrm{Mg}$ which were not active. $\mathrm{Nb}$ and Ti fluorides showed the best kinetics improvements, while $\mathrm{V}, \mathrm{Zr}$, and Ni showed similar, but slower, kinetics. Fe and $\mathrm{Cr}$ fluorides had the least influence on kinetics. The authors claimed that those elements could act in different ways: (a) by forming stable intermetallic phases with $\mathrm{Mg}$ but no hydrides and (b) by having a single valency with virtually no catalytic effect. These results meant that the improvement in hydriding properties stemmed not from the fluorides, but rather from the hydrides. The mechanism by which halides increased $\mathrm{MgH}_{2}$ decomposition kinetics was studied by Malka et al. [131]. A much stronger influence on the decomposition behavior of $\mathrm{MgH}_{2}$ was noted with fluorides than with chlorides (with the exception of $\mathrm{TiCl}_{3}$, which decreased the desorption temperature far below $300^{\circ} \mathrm{C}$ ). The DSC results from this research are shown in Figure 8. The lowest decomposition temperature was $250^{\circ} \mathrm{C}$ for the additive $\mathrm{ZrF}_{4}$. Many studies have focused on the role of $\mathrm{NbF}_{5}$ in the desorption kinetics of ball-milled $\mathrm{MgH}_{2}$ [132-134]. For noncatalyzed $\mathrm{MgH}_{2}, \mathrm{BM}$ usually changes the decomposition temperature by approximately $30^{\circ} \mathrm{C}$, while with halide addition, a decrease in decomposition temperature of up to $200^{\circ} \mathrm{C}$ can be observed.

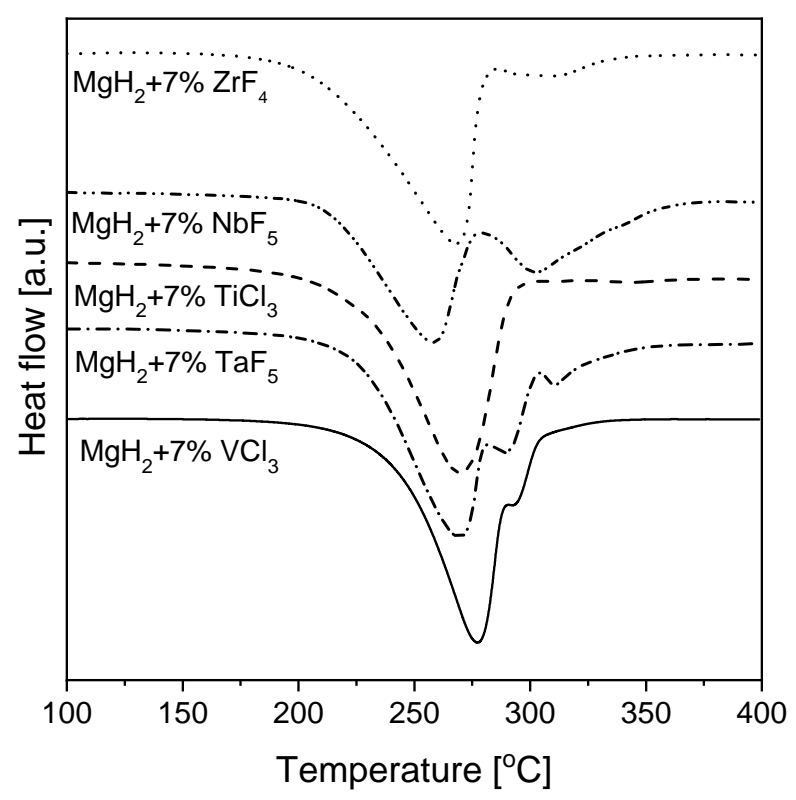

Figure 8. Endothermic peaks of $\mathrm{MgH}_{2}$ milled with halides (heating rate $5{ }^{\circ} \mathrm{C} / \mathrm{min}$ ). The graph is based on [131].

The catalytic effect of $\mathrm{Nb}_{2} \mathrm{O}_{5}$ was also examined [135], and this compound was found to be one of the best known catalysts for $\mathrm{MgH}_{2}$ decomposition. The absorption kinetics turned out to be nearly independent of the catalyst content. Thus, even the addition of a small amount of oxide played a major role in promoting a fast absorption process. It was found that the ternary solid solution $\mathrm{Mg}_{\mathrm{x}} \mathrm{Nb}_{(1-\mathrm{x})} \mathrm{O}$ was the active material responsible for the good kinetics properties [136]. Full hydrogen absorption and desorption ( $7 \mathrm{wt} . \%$ ) were obtained within 60 and $90 \mathrm{~s}$, respectively, for $0.5 \mathrm{~mol} \% \mathrm{Nb}_{2} \mathrm{O}_{5}$ at $300{ }^{\circ} \mathrm{C}$ [88]. The addition of more than $1 \mathrm{~mol} \% \mathrm{Nb}_{2} \mathrm{O}_{5}$ did not further accelerate the kinetics. The absorption rate at $250{ }^{\circ} \mathrm{C}$ was almost two times higher than that at $300^{\circ} \mathrm{C}$, likely due to the high thermodynamic driving 
force for absorption at lower temperature and the same hydrogen pressure and/or more effective heat dissipation. The mechanism of $\mathrm{Nb}_{2} \mathrm{O}_{5}$ was deeply investigated by Friedrichs et al. $[137,138]$ who proved that it is very unlikely that the oxide itself acts as a catalyst since it is reduced after short-term heating in the presence of magnesium. Thus, niobium (preferably in the form of nanoparticles) might be responsible for the activity. They also found that one of the possible positive effects is that additives prevent magnesium grain growth by occupying grain boundaries. An improvement in the hydrogen sorption kinetics of magnesium hydride powder when using $\mathrm{Nb}_{2} \mathrm{O}_{5}$ as a catalyst was presented by Hanada et al. [89], and this improvement is described broadly in the section on RBM experiments. The effect obtained by Hanada, however, might be due more to the extremely small sample size they used and the resulting improvement in heat exchange.

\subsection{5. $\mathrm{MgH}_{2}$ Destabilization}

Many studies have focused on improving diffusion rates mostly by reducing the particle or crystallite size, which leads to the shortening of diffusion distances and the introduction of defects. However, the thermodynamics of the interaction of hydrogen with magnesium (equilibrium pressure) remain virtually unchanged and clearly will not change due to certain physical reasons. The main reason is the reaction enthalpy, which cannot be simply changed. To tune the desorption thermodynamics of $\mathrm{MgH}_{2}$, an intermediate reaction with different thermodynamics must be used. The first pioneering work was performed by Reilly and Wiswall [31], who described the reaction between a $\mathrm{Mg}-\mathrm{Cu}$ alloy and hydrogen under high temperature and pressure. An improvement in hydrogenation/dehydrogenation thermodynamics was also achieved by using various additive elements to form alloys or compounds with $\mathrm{Mg}$ in the hydrogenated or dehydrogenated (or both) states. Zaluska et al. [139] proved that a Mg-Al system had specific properties that allowed a very fast solid-state reaction during the release of hydrogen from $\mathrm{MgH}_{2}$. Furthermore, the $\mathrm{Mg}$ - $\mathrm{Al}$ system had a relatively high hydrogen capacity of up to 3.5-4.5 wt.\%. Aluminum improved the heat transfer, thus modifying the hydrogenation thermodynamics. All the abovementioned factors allowed the working temperature of the hydride to decrease. It was proven that the equilibrium pressures for hydride formation could be shifted to a higher pressure range, which made the whole system more stable at low temperatures. Vajo et al. [140] investigated whether magnesium hydrides could be effectively destabilized with silicon. During dehydrogenation of the $\mathrm{MgH}_{2} / \mathrm{Si}$ system, a $\mathrm{Mg}_{2} \mathrm{Si}$ phase formed and caused the equilibrium pressure at $300^{\circ} \mathrm{C}$ to increase from 0.18 to more than $0.75 \mathrm{MPa}$. Additionally, equilibrium pressures of 0.1 and $10 \mathrm{MPa}$ were noted at $20^{\circ} \mathrm{C}$ and $150^{\circ} \mathrm{C}$, respectively. However, the kinetics at $150^{\circ} \mathrm{C}$ were too slow for direct hydrogenation, which was problematic in terms of using the investigated material for practical hydrogen storage. Later, Bystrzycki et al. [24,25] achieved the destabilization of $\mathrm{MgH}_{2}$ by adding silicon and performing a nanoscale solid-state reaction under vacuum. Moreover, $\mathrm{Mg}_{2} \mathrm{Si}$, which formed as a product of $\mathrm{MgH}_{2}$ destabilization by $\mathrm{Si}$, exhibited no hydrogen desorption at temperatures lower than $200^{\circ} \mathrm{C}$. Only the very slow destabilization of $\mathrm{MgH}_{2}$ was observed indirectly by pressure changes during desorption at $250{ }^{\circ} \mathrm{C}$ after $\mathrm{BM}$ of the $\mathrm{MgH}_{2}$-Si mixture for $20 \mathrm{~h}$.

\subsubsection{Cyclic Stability}

Hydride stability upon cycling and its thermal stability during use are important factors in the context of technical applications, mainly due to economic issues (the number of cycles that storage containers can experience without replacing the absorber). The first attempt to examine the cyclic stability of magnesium powder was conducted by Pedersen et al. [141]. Some hydrogen storage capacity loss was observed above 500 cycles. As the cycle number increased, the reaction kinetics decreased. Moreover, while the maximum desorption time turned out to be virtually independent of cycle number, the maximum absorption time was found to be dependent on this factor. More research using the above approach was conducted by Bogdanovic [142,143] and Friedlmeier [144]. 
Dehouche et al. [126] synthesized $\mathrm{MgH}_{2}$ with $0.2 \mathrm{~mol} \% \mathrm{Cr}_{2} \mathrm{O}_{3}$ to investigate long-term cycling stability and thermal stability. The presence of an oxide catalyst resulted in no need for sample activation. The changes in the thermodynamic and kinetic properties of $\mathrm{MgH}_{2}$ in a ball-milled sample were studied and compared with those of annealed and as-received samples. The absorption and desorption properties were tested at $300{ }^{\circ} \mathrm{C}$ for 1000 cycles and at $350{ }^{\circ} \mathrm{C}$ for 17 cycles. The results are presented in Figure $9 a, b$. The kinetics changed significantly after the long annealing process but did not change much after cycling. Prolonged annealing decreased the reaction kinetics, which was similar to the results observed for the as-received sample. However, it was noted that the hydrogen storage capacity increased during cycling. Between the 1st and 500th cycle, the capacity increased by approximately $8 \%$ (from 5.9 to $6.4 \mathrm{wt} . \% \mathrm{H}_{2}$ ). Unfortunately, that improvement was lost after 1000 cycles. The authors concluded that sample cycling had an influence on the desorption behavior. However, the absorption characteristics were found not to be related to the cycle number. This result was opposite to the observation of Pedersen [141], who demonstrated excellent thermal and cycling stability at $300{ }^{\circ} \mathrm{C}$ for 1000 cycles. A temperature of $300{ }^{\circ} \mathrm{C}$ is sufficient for technical applications (with an equilibrium pressure significantly over $0.1 \mathrm{MPa}$ ). These results were in good agreement with a previous investigation of a $\mathrm{MgH}_{2}-5$ at.\% V composite [125]. Testing the material for 2000 cycles at $300{ }^{\circ} \mathrm{C}$ resulted in no significant change in the thermodynamic and kinetic properties. Notably, the hydrogen capacity of the material increased marginally, while a constant rate of absorption and only a small decrease in the desorption rate were observed. Polanski et al. [145] also investigated the effect of $\mathrm{Cr}_{2} \mathrm{O}_{3}$ on the cyclic hydrogen storage behavior of magnesium hydride. After 150 cycles of desorption/absorption at $325^{\circ} \mathrm{C}$, a gradual loss of hydrogen storage capacity from $\sim 5.2 \mathrm{wt} . \%$ (after one cycle) to $\sim 4.6 \mathrm{wt} . \%$ was observed at the end of cycling. The temperature-programmed desorption (TPD) spectra for hydrogen desorption showed that the decomposition temperature shifted to a higher range as the number of cycles increased. A partial reduction of chromium oxide was observed with the formation of magnesium oxide, as well as crystalline growth in the structure. In general, it may be concluded that the cyclic stability of magnesium hydrides depends on the additives and possible reactions taking place, as well as the hydrogen purity and the way the investigation is performed. Cycling in a "closed-loop" system that uses the same hydrogen usually shows better results than using "fresh" hydrogen each time since even a small amount of impurities may cause powder bed degradation after thousands of cycles.
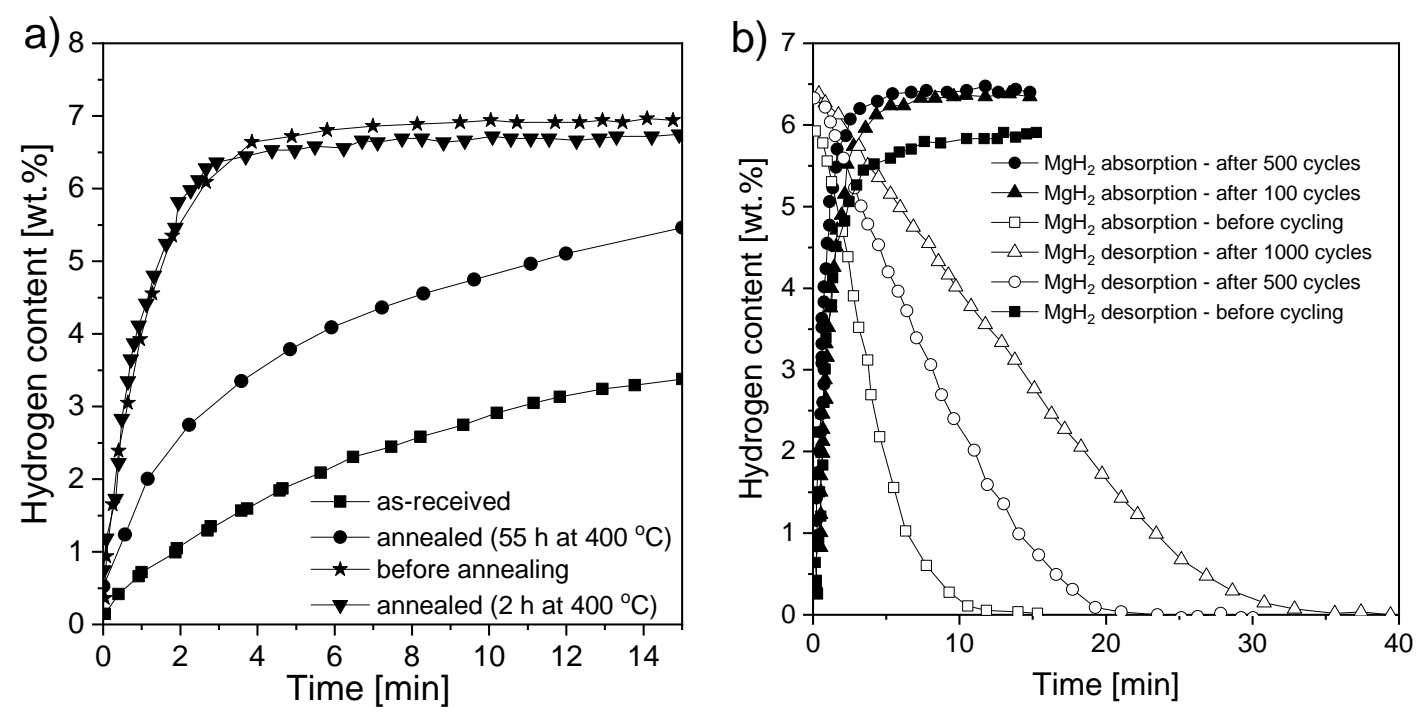

Figure 9. Absorption kinetics of (a) pure $\mathrm{MgH}_{2}$ (at $350{ }^{\circ} \mathrm{C}$ ) before and after annealing and (b) $\mathrm{MgH}_{2}-0.2$ mol\% $\mathrm{Cr}_{2} \mathrm{O}_{3}$ after different cycling times. The graphs are based on [126]. 


\subsubsection{Carbon Additives}

Among the many approaches applied to improve hydrogen sorption/desorption kinetics, BM with carbon additives has been widely examined. To date, magnesium-carbon composites have been synthesized by $\mathrm{BM}$ of $\mathrm{Mg}$ or $\mathrm{MgH}_{2}$ with different carbon allotropes (graphite [146-152]; nanotubes [150,151,153-155]; nanowires, fullerenes and activated carbon [150,151]; amorphous carbon, black carbon and nanodiamonds [150,156-158]) and are suggested to be a solution for solid-state hydrogen storage problems. In the past few years, carbon materials have been proven to improve the thermodynamics and kinetics of hydrogen sorption in different hydride systems. One of the most impressive examples of the influence of carbon on metal hydride was shown by Baldé et al. [159], and C-containing additives have been broadly investigated since then.

The main research papers are broadly described in other reviews by Aldelhelm et al. [160], Sun et al. [161], and others [161-164]. Carbon materials were shown to be suitable in combination with metal hydrides due to their relative chemical inertness. However, possible reactions such as interactions with defects or terminating groups, intercalation, or carbide formation may occur. Moreover, carbon can conduct heat efficiently and can enable hydrogen to diffuse along with the carbon phases, which is beneficial to the sorption properties [160].

One of the first authors investigating the potential of carbon additives with ball-milled magnesium hydride was Imamura et al. [146,147,165-167]. His first synthesis was based on mechanical milling of $\mathrm{Mg}+5 \mathrm{wt} . \%$ Pd-supporting graphite $(5 \mathrm{wt} . \% \mathrm{Pd} / \mathrm{G})$ in the presence of tetrahydrofuran (THF) [146]. The compound absorbed hydrogen even at low pressure $(0.06 \mathrm{MPa})$ and temperature $(26$ and $\left.180^{\circ} \mathrm{C}\right)$. The samples had very good reversibility for cycling, and the hydriding kinetics were improved with repeated cycles. THF, benzene, or cyclohexane $(\mathrm{CH})$ was used due to the synergic interactions these compounds promote between magnesium and atoms of graphite, which improved the synthesis outcome [147]. Later, the authors characterized mechanically ground Mg-graphite (Mg/G) composites and investigated the influence of different additives (CH and THF) on the compounds [165]. Organic additives strongly affected the physicochemical properties (structures of the surface and the interface) of $\mathrm{Mg} / \mathrm{G}$ composites and their hydriding characteristics. Magnesium graphite composites with $\mathrm{CH}$ and THF are described as $(\mathrm{Mg} / \mathrm{G}) \mathrm{CH}$ and $(\mathrm{Mg} / \mathrm{G}) \mathrm{THF}$, respectively. $\mathrm{CH}$ and THF addition influenced the specific surface area, but as the addition amount increased, the reduction in crystal size stopped. Depending on the process parameters and the type and amount of organic additive, the $\mathrm{Mg}$ crystallite size was in the range of $15-26 \mathrm{~nm}$. Moreover, the graphite layer structure in composites with $\mathrm{CH}$ and THF was shattered during grinding. Other research aimed to examine the influence of benzene [166].

Studies conducted with the BM of magnesium or magnesium hydride showed that the DSC decomposition peak shifted toward lower temperatures (from $380{ }^{\circ} \mathrm{C}$ to $300{ }^{\circ} \mathrm{C}$ [168] and from $434{ }^{\circ} \mathrm{C}$ to $\sim 390^{\circ} \mathrm{C}[169]$ ). Additional research [151] examined the effect of carbon additives on the hydrogen desorption properties of ball-milled magnesium hydride. The authors investigated the influence of the added "novel" and "conventional" carbons on the alloy. The DSC decomposition curves for both types of carbon are presented in Figure 10 [151]. The decomposition peak shifted by more than $50^{\circ} \mathrm{C}$ in some cases compared to that of the reference material. Shang et al. [149] showed that the absorption process was enhanced by adding graphite $(1,10$, and $30 \mathrm{~mol} \%)$ before milling. According to the authors' statement, the beneficial effect of graphite is connected with preventing oxide film formation on the Mg surface. Nevertheless, the stability of magnesium hydride is still a challenge, and the role of the C-containing compounds remains unclear. For these reasons, more research was conducted to understand the role of novel forms of carbon (carbon nanotubes, nanofibers, fullerenes, graphene, etc.) $[151,153,155,158,170,171]$. As a result of this research, it was found that the hydriding conditions can be modified by carbon additives (especially when they contain catalytic metal nanoparticles). Nanofibers and multiwalled carbon nanotubes (MWCNTs) alloyed with nickel or iron showed better dehydriding kinetics properties than did other materials. 
a)

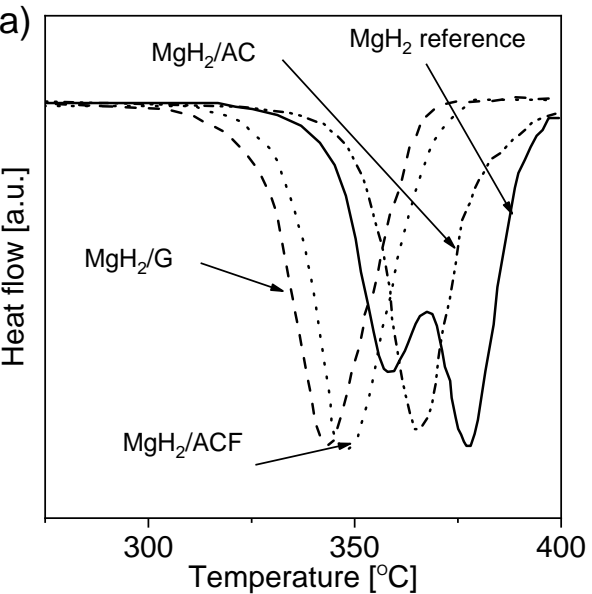

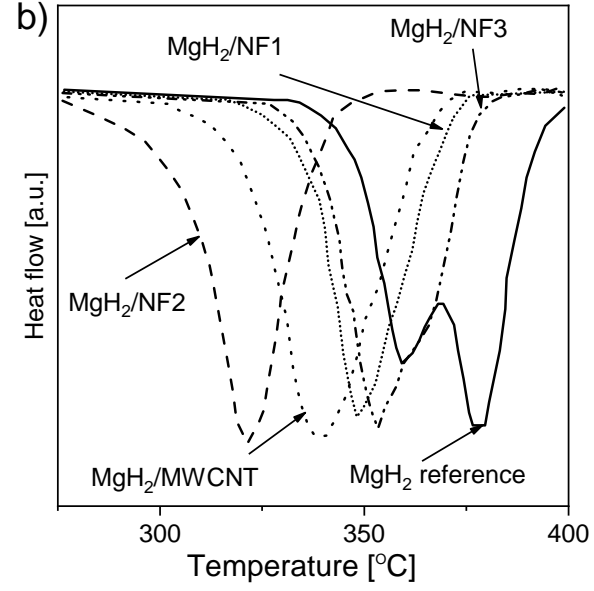

Figure 10. DSC decomposition curves for $\mathrm{MgH}_{2}$-carbon compounds containing (a) $5 \mathrm{wt}$ \% "conventional" carbons or (b) $5 \mathrm{wt} . \%$ nanocarbon; both samples were treated by BM for $2 \mathrm{~h}$. The graph is based on [151].

Another approach was presented by Skripnyuk et al. [153]. Mg powder and MWCNTs (prepared by the decomposition of acetylene with the aid of $5 \% \mathrm{Co}, \mathrm{Fe} / \mathrm{CaCo}_{3}$ ) were milled for $4 \mathrm{~h}$ and then hot pressed under a pressure of $50 \mathrm{MPa}$ at $600^{\circ} \mathrm{C}$. The hydrogen absorption/desorption kinetics at $300^{\circ} \mathrm{C}$ of Mg-2 wt.\% MWCNTs was found to be much faster than that of reference samples of pure magnesium processed by BM or equal-channel angular pressing (ECAP). The as-synthesized composite could reversibly store approximately $7 \mathrm{wt} . \%$ hydrogen (Figure 11a,b) and exhibited increased equilibrium hydrogen pressures of adsorption and desorption at high hydrogen contents. The authors suggested that the improved kinetics were connected with the fast diffusion of hydrogen through the MWCNT cores, and they proposed that the increase in the equilibrium pressure of hydrogen is related to the elastic constraints placed on the magnesium matrix by the carbon nanotubes. Other exceptional research was provided by Sartori et al. [172]. In addition to adding C-containing compounds to the magnesium alloy, a metal oxide $\left(\mathrm{Nb}_{2} \mathrm{O}_{5}\right)$ was mixed with the material. The absorption kinetics of the Mg-20 wt.\% MWCNT composite worsened, and the absorption rate slowed. With added $\mathrm{Nb}_{2} \mathrm{O}_{5}$, the enthalpy of hydride formation was almost unaffected, so it can be concluded that neither graphite nor niobium oxide influenced the absorption/desorption thermodynamics.
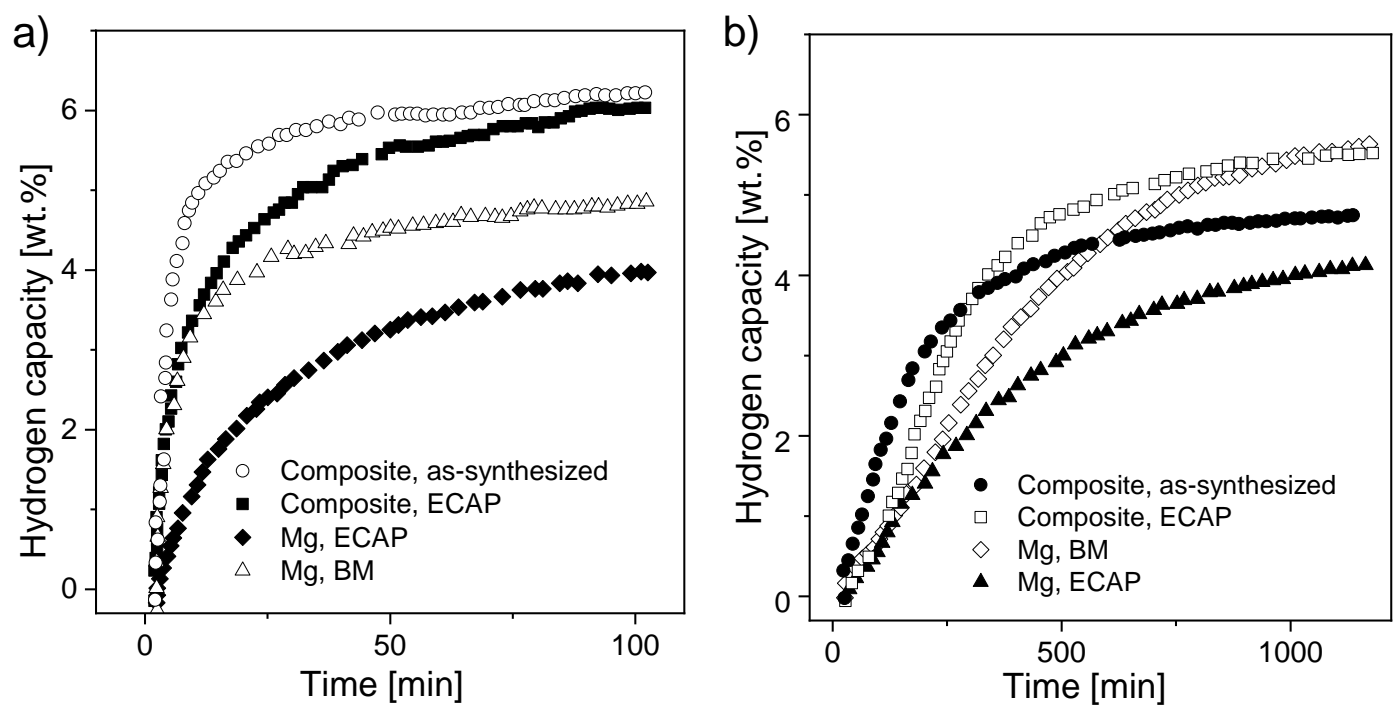

Figure 11. Kinetics of hydrogen (a) absorption and (b) desorption at $300{ }^{\circ} \mathrm{C}$ by as-synthesized and ECAP-processed Mg-2 wt.\% MWCNTs compounds compared with $4 \mathrm{~h}$ ball-milled $\mathrm{Mg}$ and ECAP-processed bulk material. The graphs are based on [153]. 


\subsection{Reactive Ball Milling}

Another approach to $\mathrm{MgH}_{2}$ synthesis involves milling in a hydrogen atmosphere. Mechanochemical activation improves hydrogen diffusion into the material by lowering the diffusion distance, which is a significant feature of the hydriding reaction. BM of alloys in a hydrogen atmosphere causes both hydrogen uptake and mechanical deformations to occur simultaneously. RBM, due to the high mechanical pressures, promotes the formation of high-pressure polymorphs of powders. Thus, the metastable $\gamma$ phase is visible [53]. The first attempt at a reactive synthesis of $\mathrm{MgH}_{2}$ was reported by Chen and Wiliams [83]. The experiment showed the possibility of fast metal hydride synthesis by mechanical alloying (MA) from metal powders (magnesium, zirconium, or titanium) in a relatively low-hydrogen-pressure atmosphere $(0.1 \mathrm{MPa})$ at room temperature. It was proven that the properties of the obtained products (in terms of decomposition kinetics) were even better than those of materials produced by conventional methods. The hydriding process occurred as a two-step reaction, which ended when a stable pressure level was achieved. During the investigation of the product, an endothermic reaction was noticed in the DSC graph at $382{ }^{\circ} \mathrm{C}$, and the total weight loss for the Mg sample was $5.60 \mathrm{wt} . \%$ (from the TGA data). Additionally, the measured hydrogen content (established by combustion elemental analysis) was $7.46 \mathrm{wt} . \%$. According to the authors, this inconsistency in results was connected with the occurrence of oxidation during heating. The above sample showed an almost $2 \%$ absolute ( $>20 \%$ relative) difference when measured by two different methods, thus prompting the reader to consider which result is more accurate.

\subsubsection{Metal/Semimetal Additives}

It is well known that introducing even a small amount of metal additives into magnesium can significantly improve the hydrogen absorption and desorption kinetics. The most popular metal catalysts are transition metals, e.g., $\mathrm{Fe}, \mathrm{Pd}, \mathrm{Ni}, \mathrm{V}, \mathrm{Nb}, \mathrm{Ti}, \mathrm{Mn}$, and $\mathrm{Cr}$ (synthesized together with $\mathrm{Mg}$ by $\mathrm{BM}$ and RBM techniques) [85,94-98,173]. Ryoung et al. [106] investigated the influence of $\mathrm{Mg}, \mathrm{Ni}, \mathrm{Fe}$, and Ti additives on the hydriding and dehydriding properties of $\mathrm{Mg}$. Long milling times led to low initial sorption rates and low amounts of absorbed and desorbed hydrogen. Reilly and Wiswall [31] noted the possibility of using $\mathrm{Mg}_{2} \mathrm{Ni}$ as a catalyst for $\mathrm{MgH}_{2}$ formation. With this knowledge, an attempt to synthesize $\mathrm{MgH}_{2}$ by reactive milling was conducted by Huot et al. [82]. Notably, pure nickel does not absorb any hydrogen in a reasonable temperature and pressure range [174]. The $\mathrm{MgH}_{2}$ decomposition DSC peak for pure $\mathrm{Mg}$ that was milled for $25 \mathrm{~h}$ in $\mathrm{H}_{2}$ was observed at $440.7^{\circ} \mathrm{C}\left(10^{\circ} \mathrm{C} /\right.$ min heating rate $)$. Even a small addition of nickel significantly decreased this temperature to $225.4^{\circ} \mathrm{C}$. Neither $\mathrm{Mg}_{2} \mathrm{Ni}$ nor the $\mathrm{Mg}_{2} \mathrm{NiH}_{4}$ phase was observed, in contrast to the results for $\mathrm{BM}$ in an argon atmosphere.

A broad analysis of the $\mathrm{Mg}-\mathrm{Ti}, \mathrm{Mg}-\mathrm{V}$, and $\mathrm{Mg}-\mathrm{Nb}$ systems in terms of the most effective additive for improving hydrogen interaction properties was performed by Korablov et al. [97]. Hydrogen uptake, especially at room temperature, was the highest with the vanadium additive (demonstrating the highest degree of conversion into the hydride phase). On the other hand, the titanium additive resulted in the lowest activation energy, which was beneficial for the dehydrogenation process. De Castro et al. [175] performed a synthesis of $\mathrm{MgH}_{2}-5 \% \mathrm{Nb}$ and determined cooperative behavior at the $\mathrm{Mg} / \mathrm{Nb}$ nanointerface and its catalytic effect on the reaction kinetics. The authors showed that $\mathrm{Mg}$ promoted $\mathrm{Nb}$ hydrogenation as much as $\mathrm{Nb}$ promoted $\mathrm{Mg}$ hydrogenation. The niobium additive improved the hydrogenation process, and $\mathrm{NbH}_{2}$ was observed. The influence of $\mathrm{Pd}$ and $\mathrm{Ni}$ additives on magnesium hydride synthesized by RBM proved that the combination of these two elements provided great cyclic stability and improved kinetics under moderate absorption conditions [176]. Another important study [177] proved that different particle sizes of catalytic additives (Co in that case) and different types of lattices had different catalytic effects on $\mathrm{MgH}_{2}$ (different hydrogen storage capacities and different sorption kinetics). Kral et al. [94] improved hydrogen storage properties by utilizing the catalytic effects of $\mathrm{Mg}-\mathrm{Al}-\mathrm{Ti}-\mathrm{Zr}-\mathrm{C}$ powders. The synergistic effect of the phases caused increased hydrogen desorption enthalpy, with a value that was close to the lowest published values for $\mathrm{MgH}_{2}$. 
The hydrogen desorption properties of a catalyzed $\mathrm{MgH}_{2}$ composite prepared by mechanical milling of a mixture of $\mathrm{MgH}_{2}$ with transition metal nanoparticles were measured by Hanada et al. [178]. Iron, cobalt, nickel, and copper particles were used as catalysts in RBM (in a 1 MPa hydrogen atmosphere). The nanocrystalline particles could be activated much more easily than their polycrystalline analogs. All synthesized composites showed improved $\mathrm{H}_{2}$ desorption properties. However, Ni nanoparticles had the largest influence on the hydrogen desorption properties. A mixture of $\mathrm{MgH}_{2}$ with $2 \mathrm{~mol} \% \mathrm{Ni}$ had an $\sim 6.5 \mathrm{wt} . \%$ hydrogen capacity and was characterized by a peak temperature that was $\sim 100{ }^{\circ} \mathrm{C}$ lower than that of $\mathrm{MgH}_{2}$ alone. However, a small decrease was noticed during the second cycle. The authors suggested that this decrease occurred because a $\mathrm{Mg}_{2} \mathrm{Ni}$ phase formed at the boundary between $\mathrm{MgH}_{2}$ and $\mathrm{Ni}$ after hydrogen desorption, thereby forming a ternary hydride with low capacity. No simple correlation between the particle and crystallite sizes and the desorption kinetics was noted. Long milling ( $>15 \mathrm{~min}$ ) led to better kinetics by increasing the activated surface area. Hence, the increased activated surface area decreased the hydrogen desorption activation energy. All of these factors resulted in $90 \%$ hydrogen desorption at $163{ }^{\circ} \mathrm{C}$ in $\mathrm{He}$ gas flow without a partial hydrogen pressure during the first $100 \mathrm{~min}$ of the process. The improvement in the hydrogen desorption kinetics was said to be strongly correlated with the change in the microstructure, i.e., the formation of a composite material.

Gennari et al. [179] used RBM to produce a mixture of Mg and Ge. Ge addition led to significant structural modifications and changes in desorption properties. Studies have proven that with increased milling time, the $\mathrm{MgH}_{2}$ phase will destabilize and $\mathrm{Mg}_{2} \mathrm{Ge}$ will form. Figure 12 shows that after $100 \mathrm{~h}$ of milling with added $\mathrm{Ge}$, the amount of magnesium hydride started to decrease (based on DSC and XRD measurements). Moreover, milling $\mathrm{Mg}$ with Ge led to a low $\mathrm{MgH}_{2}$ decomposition temperature (compared with that of samples produced by $\mathrm{BM}$ of only $\mathrm{Mg}$ ). The overall catalytic effect was noted to be independent of $\mathrm{Mg}_{2} \mathrm{Ge}$ but strongly dependent on Ge. The authors deduced that Ge could provide special areas for hydrogen atom transfer from the bulk to the surface, which favored the recombination of molecular hydrogen. Another hypothesis was that Ge could generate alternative diffusion paths, thus improving hydrogen mobility through the material. However, the mechanism itself has only been proposed and has not been proven.

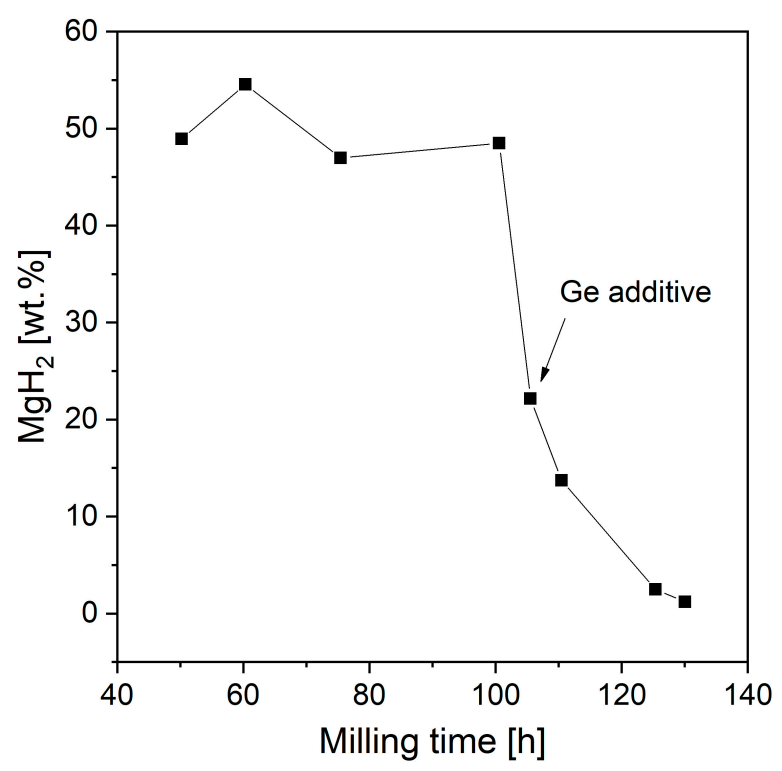

Figure 12. $\mathrm{MgH}_{2}$ yield as a function of milling time for samples with and without added Ge. The graph is based on [179].

Sashi et al. [180] provided the results of $\mathrm{MgH}_{2}$ synthesis with the most catalytically effective transition metals, i.e., $\mathrm{Ti}, \mathrm{Fe}$, and $\mathrm{Ni}$, and the influence of each catalyst on the sorption characteristics 
was investigated. Magnesium hydride milled together with 5 wt.\% of each element in a $1.2 \mathrm{MPa}$ hydrogen atmosphere led to the formation of nano-Ti5Fe5Ni5, nano-Ti5, nano-Fe5, and nano-Ni5. The decomposition temperature of the produced materials was lower than that of nano- $\mathrm{MgH}_{2}$ alone, while the rehydrogenation kinetics were enhanced due to the cocatalyst effect of $\mathrm{Ti}, \mathrm{Fe}$, and $\mathrm{Ni}$. The hydrogen absorption value for nano-Ti5Fe5Ni5 was $5.3 \mathrm{wt} . \%$ at $270{ }^{\circ} \mathrm{C}$ and $1.2 \mathrm{MPa} \mathrm{H}_{2}$ pressure during a $15 \mathrm{~min}$ cycle, while a reabsorption value of $4.2 \mathrm{wt}$ \% was obtained for nano- $\mathrm{MgH}_{2}$ under identical conditions (Figure 13a). The desorption temperature, with a visible peak at the maximum desorption rate, of different samples is presented in Figure 13b. For $\mathrm{MgH}_{2}-\mathrm{Ti} 5 \mathrm{Fe} 5 \mathrm{Ni}$, the decomposition temperature was $280^{\circ} \mathrm{C}$, which was the lowest temperature obtained for the examined samples $(310,320$, 340 , and $370{ }^{\circ} \mathrm{C}$ for nano-Fe5, nano-Ti5, nano- $\mathrm{Ni5}$, and nano- $\mathrm{MgH}_{2}$, respectively).
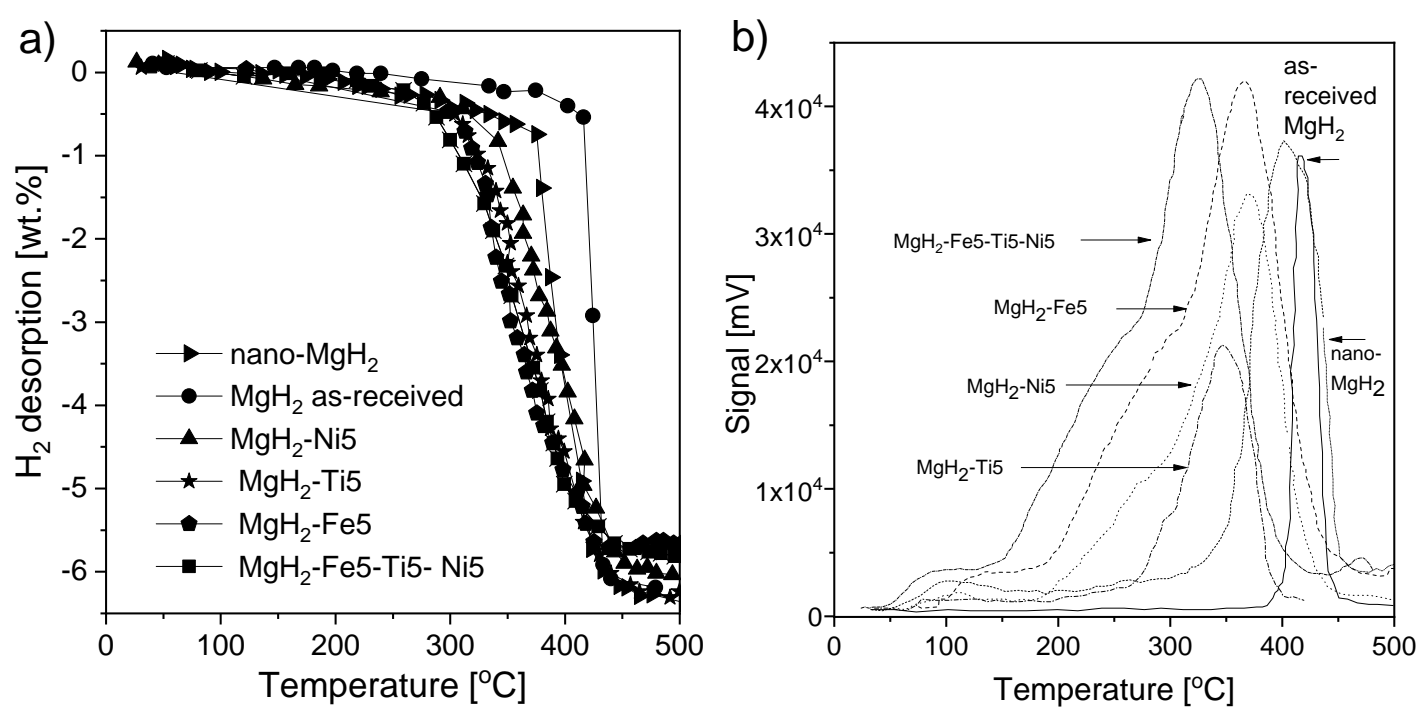

Figure 13. (a) Temperature dependence of the hydrogen content of $\mathrm{MgH}_{2}$ with and without catalysts. (b) TPD (peak at maximum desorption) of $\mathrm{MgH}_{2}$ with and without a catalyst. The graphs are based on [180].

\subsubsection{Oxide Additives in Reactive Ball Milling}

Crucial changes in hydriding behavior have been noted when using metal oxides as catalysts [21,121,126,181]. Song et al. [182] showed that the oxides $\mathrm{Cr}_{2} \mathrm{O}_{3}, \mathrm{Al}_{2} \mathrm{O}_{3}$, and $\mathrm{CeO}_{2}$ influenced magnesium hydride during RBM. After $2 \mathrm{~h}$ of $\mathrm{RBM}$, the $\mathrm{Mg}$ was only partially transformed into $\mathrm{MgH}_{2}$ (20.6, 10.1 and 13.7 wt. $\% \mathrm{MgH}_{2}$ from the $\mathrm{Mg}+10$ wt. $\% \mathrm{Cr}_{2} \mathrm{O}_{3}, \mathrm{Mg}+10$ wt. $\% \mathrm{Al}_{2} \mathrm{O}_{3}$ and $\mathrm{Mg}+10$ wt. $\%$ $\mathrm{CeO}_{2}$ phases, respectively). The largest hydriding rates of absorption and desorption was noted for $\mathrm{Mg}$ +10 wt. $\% \mathrm{Cr}_{2} \mathrm{O}_{3}$ powder. It absorbed 5.87 wt. $\%$ at $300{ }^{\circ} \mathrm{C}$ in a $1.1 \mathrm{MPa} \mathrm{H}_{2}$ atmosphere and desorbed 4.44 wt. $\%$ at $300{ }^{\circ} \mathrm{C}$ and $0.05 \mathrm{MPa} \mathrm{H}_{2}$ over $60 \mathrm{~min}$ in the first cycle. Absorption curves for all powders are presented in Figure 14. The amount of absorbed/desorbed hydrogen increased with decreasing particle size because the diffusion distance became shorter. In the case of $\mathrm{Cr}_{2} \mathrm{O}_{3}$, hydriding/dehydriding cycles led to its reduction because of the much greater chemical affinity of magnesium to oxygen than chromium. In fact, many transition metal oxides become reduced when in contact with magnesium. However, most of the published data about these added transition metal oxides do not deeply discuss how the oxides transform. Instead, the initial states of the oxides (as well as halides) are considered input variables when discussing these catalysts. 


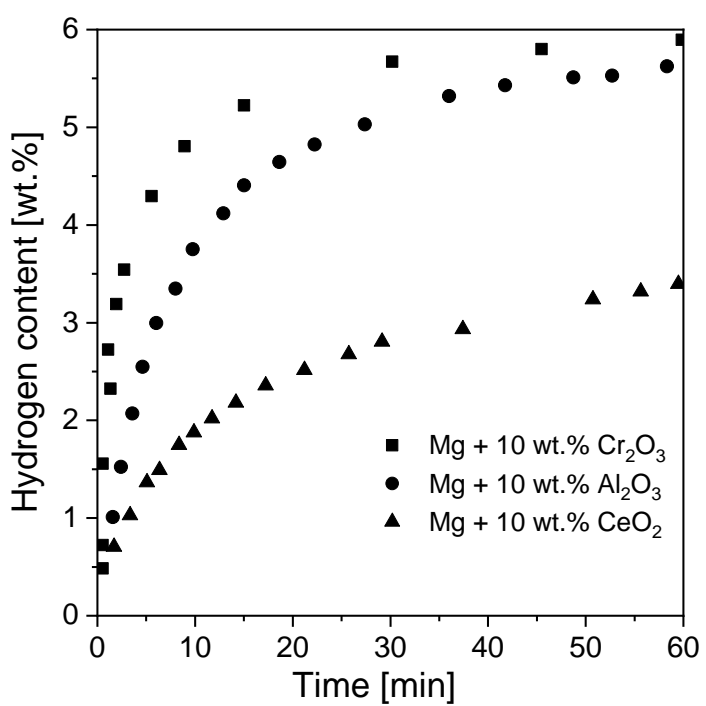

Figure 14. Weight percentage of $\mathrm{H}_{2}$ absorbed over time for the first hydriding cycle at $300{ }^{\circ} \mathrm{C}$ at $1.1 \mathrm{MPa}$ $\mathrm{H}_{2}$. The graph is based on [182].

Another study showed results for $\mathrm{BM}$ of $\mathrm{Mg}-10$ wt. $\% \mathrm{Fe}_{2} \mathrm{O}_{3}$ under $\mathrm{H}_{2}$ pressure [183]. Defects created on the surface of $\mathrm{Mg}$ particles with decreased size (easier nucleation) showed increased hydrogen absorption, up to $5.56 \mathrm{wt} . \%$. It was shown that the absorption rate changed with milling time because of the reduced particle size of $\mathrm{Mg}$, which decreased the diffusion distances. The reaction kinetics improved with milling time since, as already mentioned, materials with nanocrystalline particles are characterized by a low packing density. This low packing density resulted in faster diffusion through grain boundaries than through the less distorted lattice of a microcrystalline material. Grain boundaries acted as nucleation sites for hydride phase formation and decomposition. Another improvement in the hydrogen sorption kinetics of magnesium hydride powder was accomplished with the use of $\mathrm{Nb}_{2} \mathrm{O}_{5}$ as a catalyst, as presented by Hanada et al. [89]. Kinetics curves of the hydrogen absorption and desorption reactions for powders ball milled for $20 \mathrm{~h}$ showed up to $5 \mathrm{wt} . \%$ hydrogen absorption at room temperature at $1 \mathrm{MPa}$ (after dehydrogenation at $200^{\circ} \mathrm{C}$ ). Even at room temperature, the product quickly absorbed hydrogen at pressures lower than 0.1 MPa. After rehydrogenation, the material desorbed $\sim 6 \mathrm{wt} . \%$ hydrogen at $160^{\circ} \mathrm{C}$ for $100 \mathrm{~min}$. The desorption reaction was conducted in a helium flow with a zero partial pressure of hydrogen (otherwise, it would be impossible to desorb hydrogen at this temperature). Thus, $\mathrm{Nb}_{2} \mathrm{O}_{5}$ was proven to cause a sufficient decrease in the activation energy of hydrogen desorption.

\subsubsection{Polymorphic Forms after Synthesis}

RBM is a synthesis technique in which the existing phases of the examined materials play a crucial role. Knowledge of these phases is necessary to understand the structural changes that can influence the synthesis outcome. An analysis of the existence of $\beta$ and $\gamma$ phases after RBM was performed by Gennari et al. [184]. Thermal behavior examination proved the influence of milling time on the properties of the formed hydrides. Three types of desorption behavior were noticed to be connected with the structural changes introduced by RBM. The phase content for each sample was dependent on milling time. With shorter milling times, only the $\beta-\mathrm{MgH}_{2}$ phase was observed as a sharp endothermic desorption peak. Both phases were visible after milling for a long time, appearing as two peaks or as a double peak of the endothermic reaction. The $\gamma-\mathrm{MgH}_{2}$ phase decomposed before the transformation from $\gamma$ to $\beta$. The authors deduced that there was a synergistic effect between the two phases during hydrogen desorption, which caused the $\beta-\mathrm{MgH}_{2}$ desorption temperature to decrease. As a result, the hydrogen desorption properties were influenced by increases in milling time. $\mathrm{MgH}_{2}$ synthesis and reaction analysis were also presented by El-Eskandarany et al. [185]. The authors claimed that under 
RBM in a hydrogen atmosphere, cyclic phase transformation between the two phases $\beta$ and $\gamma$ took place with increasing milling time. Therefore, it was suggested that the formation enthalpy values for both phases were similar, with a relatively low energy barrier between them, thereby allowing for cyclic phase transitions. Long RBM times led to a decrease in the grain size of $\mathrm{MgH}_{2}$ and a simultaneous increase in Fe contamination level. Iron contamination was introduced by using steel milling tools. Both factors improved the kinetics of absorption/desorption. For powders ball-milled for $200 \mathrm{~h}$, a high hydrogen storage capacity (7.54 wt.\%) was noted after the completion of 600 absorption/desorption cycles at $300^{\circ} \mathrm{C}$. In general, this kinetics improvement was achieved because of the nanocrystalline nature of the powders, the presence of the $\gamma$ phase and Fe contamination. However, the above results seem to be very controversial, and most likely, the described phenomena (cyclic transformation from $\beta$ to $\gamma$ ) should be analyzed again to assess their validity. Both $\gamma-\mathrm{MgH}_{2}$ and nanostructured $\mathrm{MgH}_{2}$ were also synthesized by a direct reaction in a ball mill in a hydrogen atmosphere with the catalytic effect of added $\mathrm{ZrFe}_{1.4} \mathrm{Cr}_{0.6}$ [186]. The formation of the $\gamma-\mathrm{MgH}_{2}$ phase was achieved by applying proper conditions, in which high-energy collisions were conducted with steel balls.

\subsubsection{Carbon Additives in Reactive Ball Milling}

One of the most popular carbon additives is graphite, which can be milled with magnesium hydride under a hydrogen atmosphere $[154,157,187,188]$. Fuster et al. [189] performed a broad investigation of the role of carbon additives, noting some aspects of the influence of carbon on the hydride and some inconsistencies. For example, some authors claim that graphite acts as a catalyst to improve hydrogen sorption $[157,188]$, while others disagree [151,190]. Fuster et al. [189] proved that the addition of graphite improves the hydriding rate by reducing the time required to achieve a full reaction with hydrogen by half. Moreover, graphite restrained the cold welding of Mg particles, which caused particle size refinement and thus a more efficient hydriding process. However, the catalytic effect of graphite seemed to be relevant on the surface of Mg particles, which was attributed to the increased decomposition temperature with milling time. Given the characteristics of graphite and its lubricating properties, a possible explanation might be that the mechanical, not chemical, properties of the additive play a role here. A similar phenomenon was previously observed when steel (instead of iron) was used as the synthesis substrate in the formation of ternary hydrides. Despite the very similar compositions, differences in the mechanical properties and conditions of BM were found to be responsible for the final synthesis results and properties of the obtained material [49]. This deviation is an important issue and hints that not only the chemical composition should always be considered when discussing the influence of additives.

Other research was performed by Chen et al. [154]. In addition to adding C-containing compounds to a magnesium alloy, some metals were also mixed in. Composites of magnesium, MWCNTs, and suitable additives (zirconium for improving the absorption kinetics and nickel as a binder) were prepared by RBM to obtain a better hydrogen source for proton exchange membrane (PEM) fuel cells [154]. The obtained microstructure was on the nanometer scale (several to several dozen nanometers, as proven by XRD and transmission electron microscopy (TEM) analysis). The maximum hydrogen storage capacities of Mg-5 wt.\% MWCNTs and Mg-20 wt.\% MWCNTs were 6.08 and $2.75 \mathrm{wt} . \%$, respectively, at $280{ }^{\circ} \mathrm{C}$. The Mg- $5 \mathrm{wt} . \%$ MWCNTs composite retained its maximum capacity and exhibited a good reaction kinetics rate under certain temperature and pressure conditions. Huot et al. [187] showed faster decomposition kinetics at $350{ }^{\circ} \mathrm{C}$ due to the presence of graphite. Huang et al. [191] showed that the desorption temperature of the rehydrogenated compound decreased by approximately $35^{\circ} \mathrm{C}$ (in the range of $400{ }^{\circ} \mathrm{C}$ ) in comparison to that of the as-prepared compound.

\subsection{Nanoconfinement}

Among the abovementioned methods of modifying magnesium-based hydrides, nanoconfinement is also important. Nanoconfinement is, in general, a modification method based on two aspects: nanosizing and confinement. In theory, nanoconfinement is supposed to significantly enhance kinetics 
and modify thermodynamic properties by lowering the size of clusters to the extent that the hydride becomes less stable. Accordingly, three possible mechanisms can be distinguished: the first option is reducing the particle size of the hydride, the second option is hindering the growth and agglomeration of particles by compartmentalizing the nanoparticles with the use of a scaffold material, and the third option is limiting the mobility of the decomposition products and preserving the distance between them. Nielsen et al. [68] published a broad review regarding the utilization of nanoporous materials as scaffolds to prepare and confine nanosized metal hydrides. The review aimed to highlight important aspects of nanoconfined chemistry for hydrogen storage materials in the context of hydride characteristics such as kinetics, stability, and thermodynamic properties. The authors mainly focused on the preparation and properties of light metal hydride nanocomposites infiltrated into nanoporous scaffold materials [68]. Another broad review article regarding modification through nanoconfinement was provided by Zhang et al. [56,164]. The authors focused on different ways of modifying one of the most promising candidates for hydrogen storage-magnesium hydride. In addition to describing the influence of C-containing compounds (1D, 2D, and 3D) on the properties of $\mathrm{MgH}_{2}$, the authors also focused on the importance of catalysts in the context of nanoconfinement.

From the synergetic effect of nanoconfinement with catalysts, three working principles can be distinguished in terms of where the nanoconfined materials are confined: (a) in both $\mathrm{Mg} / \mathrm{MgH}_{2}$ and the catalyst, (b) in only the catalyst, and (c) in the catalyst, which plays a dual role of nanoconfinement and catalysis [56]. One of the problems with catalyst-added Mg-based composites is a reduction in capacity due to particle agglomeration. Several methods have been proposed for confining $\mathrm{Mg} / \mathrm{MgH}_{2}+$ catalyst ( $\mathrm{Pd}, \mathrm{ZrO}_{2}, \mathrm{Nb}_{2} \mathrm{O}_{5}$, etc.) systems. Many studies have examined the influence of additives such as carbon nanotubes (CNTs), nanorods, graphene, and nanofibers [192-200]. All of this research has proven that mixed compounds of magnesium-based hydrides with catalysts and carbons influence the hydride synthesis outcome. Ranjbar [195] proved that $5 \mathrm{wt} . \% \mathrm{CNTs}$ added to $\mathrm{MgH}_{2}+10 \mathrm{wt} . \%$ $\mathrm{Ti}_{0.4} \mathrm{Mn}_{0.22} \mathrm{Cr}_{0.1} \mathrm{~V}_{0.28}$ lowered the initial temperature of desorption by approximately 125 and $59^{\circ} \mathrm{C}$ for the pure sample and the binary mixture, respectively. The gravimetric capacities at $300{ }^{\circ} \mathrm{C}$ and $250{ }^{\circ} \mathrm{C}$ were $6 \mathrm{wt} . \%$ and $5.6 \mathrm{wt} . \%$ hydrogen, respectively.

The nanoconfinement of magnesium hydride is still not fully known, and more research is needed on this topic. Nevertheless, alloying effects clearly lead to kinetic enhancements and thermodynamic property alterations. Many studies have proven an apparent improvement in the hydrogen sorption properties of nanoconfined materials compared to those of bulk samples [67,201,202]. Nanoconfinement can be considered a milestone in regard to improving the kinetics and thermodynamic properties of hydrides.

\section{3. $\mathrm{Mg}_{2} \mathrm{FeH}_{6}$}

$\mathrm{Mg}_{2} \mathrm{FeH}_{6}$ is another magnesium-based hydride that has been commonly investigated. The first information about this compound is from 1971, but since it was only in the title of the conference paper [203] that can no longer be accessed, it is difficult to judge now whether the author synthesized the compound or just predicted its existence. $\mathrm{Mg}_{2} \mathrm{FeH}_{6}$ has a cubic $\mathrm{K}_{2} \mathrm{PtCl}_{6}$-type structure [35] (with no known polymorphs) and the highest known volumetric density of hydrogen $\left(150 \mathrm{~kg} / \mathrm{m}^{3}\right)$ compared with those of all "popular" hydrides. The gravimetric density is $5.43 \mathrm{wt} . \%$, and the most commonly provided desorption enthalpy, calculated from Van't Hoff's equation by Bogdanovic [37] and confirmed by Reiser [204], is $-77.4 \mathrm{~kJ} / \mathrm{mol} \mathrm{H}_{2}$. This value is different from data reported by Gennari [38] and Wang [205] (values equal to $-98 \mathrm{~kJ} / \mathrm{mol} \mathrm{H}_{2}$ and $-67 \mathrm{~kJ} / \mathrm{mol} \mathrm{H}_{2}$, respectively). Because the enthalpy value is lower than that of magnesium hydride, $\mathrm{Mg}_{2} \mathrm{FeH}_{6}$ is more stable $\left(\mathrm{Mg}_{2} \mathrm{FeH}_{6}\right.$ has a lower decomposition pressure than $\mathrm{MgH}_{2}$ at the same temperature). On the other hand, the volumetric capacity of $\mathrm{Mg}_{2} \mathrm{FeH}_{6}$ is higher than that of $\mathrm{MgH}_{2}$, which seems to be a very large advantage. The synthesis of magnesium-iron hydride has always been described as complicated because of the lack of a $\mathrm{Mg}_{2} \mathrm{Fe}$ intermetallic phase [39]. This feature is in contrast to the properties of $\mathrm{Mg}_{2} \mathrm{NiH}_{4}$, which has a $\mathrm{Mg}_{2} \mathrm{Ni}$ intermetallic precursor. Fe is also not significantly soluble in $\mathrm{Mg}$ (in either solid 
or liquid form), and any intermetallic compound can be formed from both elements [206]. However, given the many successful attempts at $\mathrm{Mg}_{2} \mathrm{FeH}_{6}$ synthesis, it is hard to judge whether using an intermetallic phase as a starting material will give any advantage compared with already known methods. An advantage may be observed in mass production, for instance, when massive ingots can be cast and then hydrogenated. Thus, the above complex hydride was first reported to be successfully synthesized in 1984 by direct hydrogenation-sintering of $\mathrm{Mg}$ and Fe powder mixtures [35]. The process was conducted at $2-12 \mathrm{MPa}$ hydrogen pressure for several days at $\sim 500{ }^{\circ} \mathrm{C}$, and the product was formed with a purity of approximately $50 \%$ according to reaction (1).

$$
2 \mathrm{Mg}+\mathrm{Fe}+3 \mathrm{H}_{2} \rightleftarrows \mathrm{Mg}_{2} \mathrm{FeH}_{6}
$$

$\mathrm{Mg}_{2} \mathrm{FeH}_{6}$ should form as the first product during hydrogenation because it is more stable than magnesium hydride. However, a quite common and effective path is a two-step reaction with $\mathrm{MgH}_{2}$ acting as a $\mathrm{Mg}_{2} \mathrm{FeH}_{6}$ precursor [49,207-211]. Usually, hydride synthesis involves sintering at elevated temperatures (up to $500{ }^{\circ} \mathrm{C}$ ) and at a high hydrogen pressure. $\mathrm{Mg}_{2} \mathrm{FeH}_{6}$, a complex hydride, can also be prepared by MA/milling (MA/M) (RBM under a certain hydrogen pressure or in an inert atmosphere). Both techniques can be combined with sintering, but they can also exist separately. Furthermore, both a mixture of $\mathrm{MgH}_{2}+\mathrm{Mg}_{2} \mathrm{FeH}_{6}$ and $\mathrm{Mg}_{2} \mathrm{FeH}_{6}$ alone are appropriate materials for thermal energy storage (unfortunately, at a high temperature of $\sim 500^{\circ} \mathrm{C}$ ) due to their high cycle life, relatively low cost of production (including raw materials) and constant and significant heat delivery without heat loss [37,212-215].

\section{1. $\mathrm{Mg}_{2} \mathrm{FeH}_{6}$ Synthesis/Mechanical Modifications}

The conventional method of preparing pure magnesium-iron hydride $\left(\mathrm{Mg}_{2} \mathrm{FeH}_{6}\right)$ involves sintering at temperatures ranging from $350-500^{\circ} \mathrm{C}$ and at high hydrogen pressure (1.1-12 MPa) over several days $[35,216]$. An improvement to this synthesis method was made by applying MA/M in an inert or hydrogen atmosphere, a process known as reactive mechanical alloying (RMA). The above methods can be combined with sintering techniques $[36,214,216]$, but mostly, MA is used alone to produce the hydride. Bogdanovic et al. [37] carried out thermodynamic and microstructural investigations of $\mathrm{Mg}_{2} \mathrm{FeH}_{6}$, and the initial formation and subsequent de- and rehydrogenation process of $\mathrm{Mg}_{2} \mathrm{FeH}_{6}$ and the mixed $\mathrm{Mg}_{2} \mathrm{FeH}_{6}-\mathrm{MgH}_{2}$ system at the micro- and nanoscale levels were investigated. Both the reversible $\mathrm{Mg}_{2} \mathrm{FeH}_{6}$ and the $\mathrm{Mg}_{2} \mathrm{FeH}_{6}-\mathrm{MgH}_{2}$ mixture had high gravimetric and volumetric densities. Both systems had very good cycling stability, and the hydrogen storage capacity of the latter system had a high potential to be improved by varying the cycling conditions. Zhou et al. [217] studied the energy and electronic structure of $\mathrm{Mg}_{2} \mathrm{FeH}_{6}$ by using the first-principles plane-wave pseudopotential method to calculate the heats of formation and the formation mechanism, which was then proven by experimental methods. The mechanism proposed by the authors is as follows: $\mathrm{H}$ atoms are first dissolved in the magnesium lattice, forming $\mathrm{MgH}_{2}$, and then iron dissolves into the lattice to form a $(\mathrm{MgFe}) \mathrm{H}_{2}$ solid solution. With increasing Fe concentration, $\mathrm{Mg}_{2} \mathrm{FeH}_{6}$ is formed.

$\mathrm{Mg}_{2} \mathrm{FeH}_{6}$ has been broadly synthesized with various proportions of initial compounds by using different methods that have resulted in different outcomes. The $\mathrm{Mg}$ to Fe ratio can be extremely different, ranging from 1:1 to 40:1 [37]. Puszkiel et al. studied compositions from 2:1 to 15:1 [218]. It has also been shown that it is possible to produce a material with a relatively high hydrogen capacity (up to $5.2 \mathrm{wt} . \%$ $\mathrm{H}_{2}$ after 550-600 cycles) even without BM [37] by just thermal cycling. Magnesium-iron hydride has attracted attention not only for its high volumetric hydrogen density but also as a thermochemical storage system. The material absorbs heat and releases hydrogen during desorption, while the stored heat is released during hydrogenation and can be utilized. Recently, it has been shown that the $\mathrm{Mg}-\mathrm{Fe}-\mathrm{H}$ system can be used for short- and long-term storage applications at temperatures up to $550{ }^{\circ} \mathrm{C}$ [219]. Moreover, the electrochemical reaction of lithium ions with $\mathrm{Mg}_{2} \mathrm{FeH}_{6}$ has also been investigated [220]. Previous research [37] proved that $\mathrm{Mg}_{2} \mathrm{FeH}_{6}$ could be formed from elemental $\mathrm{Mg}$, 
$\mathrm{Fe}$, and $\mathrm{H}_{2}$ without $\mathrm{MgH}_{2}$ as an intermediate product. Different milling parameters were applied to optimize the process and increase the efficiency of the reaction. There is still little research showing the results of mechanochemical synthesis without further sintering or other techniques. Hence, there are four main methods for obtaining $\mathrm{Mg}_{2} \mathrm{FeH}_{6}$ using MA: (a) milling $\mathrm{Mg}$ and Fe in an inert atmosphere (e.g., Ar) and then hydriding the material, (b) milling $\mathrm{Mg}$ and $\mathrm{Fe}$ in a $\mathrm{H}_{2}$ atmosphere (RMA), (c) milling $\mathrm{MgH}_{2}$ and $\mathrm{Fe}$ in an inert atmosphere, and (d) milling $\mathrm{MgH}_{2}$ and $\mathrm{Fe}$ in a $\mathrm{H}_{2}$ atmosphere.

\subsection{Ball Milling}

Although magnesium and iron are known for their immiscibility in classical metallurgical processes, the first attempt to mechanically alloy $\mathrm{Mg}$ and Fe was conducted by Hightower et al. [221]. The main aim of the research was to determine a possible increase in the solid solubility of either $\mathrm{Mg}$ in $\mathrm{Fe}$ or $\mathrm{Fe}$ in $\mathrm{Mg}$. The results showed that $\mathrm{Mg}$ and Fe milled together formed very finely dispersed clusters of one phase in another. Alloys with less than 20 at.\% Mg were found to have only one phase, namely BCC, with an enlarged lattice parameter. On the other hand, a high Mg concentration (from 20 to 95 at.\%) led to a mixture of both bcc and hcp phases. These results strongly suggested the increased solubility of magnesium in iron. However, the authors stated that there was no strong evidence of achieving up to $20 \%$ magnesium dissolved in iron.

\subsubsection{Reaction Yield Analysis}

The success of the hydrogenation process is indicated by the yield of the reaction. An initial problem limiting the effectiveness of $\mathrm{Mg}_{2} \mathrm{FeH}_{6}$ synthesis is based on the presence of $\mathrm{Fe}, \mathrm{MgH}_{2}, \mathrm{Mg}$, and $\mathrm{MgO}$ contamination. J. Huot et al. [222] presented an approach for $\mathrm{Mg}_{2} \mathrm{FeH}_{6}$ synthesis by BM without further sintering. After $60 \mathrm{~h}$ of milling $\mathrm{MgH}_{2}$ with $\mathrm{Fe}$ in argon, $55 \mathrm{wt} . \% \mathrm{Mg}_{2} \mathrm{FeH}_{6}$ was synthesized. A very fine microstructure was obtained, which was quite the opposite of that obtained by sintering, and this fine microstructure exhibited better reversibility. Additionally, the loss of hydride capacity upon cycling decreased. Notably, a low yield was caused by an obvious hydrogen deficit in the reaction since the milling was conducted in argon. Puszkiel et al. [212] showed hysteresis phenomena during the absorption-desorption cycle. Mechanically milled material in an argon atmosphere was further sintered to obtain 49 wt. $\% \mathrm{Mg}_{2} \mathrm{FeH}_{6}, 18$ wt. $\% \mathrm{MgH}_{2}$, and 6 wt. $\%$ and 27 wt. $\%$ unreacted $\mathrm{Mg}$ and $\mathrm{Fe}$, respectively. With the formation of $\mathrm{Mg}_{2} \mathrm{FeH}_{6}$ and $\mathrm{MgH}_{2}$ in the sample, the observed hysteresis tended to increase in size. The rate of hydrogen uptake increased with increasing temperature (in the range between $300{ }^{\circ} \mathrm{C}$ and $350^{\circ} \mathrm{C}$ ), while the total hydrogen content was $4.5 \mathrm{wt} . \%$.

The influence of milling time on the yield of $\mathrm{Mg}_{2} \mathrm{FeH}_{6}$ was examined for a ball-milled mixture of $\mathrm{MgH}_{2}$ and Fe powders in a two-step reaction by Polanski et al. [207,209]. The authors proved that the optimization of milling time was crucial, and the best yield $\left(>94 \% \mathrm{Mg}_{2} \mathrm{FeH}_{6}\right)$ was observed after $2 \mathrm{~h}$ of milling (so-called mechanical activation) with the setup used. Prolonged milling resulted in low yields after sintering. The two pressure plateaus suggested the occurrence of two phases $\left(\mathrm{MgH}_{2}\right.$ and $\left.\mathrm{Mg}_{2} \mathrm{FeH}_{6}\right)$, which was proven by XRD analysis. The authors could not precisely explain the phenomena behind the higher yield of the sample milled for two hours. However, they provided some hypotheses. Mechanical milling, in addition to forming a composite and lowering the diffusion distance, caused lattice deformation and partial amorphization. Hence, it is crucial to choose proper milling parameters. Later, a synthesis "efficiency map" was provided by Witek et al. [210] for the same two-step synthesis. The dependence of the $\mathrm{Mg}_{2} \mathrm{FeH}_{6}$ yield on the sintering temperature of the powders and the BM time was presented, providing an easy tool for readers to choose processing windows to obtain the best synthesis results. Yield calculations for each synthesis were based on a comparison of the closed crucible mass of samples before and after synthesis. Samples that were sintered at the same temperature had a highly similar phase composition despite differences in milling time. A yield of $97 \%$ was recorded for samples sintered at $500{ }^{\circ} \mathrm{C}$, which suggested almost full transformation. These results proved the research findings mentioned above. Too long or too short milling time was not beneficial for hydride synthesis, especially at low temperatures. It was suggested that this dependence might not be 
connected with the reaction kinetics but with the material properties after milling. A long milling time could lead to distinctly low heat conductivity. For this reason, samples with a high volume sintered for a relatively short time could not fully transform due to the lack of temperature equilibrium over the sample volume. With insufficient time, even further sintering would not guarantee full transformation. The authors suggested that since perfectly pure powders (substrates) cannot be assumed, a 100\% yield is clearly not possible, especially given the significant problems associated with obtaining $\mathrm{MgH}_{2}$ of high purity (more than $90 \%$ ) in reality.

Since it is difficult to perform magnesium-iron hydride synthesis with a reaction yield higher than $90 \%$, Nyallang et al. [223] preceded their synthesis by heat treatment of the starting materials $(2 \mathrm{Mg}+\mathrm{Fe}$ elemental powders). A maximum reaction yield of $84 \%$ was obtained in less than $5 \mathrm{~h}$ of milling. The two-step reaction-based synthesis exhibited very fast reaction kinetics and low thermal stability (in comparison to those of $\mathrm{MgH}_{2}$ ). These results were explained by Fe acting as a catalyst for the $\mathrm{MgH}_{2}, \mathrm{Mg}_{2} \mathrm{FeH}_{6}$, and Fe mixture.

\subsubsection{Formation Mechanism Analysis}

The formation mechanism of complex hydrides of $\mathrm{Mg}_{2} \mathrm{FeH}_{6}$ under equilibrium conditions has been broadly investigated recently $[38,209,210,224,225]$. In most cases, hydride synthesis results in a $\mathrm{MgH}_{2}-\mathrm{Mg}_{2} \mathrm{FeH}_{6}$ hydride mixture [35-38,204,226]. The above studies showed two different equilibrium pressures during dehydrogenation (a high pressure for $\mathrm{MgH}_{2}$ and low pressure for $\mathrm{Mg}_{2} \mathrm{FeH}_{6}$ ). However, only one equilibrium pressure was observed for hydrogenation from a $2 \mathrm{Mg}$-Fe stoichiometric mixture.

Puszkiel et al. [224] proposed a mechanism of $\mathrm{Mg}_{2} \mathrm{FeH}_{6}$ formation under equilibrium conditions for a $2 \mathrm{MgH}_{2}$-Fe powder mixture. During $\mathrm{BM}$ of the mixture, $\mathrm{Mg}_{2} \mathrm{FeH}_{6}$ and $\mathrm{MgH}_{2}$ were found to exist together from the beginning, but $\mathrm{Mg}_{2} \mathrm{FeH}_{6}$ was a result of reactions between elemental Fe and $\mathrm{Mg}$. The formation of $\mathrm{MgH}_{2}$ was enhanced by the presence of $\mathrm{Fe}$, but $\mathrm{MgH}_{2}$ did not take part as an intermediate in the formation of $\mathrm{Mg}_{2} \mathrm{FeH}_{6}$. It was noted that the partial formation of $\mathrm{Mg}_{2} \mathrm{FeH}_{6}$ could be attributed to the presence of $\mathrm{MgH}_{2}$ around Fe-rich particles, which acted as a solid-solid diffusion barrier. Polanski et al. [207] synthesized $\mathrm{Mg}_{2} \mathrm{FeH}_{6}$ by a two-step method with the use of a magnesium hydride powder and an iron powder as the starting materials. The synthesis first comprised mechanical milling of the $\mathrm{MgH}_{2}$ and Fe mixture over a short period in argon, followed by sintering at a high hydrogen pressure (>8.5 MPa). The samples were milled for different times (up to $3 \mathrm{~h}$ ), but the best results were obtained for the samples milled for $2 \mathrm{~h}$ after annealing at $500{ }^{\circ} \mathrm{C}$. Furthermore, the $\mathrm{Mg}_{2} \mathrm{FeH}_{6}$ synthesis/decomposition mechanisms were investigated. This time, the direct reaction of the $\mathrm{MgH}_{2}$ phase with Fe was shown to involve a two-step reaction: synthesis and then hydrogenation. The precursor for the formation of a ternary hydride (from the $\mathrm{MgH}_{2}-\mathrm{Fe}$ mixture) was $\mathrm{MgH}_{2}$. On the other hand, the decomposition path did not involve the above two-step reaction.

The two abovementioned cases prove that the formation of $\mathrm{Mg}_{2} \mathrm{FeH}_{6}$ may occur both as a reaction of magnesium hydride with iron and as a reaction of magnesium and iron in the presence of hydrogen, depending on the conditions. Decomposition, however, proceeds in only one way, whereby the ternary hydride is decomposed directly to two metals, and no magnesium hydride formation has ever been observed. Moreover, direct decomposition is quite understandable when considering the thermodynamics of both hydrides. Because the ternary hydride is more stable than magnesium hydride, under the pressure and temperature conditions that allow the decomposition of $\mathrm{Mg}_{2} \mathrm{FeH}_{6}$, no existence of magnesium hydride is possible.

\subsubsection{Light Complex Hydride Additives}

Several reports have shown that the decomposition temperature and sorption of ternary hydride kinetics may be improved. The beneficial effects of additives on $\mathrm{Mg}_{2} \mathrm{FeH}_{6}$ have been broadly investigated. Puszkiel and Gennari [227] showed that a composite mixture of Mg-Fe powders doped with $10 \mathrm{~mol} \%$ $\mathrm{LiBH}_{4}$ did not change the thermodynamics but led to a much higher capacity and faster kinetics than those of an undoped composite. Much research has focused on the interaction between $\mathrm{MgH}_{2}$ 
and light complex hydrides (such as $\mathrm{LiBH}_{4}$ and $\mathrm{LiNH}_{2}$ ). It was found that the sorption properties improved with the use of $\mathrm{LiBH}_{4}$ [228-230], whereas other Mg-based hydrides were treated rather as catalytic additives. Gosselin et al. [231] suggested that $\mathrm{LiBH}_{4}$, instead of acting as a catalyst for the synthesis of $\mathrm{Mg}_{2} \mathrm{FeH}_{6}$, inhibited its formation and promoted the existence of $\mathrm{MgH}_{2}$ during $\mathrm{BM}$ in an argon atmosphere. This effect resulted in obtaining the fastest kinetics for the $\mathrm{MgH}_{2}-\mathrm{Fe}$ sample without the borohydride dopant. However, the absorption situation was slightly different. Figure 15 shows the absorption kinetics curves for the three synthesized materials following the desorption of the ball-milled samples. Clearly, the samples with $\mathrm{LiBH}_{4}$ possessed not only faster kinetics but also a higher capacity. This effect was, however, hard to explain since the materials without the additive in such stoichiometry should have more than $5 \%$ capacity. Thus, the reason for this behavior has not been fully explained.

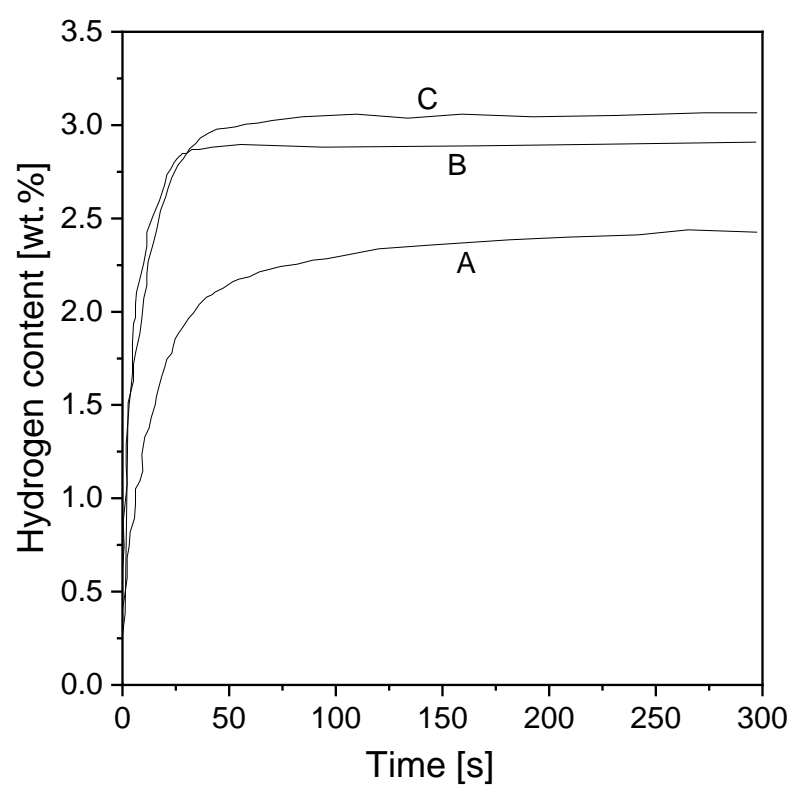

Figure 15. Absorption kinetics at $623 \mathrm{~K}$ for the first hydrogenation at $3 \mathrm{MPa}$. (A) $2 \mathrm{MgH}_{2}+\mathrm{Fe}$ ball milled for $10 \mathrm{~h}$, (B) $2 \mathrm{MgH}_{2}+$ Fe ball milled for $10 \mathrm{~h}$ and further milled with $\mathrm{LiBH}_{4}$ for an additional $1 \mathrm{~h}$, and (C) $2 \mathrm{MgH}_{2}+\mathrm{Fe}+\mathrm{LiBH}_{4}$ ball milled for $10 \mathrm{~h}$. The graph is based on [231].

\subsection{4. $\mathrm{Mg}_{2} \mathrm{FeH}_{6}$ as a Catalyst}

In some cases, the $\mathrm{Mg}_{2} \mathrm{FeH}_{6}$ phase is used not as a base compound but as a catalyst [232,233]. In an initial study, the hydrogen storage properties of a $5 \mathrm{LiBH}_{4}+\mathrm{Mg}_{2} \mathrm{FeH}_{6}$ system were investigated. Magnesium-iron hydride was synthesized using $2 \mathrm{Mg}$-Fe powders as starting materials. During low-pressure decomposition, improved dehydrogenation was noted as a result of the in situ formation of $\mathrm{Mg}$ and Fe particles. These particles were products of the self-decomposition of magnesium-iron hydride before the dehydrogenation of $\mathrm{LiBH}_{4}$. A three-step desorption was observed with a total hydrogen desorption capacity of $8 \mathrm{wt} . \%$ over $300 \mathrm{~min}$. Even after several cycling tests, the dehydrogenation capacity for the mixture was approximately $6.5 \mathrm{wt} . \%$ at $450{ }^{\circ} \mathrm{C}$. Moreover, the $\mathrm{MgH}_{2}$-to- $\mathrm{Mg}_{2} \mathrm{FeH}_{6}$ transformation did not fully occur, which caused a decrease in the hydrogen sorption capacity and in the kinetics of the final dehydrogenation step as a result of the formation of Fe-boride, which acted as a formation nucleus for $\mathrm{MgB}_{2}$.

Later, the dehydriding properties of $\mathrm{LiBH}_{4}$ with $\mathrm{Mg}_{2} \mathrm{FeH}_{6}$ were examined by $\mathrm{Li}$ et al. [233]. $\mathrm{Mg}_{2} \mathrm{FeH}_{6}$ was synthesized by the mechanical milling of magnesium hydride and elemental Fe powder. Subsequent heat treatment was performed in a hydrogen atmosphere, and then the materials were mixed with $\mathrm{LiBH}_{4}$. The addition of magnesium-iron hydride to $\mathrm{LiBH}_{4}$ caused simultaneous dehydriding reactions, although their dehydriding temperatures were distinctly different by approximately $73^{\circ} \mathrm{C}$. 
The peaks occurred at 225 and $455{ }^{\circ} \mathrm{C}$ for pure $\mathrm{Mg}_{2} \mathrm{FeH}_{6}$ and $\mathrm{LiBH}_{4}$, respectively. Mixing these two compounds resulted in hydrogen desorption from $255-305{ }^{\circ} \mathrm{C}$. With a low magnesium-iron hydride concentration (according to the chemical formula of the compound $\mathrm{xLiBH}_{4}+(1-\mathrm{x}) \mathrm{Mg}_{2} \mathrm{FeH}_{6}$ ), the dehydriding temperature increased, and the one-step reaction transformed into a multistep reaction.

\subsection{Reactive Ball Milling}

$\mathrm{MgH}_{2}$ was milled together with $\mathrm{Fe}$ in a $\mathrm{H}_{2}$ atmosphere at room temperature for the first time by Huot et al. [222]. Notably, it took $10 \mathrm{~h}$ to observe the presence of $\mathrm{Mg}_{2} \mathrm{FeH}_{6}$. The $\mathrm{MgH}_{2}$ phase disappeared after $30 \mathrm{~h}$ of $\mathrm{BM}$, replaced by $\mathrm{Mg}_{2} \mathrm{FeH}_{6}$ and pure magnesium. An increase in milling time (up to $60 \mathrm{~h}$ ) did not change the distribution of existing phases. The hydride efficiency after $60 \mathrm{~h}$ of milling was $56 \%$. Furthermore, compared with sintered samples, the as-prepared samples demonstrated better reversibility and decreased hydride capacity after cycling (reduction by $\sim 5 \%$ ). Later, Castro et al. [39] performed $140 \mathrm{~h}$ of total milling of a $2 \mathrm{MgH}_{2}+\mathrm{Fe}$ mixture, obtaining a $\mathrm{Mg}_{2} \mathrm{FeH}_{6}$ yield no higher than $15.6 \mathrm{wt} . \%$ at $100 \mathrm{~h}$. Further increases in milling time caused the $\mathrm{Mg}_{2} \mathrm{FeH}_{6}$ peak intensity to decrease and the $\mathrm{MgO}$ peaks to increase. After $10 \mathrm{~h}$ of milling, one endothermic reaction was noted at $370{ }^{\circ} \mathrm{C}$. Samples milled for $60 \mathrm{~h}$ were characterized by a two-step reaction, but increased milling time (80-100 h) again showed a one-step reaction. Due to a decrease in particle size and more uniform mixing between $\mathrm{MgH}_{2}$ and Fe particles, the endothermic peaks shifted toward lower temperatures. In the same research, a $2 \mathrm{Mg}+\mathrm{Fe}$ mixture milled under similar conditions demonstrated an almost two-fold higher reaction yield $(\sim 30 \mathrm{wt} . \%)$. Both values were determined from the area under the DSC curves (Figure 16). The decomposition temperature was found to be $\sim 50{ }^{\circ} \mathrm{C}$ lower than that for the $2 \mathrm{MgH}_{2}+\mathrm{Fe}$ mixture for short milling times. For long milling times, the peak angle positions did not change significantly, but the gap between the two mixtures was $\sim 25{ }^{\circ} \mathrm{C}$. Similar research was reported by Asselli et al., in which milling and reactive mechanical milling (RMM) were used to synthesize $2 \mathrm{Mg}+\mathrm{Fe}$ and $2 \mathrm{MgH}_{2}+\mathrm{Fe}$ mixtures [234]. The hydrogen atmosphere caused the particle size to decrease, which improved homogeneity and resulted in a phase abundance of up to $~ 88 \mathrm{wt} . \%$ $\mathrm{Mg}_{2} \mathrm{FeH}_{6}$ (for a $2 \mathrm{MgH}_{2}+\mathrm{Fe}$ mixture synthesized at a certain hydrogen pressure).

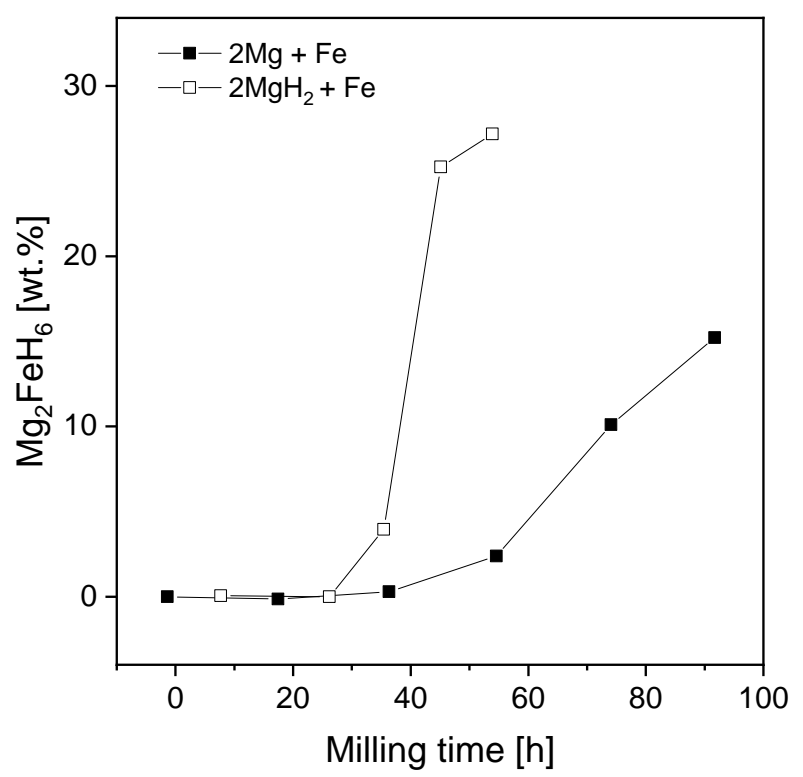

Figure 16. Amount of $\mathrm{Mg}_{2} \mathrm{FeH}_{6}$ as a function of milling time for two mixtures: $2 \mathrm{Mg}+\mathrm{Fe}$ and $2 \mathrm{MgH}_{2}+\mathrm{Fe}$. The curves are based on [39].

Herrich et al. [40] used an RBM method at room temperature with mixtures of $\mathrm{MgH}_{2}$ and $\mathrm{Fe}$ powders at different atomic stoichiometries. The effect of different addition amounts of Fe on the synthesized powders was studied. The hydrogen storage capacity of the material after $80 \mathrm{~h}$ milling 
was 5.2 wt.\%., and 78 wt. $\% \mathrm{Mg}_{2} \mathrm{FeH}_{6}$ was achieved, as well as 20 wt.\% pure Fe, 0.5 wt.\% magnesium hydride and $\sim 1.5 \mathrm{wt} . \% \mathrm{MgO}$. Magnesium oxide was most likely present due to the presence of oxygen during milling. Finally, a 92 wt. $\% \mathrm{Mg}_{2} \mathrm{FeH}_{6}$ yield was achieved by changing the Fe concentration during milling. The decomposition temperature was established as $355^{\circ} \mathrm{C}$, which is significantly lower than the previously reported value of $428{ }^{\circ} \mathrm{C}$ [222]. During reabsorption at $1 \mathrm{MPa}$ of hydrogen pressure and $300{ }^{\circ} \mathrm{C}$, the hydrogen uptake decreased to $\sim 3 \mathrm{wt} . \%$. This decrease was a result of the disproportionation of $\mathrm{Mg}_{2} \mathrm{FeH}_{6}$ into elemental magnesium and iron upon desorption and the formation of magnesium hydride during rehydrogenation. The authors claimed that the synthesis rate of magnesium-iron hydride was not enhanced by the temperature of the vial but rather the high energy input during milling. With the above method, a reaction yield of up to $92 \mathrm{wt}$ \% was achieved. Another study [235] consisted of premilling Mg and Fe powder in an inert atmosphere (argon) and further BM at a certain hydrogen pressure. Unfortunately, the efficiency was relatively low (with the highest yield being $\sim 34 \mathrm{wt} . \%$ ) due to the presence of unreacted Fe. The premilling of elemental powders can accelerate $\mathrm{Mg}_{2} \mathrm{FeH}_{6}$ formation, but such premilling needs to be optimized because a $90 \mathrm{wt} \% \mathrm{Mg}_{2} \mathrm{FeH}_{6}$ phase abundance was achieved in a later work [205,236].

An investigation of the microstructure and the hydrogenation behavior of magnesium-iron hydride was conducted with mechanically alloyed 2Mg-Fe [217], and a broad description of the $\mathrm{Mg}_{2} \mathrm{FeH}_{6}$ phase forming process was provided. All powders were synthesized in a $0.88 \mathrm{MPa}$ hydrogen atmosphere with different alloying times (in the range of 18-270 h). The presence of different phases was noticed after continuous and sequential milling. For all powders, only a single endothermic peak was visible, even for the material containing both $\beta-\mathrm{MgH}_{2}$ and $\mathrm{Mg}_{2} \mathrm{FeH}_{6}$ phases (in the temperature range of $274-289^{\circ} \mathrm{C}$ ). The TGA curves showed a maximum weight loss of $3.7 \mathrm{wt}$. $\%$ for the $2 \mathrm{Mg}-\mathrm{Fe}$ mixture ball milled for $270 \mathrm{~h}$.

\subsubsection{Improvements in Reaction Yield}

In the context of $\mathrm{Mg}_{2} \mathrm{FeH}_{6}$ synthesis, most research is focused on improving the reaction yield. Since a yield of $55 \mathrm{wt}$ \% had been previously achieved by a nonreactive BM method, Gennari et al. [38] attempted $\mathrm{Mg}_{2} \mathrm{FeH}_{6}$ synthesis from a $2 \mathrm{Mg}+$ Fe mixture by $\mathrm{RBM}$ without a subsequent sintering step. The first $\mathrm{Mg}_{2} \mathrm{FeH}_{6}$ peak was visible in the XRD pattern after $40 \mathrm{~h}$ of milling. After $60 \mathrm{~h}$ of milling, no $\mathrm{MgH}_{2}$ peak was visible, but the presence of metallic Fe with $\mathrm{Mg}_{2} \mathrm{FeH}_{6}$ was noted. According to the authors, a decrease in crystallite size, amorphization, and/or plastic deformation occurred by the end of the process, as indicated by peak broadening. DSC analysis showed an endothermic peak at 321 and $303{ }^{\circ} \mathrm{C}$ after 10 and $30 \mathrm{~h}$ of milling, respectively, proving the decomposition of $\mathrm{MgH}_{2}$. The decomposition temperatures shifted to low values of approximately $100{ }^{\circ} \mathrm{C}$ (in comparison to that of pure magnesium hydride synthesized by MA) due to the presence of Fe, particle size reduction, increased surface area, and morphological changes. The authors observed that the presence of Fe had an influence on the thermal stability of magnesium hydride and acted as a catalyst in the desorption process for samples with short milling times. Hence, this approach caused a decrease in activation energy of approximately $60 \mathrm{~kJ} / \mathrm{mol}$. After $60 \mathrm{~h}$ of milling, the $\mathrm{Mg}_{2} \mathrm{FeH}_{6}$ yield was approximately $30 \mathrm{wt} . \%$, and an increase in milling time did not further increase the yield. It was shown that the two-step formation of $\mathrm{Mg}_{2} \mathrm{FeH}_{6}$ involved the presence of the $\mathrm{MgH}_{2}$ phase. The experiment proved that $\mathrm{MgH}_{2}$ was unstable upon the formation of $\mathrm{Mg}_{2} \mathrm{FeH}_{6}$. During the first $40 \mathrm{~h}$ of milling, the amount of $\mathrm{MgH}_{2}$ increased to $23 \mathrm{wt} \%$ and then dropped significantly. From that moment, $\mathrm{Mg}_{2} \mathrm{FeH}_{6}$ started to appear.

The synthesis of $\mathrm{Mg}_{2} \mathrm{FeH}_{6}$ from elemental powders was performed by Gennari et al. [38] with a single-step reaction that required no further sintering. The investigation showed that the $\mathrm{MgH}_{2} \mathrm{phase}$ peak increased up to $60 \mathrm{~h}$ of milling, at which point $\mathrm{Mg}_{2} \mathrm{FeH}_{6}$ started to form. A further study [39] found that the synthesis of $\mathrm{Mg}_{2} \mathrm{FeH}_{6}$ proceeded by the formation of $\mathrm{MgH}_{2}$ followed by the reaction of this hydride with Fe. XRD peaks indicated that with continuous milling, the $\mathrm{MgH}_{2}$ phase disappeared due to $\mathrm{Mg}_{2} \mathrm{FeH}_{6}$ formation. The maximum yield of ball-milled $\mathrm{Mg}_{2} \mathrm{FeH}_{6}$ in an inert atmosphere was 
estimated to be 15.6 wt.\% after $100 \mathrm{~h}$, which was significantly lower than the value observed for a mixture synthesized in a hydrogen atmosphere. Moreover, the whole process lasted longer in an inert atmosphere. $\mathrm{Mg}_{2} \mathrm{FeH}_{6}$ synthesis from $2 \mathrm{MgH}_{2}+$ Fe resulted in a shorter synthesis time and a higher reaction yield as an effect of prolonged surface contact between $\mathrm{Mg}$ and Fe. Huen et al. [236] performed $\mathrm{Mg}_{2} \mathrm{FeH}_{6}$ synthesis by milling pure $\mathrm{Mg}$ with Fe powder. The product was intended for use as a conversion-type anode for solid-state lithium batteries with a $\mathrm{LiBH}_{4}$ electrolyte. The as-synthesized sample composition was 92 wt. $\% \mathrm{Mg}_{2} \mathrm{FeH}_{6}$ and 8 wt.\% unreacted Fe.

\subsubsection{Nanostructurization Effect}

As in the binary magnesium hydride case, the main focus of nanostructurization is to obtain improved solid-state hydrogen storage materials. Many attempts have been made to decrease crystallite size to achieve great improvements in the hydrogen absorption/desorption rates of magnesium-iron hydrides synthesized by RBM methods [205,208,215,235,237,238].

A natural continuation of research by Li and Varin [235] was conducted to study the synthesis of nanomagnesium-iron hydride by RBM in high-energy impact mode [237]. Two types of RMA were applied to Mg and Fe powders: sequential and continuous. Using the continuous RMA mode was predicted to inhibit $\mathrm{MgO}$ formation and provide a much higher yield because it had been proven that $\mathrm{MgO}$ is a primary factor that suppresses magnesium-iron hydride formation. After continuous milling for $270 \mathrm{~h}, \sim 57 \mathrm{wt}$ \% magnesium-iron hydride was noted (in comparison to $\sim 34 \mathrm{wt} \%$ obtained in previous work [235]). The desorption (3.13 wt.\% $\mathrm{H}_{2}$ in the DSC test and $2.83 \mathrm{wt} . \%$ in the TGA test) temperatures were in a relatively narrow range of $200-300^{\circ} \mathrm{C}$, which corresponded to $10-20 \mathrm{~min}$ of reaction. The size of the nanograins was estimated to be in the range of $\sim 5-13 \mathrm{~nm}$. Samples milled in sequential mode desorbed just under half the hydrogen content desorbed by the samples synthesized in continuous mode, but no hydrogen desorption was noted in the $250-90{ }^{\circ} \mathrm{C}$ temperature range in sequential mode.

Yan Wang et al. [205] prepared nanocrystalline $\mathrm{Mg}_{2} \mathrm{FeH}_{6}$ by $\mathrm{BM}$ a $3 \mathrm{Mg}+\mathrm{Fe}$ mixture at room temperature and $0.55 \mathrm{MPa}$ hydrogen pressure. Structural analysis was conducted and showed a chrysanthemum-like nanostructure composed of aggregated spherical $\mathrm{Mg}_{2} \mathrm{FeH}_{6}$. The total mass loss was $5.15 \mathrm{wt}$ \%, which was correlated to hydrogen desorption from the magnesium-iron hydride phase in a temperature range of 60 to $340{ }^{\circ} \mathrm{C}$. The same experiment was carried out by Asseli et al. [238] but at $3 \mathrm{MPa}$ hydrogen pressure and with the additional synthesis of a $2 \mathrm{Mg}$-Fe mixture. Under the same conditions, the synthesized $3 \mathrm{Mg}$-Fe and $2 \mathrm{Mg}$-Fe mixtures had hydrogen gravimetric density values of $\sim 5.2 \mathrm{wt} . \%$ and $\sim 3.5 \mathrm{wt} . \%$, respectively. The higher hydrogen capacity of the $3 \mathrm{Mg}$-Fe mixture was a result of the presence of $\alpha-\mathrm{MgH}_{2}$ and complete reaction between the metallic elements and hydrogen. In the case of the $2 \mathrm{Mg}$-Fe mixture, a $65 \mathrm{wt} . \% \mathrm{Mg}_{2} \mathrm{FeH}_{6}$ abundance was noted.

A highly nanocrystalline mixture of $\mathrm{MgH}_{2}$ and $\mathrm{Mg}_{2} \mathrm{FeH}_{6}$ was synthesized by $\mathrm{RBM}$ of $3 \mathrm{MgH}_{2}-\mathrm{Fe}$ (sample A) and $40 \mathrm{MgH}_{2}$-Fe (sample B) at room temperature and $3 \mathrm{MPa}$ hydrogen pressure [215]. The crystallite dimensions were estimated as $\sim 10 \mathrm{~nm}$ and increased with increasing cycling temperature. The same dependence was noticed for the sorption kinetics. The differential thermal analysis (DTA) results (performed before any hydrogenation cycling) proved that a two-step reaction occurred for sample A $\left(\sim 4.1 \%\right.$ weight loss in the 210 to $300{ }^{\circ} \mathrm{C}$ temperature range) and that a one-step reaction occurred for sample B. The two-step desorption was a consequence of the subsequent dehydrogenation of magnesium hydride and $\mathrm{Mg}_{2} \mathrm{FeH}_{6}$ in materials obtained either during the $\mathrm{BM}$ of $\mathrm{MgH}_{2}$ and $\mathrm{Fe}$ or by the direct hydrogenation of these powders. The total amount of hydrogen stored in the sample was $\sim 4.8 \mathrm{wt} . \%$. The above results indicated that the composition of sample A was $30 \mathrm{wt} . \%$ magnesium hydride and $\sim 44 \mathrm{wt} . \%$ magnesium-iron hydride at $335^{\circ} \mathrm{C}$ (first peak) and then changed to $\sim 24 \mathrm{wt} . \%$ magnesium hydride and $\sim 54 \mathrm{wt} . \%$ magnesium-iron hydride at $390{ }^{\circ} \mathrm{C}$ (second peak).

A breakthrough was made by Brutti et al. [239]. A mixture of $2 \mathrm{MgH}_{2}+\mathrm{Fe}$ was synthesized by two methods: RBM at a high hydrogen pressure (5 MPa) and hand grinding. To obtain full conversion, various hydrogenation temperatures were implemented. The full magnesium-iron hydride conversion, 
calculated from the widths of the plateaus at various temperatures, was higher than $97 \%$ at $485^{\circ} \mathrm{C}$. Decreasing the iron particle size caused the $\mathrm{Mg}$ and Fe powders to mix more easily. Much shorter diffusion occurred, which was beneficial for producing a high magnesium hydride abundance. Furthermore, increased cycling temperature promoted $\mathrm{Mg}_{2} \mathrm{FeH}_{6}$ formation (the magnesium hydride concentration at $485^{\circ} \mathrm{C}$ was lower than $3 \%$ ). A total hydrogen capacity of up to 5.4 wt. $\%$ at $485^{\circ} \mathrm{C}$ was noted for the ball-milled sample, which corresponded to pure $\mathrm{Mg}_{2} \mathrm{FeH}_{6}$.

\subsubsection{Cycling Stability}

In general, $\mathrm{Mg}$-Fe mixtures seem to be extremely stable upon cycling. However, in some cases, capacity loss has been observed. The evolution of the hydrogen storage capacity throughout hydrogenation-dehydrogenation cycles was measured by Puszkiel et al. [218] with three different $\mathrm{Mg}$-Fe ratios. The measured hydrogen capacity for a $15 \mathrm{Mg}$-Fe mixture before and after cycling at $375^{\circ} \mathrm{C}$ was 6.6 and 4.3 wt. $\% \mathrm{H}_{2}$, respectively. Two effects could be responsible for the decreased hydrogen capacity upon cycling: $\mathrm{Mg}$ evaporation under moderate pressure conditions and $\mathrm{Mg}_{2} \mathrm{FeH}_{6}$ formation. The cycling process did not affect the hydrogenation kinetics behavior, but the dehydrogenation kinetics properties worsened. Unfortunately, the relative amount of the $\mathrm{Mg}_{2} \mathrm{FeH}_{6}$ phase before and after cycling (at $375^{\circ} \mathrm{C}$ ) was 23 and $27 \mathrm{wt} . \%$ for $2 \mathrm{Mg}-\mathrm{Fe}$, respectively, and 0 and $11 \mathrm{wt} . \%$ for $15 \mathrm{Mg}-\mathrm{Fe}$. The other remaining phases were magnesium hydride and some unreacted pure Fe. On the other hand, no formation of $\mathrm{Mg}_{2} \mathrm{FeH}_{6}$ was observed by Varin et al. [240] from BM 2Mg-Fe mixtures (in only a hydrogen atmosphere or with additional prealloying in an argon atmosphere). The samples were "aged", which meant they were stored for approximately four months in an argon atmosphere and examined after that time. The authors suggested that initially, crystalline $\mathrm{Mg}$ became amorphous with increasing milling time ( $\beta-\mathrm{MgH}_{2}$ amorphization). Weight losses on the order of $\sim 2-4$ wt. $\%$ and a single DSC peak corresponding to the release of hydrogen, mostly from the amorphous hydrides, were observed. Exposing the ball-milled mixture to moisture showed for the first time that $\beta-\mathrm{MgH}_{2}$ underwent hydrolysis into $\mathrm{Mg}(\mathrm{OH})_{2}$, which was related to the high weight loss (up to 10 wt.\%). Urbanczyk et al. performed twenty-three dehydrogenation/hydrogenation cycles in a tube storage tank with a $2 \mathrm{Mg}$-Fe powder mixture [219]. The material was tested at temperatures between 395 and $515^{\circ} \mathrm{C}$ and pressures between 1.5 and 8.6 MPa. Phase analysis showed mainly $\mathrm{Mg}_{2} \mathrm{FeH}_{6}$ with a small amount of $\mathrm{MgH}_{2}$ and pure Fe, but the hydrogen capacity was only $3.8 \mathrm{wt} . \%$.

\section{4. $\mathrm{Mg}_{2} \mathrm{NiH}_{4}$}

Another popular magnesium-based hydride is $\mathrm{Mg}_{2} \mathrm{NiH}_{4}$, which was first reported by Reilly and Wiswall [31]. The precursor $\mathrm{Mg}_{2} \mathrm{Ni}$ phase existed in the $\mathrm{Mg}-\mathrm{Ni}$ binary system, and the hydride had a theoretical hydrogen gravimetric density of $3.6 \mathrm{wt}$ \% with at least two distinct polymorphs [241]. The dissociation enthalpy was $-64 \mathrm{~kJ} / \mathrm{mol} \mathrm{H}_{2}$ [38,241], which made $\mathrm{Mg}_{2} \mathrm{NiH}_{4}$ less stable than magnesium hydride (a higher equilibrium pressure at the same temperature). The first reaction path provided by Reilly and Wiswall [31] turned out to be reversible:

$$
\mathrm{Mg}_{2} \mathrm{Ni}+2 \mathrm{H}_{2} \rightleftarrows \mathrm{Mg}_{2} \mathrm{NiH}_{4}
$$

It has been reported that $\mathrm{Mg}_{2} \mathrm{Ni}$ can be produced by metallurgical methods, both pure and with intentional excess of magnesium [242]. Even if produced as a homogenous, almost single-phase material, it still needs activation at elevated temperature $\left(\sim 300^{\circ} \mathrm{C}\right)$ before it can absorb hydrogen from the gas phase [243,244]. Usually, this procedure first requires 10-20 absorption/desorption cycles. Therefore, in 1995, Singh and Zaluski $[245,246]$ used MA for the first time to produce $\mathrm{Mg}_{2} \mathrm{Ni} \mathrm{Mg}_{2} \mathrm{NiH}_{4}$ had a lower hydrogen desorption temperature $\left(250^{\circ} \mathrm{C}\right)$ than magnesium hydride and faster kinetics [241]. Further examination of this material proved that $\mathrm{Mg}_{2} \mathrm{NiH}_{4}$ exhibited changes in color with even a small microstructure change, thus exhibiting surface sensitivity. These differences were found to influence the desorption kinetics of the hydride, which was examined and described by Rönnebro [247]. 
Javadian et al. [248] successfully nanoconfined (for the first time) a $\mathrm{LiBH}_{4}-\mathrm{Mg}_{2} \mathrm{NiH}_{4}$ reactive hydride composite into two types of mesoporous carbons. The results were compared to those of a previous synthesis by ball milling performed by Vajo et al. [249]. According to the results, faster kinetics of hydrogen desorption were noted with a progressive loss of capacity upon cycling.

$\mathrm{Mg}_{2} \mathrm{NiH}_{4}$ structures have been identified as ordered low-temperature and disordered high-temperature phases with $\mathrm{C} 2 / \mathrm{m}$ and $\mathrm{C} 2 / \mathrm{c}$ space groups, respectively [241]. The high-temperature phase has a cubic structure (pseudo- $\mathrm{CaF}_{2}$ type). The $\mathrm{Ni}$ atoms are arranged on the cube edges and the cube face centers. The magnesium atoms have tetragonal positions [250], and the low-temperature phase has a monoclinic structure [250]. Despite many years of investigations, this complex hydride is still not fully known, but some research proved that several polymorphic phases exist (two low-temperature and two high-temperature phases). Increasing the temperature above $235{ }^{\circ} \mathrm{C}$ results in a phase transition [241,251,252]. In the low-temperature phase, the hydrogen atoms in the $\mathrm{NiH}_{4}{ }^{4-}$ complexes are rigid and have an orderly arrangement. In the high-temperature phase, they start to demonstrate reorientation motion around the central $\mathrm{Ni}$ atom. Cooling the hydride to room temperature leads to the introduction of a microtwinned form [43,253-255].

The transition from the low-temperature phase to the high-temperature phase was first noticed in 1979 [250]. Further analysis showed that the phase transition from the high-temperature to the low temperature phase occurred at $\sim 235^{\circ} \mathrm{C}$ [256]. Polanski et al. [254] synthesized cubic $\mathrm{Mg}_{2} \mathrm{NiH}_{4}$ with a yield of $\sim 90 \%$ from a mechanically milled $\mathrm{MgH}_{2}$ and Ni mixture at a molar ratio of 2:1 in an argon atmosphere with subsequent sintering and observed the product in situ by synchrotron powder X-ray diffraction (SRPXD). The hydride had a polymorphic form after cooling to room temperature. Subsequent heating at high hydrogen pressure (10-12 MPa) initiated the formation of the first high-temperature structure, which was followed by hydride decomposition with $\mathrm{Mg}_{2} \mathrm{Ni}$ formation. The synthesized ternary hydride had nanoscale grains and decomposed in a one-step reaction upon heating in a helium atmosphere.

$\mathrm{Mg}_{2} \mathrm{NiH}_{4}$ has a hydrogen volumetric capacity $40 \%$ lower than that of $\mathrm{Mg}_{2} \mathrm{FeH}_{6}$ and a lower theoretical gravimetric density ( $3.6 \mathrm{wt} . \%$ in comparison with $5.6 \mathrm{wt}$ \%). Currently, $\mathrm{Mg}_{2} \mathrm{NiH}_{4}$, similar to $\mathrm{MgH}_{2}$ and $\mathrm{Mg}_{2} \mathrm{FeH}_{6}$, is not the first material considered for potential use in mobile applications because of its relatively low hydrogen capacity and high desorption temperature.

\section{1. $\mathrm{Mg}_{2} \mathrm{NiH}_{4}$ Synthesis/Mechanical Modifications}

Among magnesium-based alloys, $\mathrm{Mg}_{2} \mathrm{Ni}$ is another attractive option due to its relatively high capacity and favorable thermodynamics. However, the technological application of materials with a $\mathrm{Ni}$ component is limited by their cost. Much research has been devoted to using a combustion synthesis method for $\mathrm{Mg}_{2} \mathrm{NiH}_{4}$ production [257-260], and combustion synthesis remains the most popular way of producing this particular complex hydride. On the other hand, together with other complex hydrides $\left(\mathrm{Mg}_{2} \mathrm{FeH}_{6}\right.$ and $\left.\mathrm{Mg}_{2} \mathrm{CoH}_{5}\right), \mathrm{Mg}_{2} \mathrm{NiH}_{4}$ can be synthesized by using pure metals with hydrogen gas by $\mathrm{BM}$ or by sintering in a hydrogen atmosphere at high hydrogen pressure/high hydrostatic pressure. $\mathrm{Mg}_{2} \mathrm{Ni}$ absorbs hydrogen at moderate temperatures and pressures, and the hydride $\mathrm{Mg}_{2} \mathrm{NiH}_{4}$, with a $3.6 \mathrm{wt}$ \% \% hydrogen capacity, can be formed [245]. However, this compound still desorbs hydrogen at relatively high temperatures (above $220^{\circ} \mathrm{C}$ ), which is problematic. Hydrogenation usually occurs at 250-350 ${ }^{\circ} \mathrm{C}$ and 1.5-5 MPa hydrogen pressure [246].

The crystalline $\mathrm{Mg}_{2} \mathrm{Ni}$ alloy produced by BM is characterized by better surface properties than those of corresponding materials prepared by conventional metallurgical methods [246]. The hydrogenation enthalpy of $\mathrm{Mg}_{2} \mathrm{NiH}_{4}\left(-64.5 \mathrm{~kJ} / \mathrm{mol} \mathrm{H}_{2}\right)$ is lower than the enthalpy of $\mathrm{MgH}_{2}$ formation $(-75 \mathrm{~kJ} / \mathrm{mol}$ $\mathrm{H}_{2}$ ) [42,261]. Under normal conditions, $\mathrm{Mg}_{2} \mathrm{NiH}_{4}$ is too stable and useless for room temperature applications. The main goal is to decrease the stability of $\mathrm{Mg}_{2} \mathrm{NiH}_{4}$ to produce a suitable material for practical hydrogen storage. 


\subsubsection{Synthesis Mechanism}

Baum et al. [262] performed RBM in a hydrogen atmosphere of a pure elemental 2Mg-Ni powder mixture. The total amount of hydrogen absorbed did not correspond to ideal stoichiometry. During the first $2 \mathrm{~h}$ of the experiment, stable but slow hydrogen absorption was observed. The XRD patterns showed both metallic $\mathrm{Mg}$ and $\beta-\mathrm{MgH}_{2}$ phases. The reaction between $\mathrm{Mg}_{2} \mathrm{Ni}$ and $\mathrm{H}_{2}$ resulted in the existence of both phases: $\mathrm{Mg}_{2} \mathrm{NiH}_{4}$ and $\mathrm{Mg}_{2} \mathrm{Ni}$. $\mathrm{Mg}_{2} \mathrm{NiH}_{4}$ reversibly formed from $\mathrm{Mg}_{2} \mathrm{Ni}$, which made it the only transition metal complex hydride with a corresponding hydrogen-free intermetallic precursor. The decomposition of $\mathrm{Mg}_{2} \mathrm{NiH}_{4}$ started at $274{ }^{\circ} \mathrm{C}$, which was visible as an exothermic peak.

The reactive synthesis of $\mathrm{Mg}_{2} \mathrm{NiH}_{4}$ has been previously achieved. However, with the use of pure $\mathrm{H}_{2}$ gas remains problematic. $\mathrm{Mg}_{2} \mathrm{FeH}_{6}, \mathrm{Mg}_{2} \mathrm{CoH}_{5}$, and $\mathrm{Mg}_{2} \mathrm{NiH}_{4}$ synthesis was performed by grinding metal powders at $9 \mathrm{MPa} \mathrm{H}_{2}$ pressure [220], which resulted in nanocrystallites ( $\left.\sim 10 \mathrm{~nm}\right)$. Hydriding combustion synthesis was also attempted. This method has been combined with mechanical milling for the production of magnesium-based hydrogen storage alloys [263]. BM in an inert atmosphere followed by hydrogenation has received great attention as a pioneering technique for the preparation of nanocrystalline hydrogen storage materials such as $\mathrm{Mg}_{2} \mathrm{NiH}_{4}$. Ayoagi et al. [264] attempted hydrogenation on previously ball-milled $\mathrm{Mg}_{2} \mathrm{Ni}$. The unmilled sample did not absorb hydrogen at all, while even a short milling time led to hydrogen absorption. New surfaces helped to improve the hydrogen absorption rate, which occurred even at room temperature. With an increase in milling time, the particle size decreased and reached $\sim 5 \mu \mathrm{m}$. Melting and crushing the $\mathrm{Mg}_{2} \mathrm{Ni}$ powder, followed by hydrogenation, led to $\mathrm{Mg}_{2} \mathrm{NiH}_{4}$ formation [204]. Very fast hydrogenation at relatively low temperatures $\left(230-330^{\circ} \mathrm{C}\right)$ was correlated with hydrogen capacity losses $(\sim 3 \mathrm{wt} . \%$ at $0.04-0.28 \mathrm{MPa})$.

Sashi et al. [180] performed studies on the catalytic effect of transition metals (Ti, $\mathrm{Fe}$, and $\mathrm{Ni}$ ) on the hydrogen storage properties of nano- $\mathrm{MgH}_{2}$. Mechanical milling of $\mathrm{MgH}_{2}$ separately from $\mathrm{Ni}$ showed XRD peaks corresponding to the $\mathrm{Mg}_{2} \mathrm{NiH}_{4}$ phase. On the other hand, milling magnesium hydride together with all the above elements did not cause the $\mathrm{Mg}_{2} \mathrm{NiH}_{4}\left(\right.$ or $\left.\mathrm{Mg}_{2} \mathrm{FeH}_{6}\right)$ phase to form due to the presence of Ti. According to the authors' statements, Ti had little to no solubility with $\mathrm{Mg}$. Hence, it partially screened the diffusion of $\mathrm{Ni}$ ( or $\mathrm{Fe}$ ) on the surface of magnesium hydride to form ternary hydrides.

Martinez-Coronado et al. [265] showed a simplified method of milling magnesium hydride with pure metallic nickel in a nitrogen atmosphere at room temperature. Different $\mathrm{MgH}_{2}$ to Ni ratios (2:1, 2:0.9 and 2:0.8) as well as different milling times ( $4-16 \mathrm{~h}$ ) were examined (samples B-F). A yield of up to $93.2 \% \mathrm{Mg}_{2} \mathrm{NiH}_{4}$ was achieved with hydrogen capacity values between 2.8 and $3.24 \mathrm{wt} . \%$, which were lower than the theoretical value of $3.6 \mathrm{wt} . \%$ (Figure 17). It was noted that a $\mathrm{H}_{2}$ atmosphere was not needed for hydride synthesis. The desorption process started at a temperature between 217 and $260^{\circ} \mathrm{C}$. The authors state that the complex hydride decomposed into elemental magnesium and nickel and underwent further oxidation, regardless of the presence of a reducing $\mathrm{H}_{2} / \mathrm{N}_{2}$ flow. However, this statement seems to be very controversial given that this hydride usually decomposes into a $\mathrm{Mg}_{2} \mathrm{Ni}$ intermetallic phase [254]. An endothermic peak associated with the decomposition of $\mathrm{Mg}_{2} \mathrm{NiH}_{4}$ was observed at temperatures between 267 and $297^{\circ} \mathrm{C}$. It is worth noting that the character of the TGA curves (a steep increase in mass) (Figure 17) showed that it was very likely that an oxidation reaction with nitrogen took place during the decomposition process. In this case, the validity of the obtained results is debatable and may not be trustworthy.

RMM has also been used to synthesize a $\mathrm{Mg}_{2} \mathrm{Ni}-\mathrm{H}$ system [266]. $\mathrm{Mg}_{2} \mathrm{Ni}$ was milled in a hydrogen atmosphere. The achieved hydrogen capacity was $1.6 \mathrm{wt} . \% \mathrm{H}_{2}$ without changing the crystal structure $\left(\mathrm{Mg}_{2} \mathrm{Ni}\right.$ type). The hydriding properties were described as most likely reversible at temperatures below $200{ }^{\circ} \mathrm{C}$, whereas above $200^{\circ} \mathrm{C}$, the disordered intergrain area changed into a crystalline phase. 


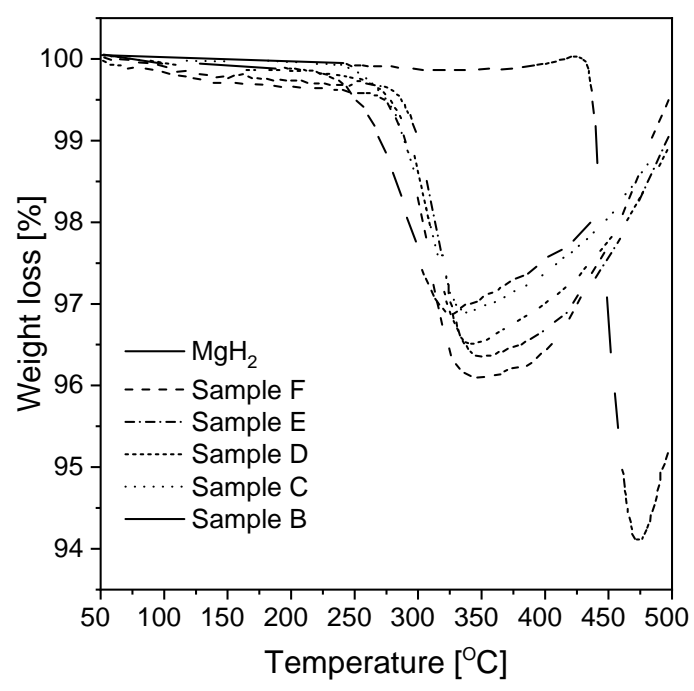

Figure 17. TGA curves for the synthesized samples and $\mathrm{MgH}_{2}$. The graph is based on [265]. B-F represent different technological parameters and compositions (for details, please see [265]).

\subsubsection{Microtwinning Phenomena}

Blomqvist [43] carried out the synthesis of $\mathrm{Mg}_{2} \mathrm{NiH}_{4}$ by using $\mathrm{Mg}_{2} \mathrm{Ni}$ alloys manufactured by different methods. Cooling the high-temperature phase of $\mathrm{Mg}_{2} \mathrm{NiH}_{4}$ to room temperature was followed by the formation of a low-temperature phase that exhibited microtwinning. Rehydrogenation led to a decrease in the amount of the microtwinned phase. This result was consistent with the phase change, which was revealed by the color change of the powder. No impurity phase of $\mathrm{MgH}_{2}$ was observed. The phase transition kinetics were strongly dependent on the microtwinned sample content. It was proven that with respect to the microtwinned phase, not only was the thermal history of the sample important but also the presence of free magnesium (an unwanted dopant changing the color of the low-temperature phase) in the compound. A lower synthesis temperature was suggested to avoid the stabilizing effects of $\mathrm{Mg}_{2} \mathrm{NiH}_{4}$. Both the microtwinned phases and the $\mathrm{Mg}$ dopants acted the same way-they behaved as nucleation centers, which improved the transition between the low- and high-temperature phases [267]. These stabilization mechanisms competed with each other, but the details about this behavior remain unclear. When the low-temperature $\mathrm{Mg}_{2} \mathrm{NiH}_{4}$ phase was synthesized by MA with additional magnesium hydride, the amount of microtwinning after rehydriding was reduced, and the color of the powder was orange. XRD profiles are presented in Figure 18. The $\mathrm{MgH}_{2}$ dopant in the mixture also influenced the appearance of the powder, changing the color from brownish-gray to orange.

\subsubsection{Carbon Additives}

Nohara et al. [268] proved that the surface modification of $\mathrm{BM} \mathrm{Mg}_{2} \mathrm{Ni}$ with a graphite additive improves the hydrogen capacity and hydrogenation/dehydrogenation cycling as a result of the increased number of active sites for absorption. Another explanation involved the formation of chemical bonds between magnesium and graphite. The rate of hydrogen absorption turned out to be barely dependent on the particle size in that case, which indicated the importance of surface modification in the context of hydrogen absorption. Another attempt to examine the hydriding behavior of various $\mathrm{Mg}_{2} \mathrm{Ni}$ alloys was provided by Bouaricha et al. [269]. $\mathrm{Mg}_{2} \mathrm{Ni}$ was ball milled with $5 \mathrm{wt} . \%$ fullerene $\left(\mathrm{C}_{60}\right)$ and leached in an organic solvent, which caused crystallite size refinement (in a range of 11-19 nm). Figure 19 presents pressure-composition isotherms of $\mathrm{Mg}_{2} \mathrm{Ni}$ and $\mathrm{Mg}_{2} \mathrm{Ni} / \mathrm{C}_{60}$ samples (before and after leaching). All curves show a plateau pressure at $\sim 2$ or $4 \mathrm{~atm}(0.2$ or $0.4 \mathrm{MPa})$ during desorption and absorption, respectively. On this basis, it can be concluded that neither additional milling with fullerene nor leaching treatment in toluene caused any modifications leading to improved thermodynamics properties. Even a small amount (5 wt.\%) of C-containing compounds (such as fullerene, graphite, and Vulcan) causes 
an $\sim 5 \%$ decrease in $(\mathrm{H} / \mathrm{M})_{\max }$. On the other hand, the time needed to reach complete desorption was reduced by 2-3 times. Properly chosen $\mathrm{C}$ compounds can be used to increase the specific surface area but have no effect on hydrogen desorption kinetics. On the other hand, changing the surface area can be helpful in the preparation of hydrogen absorption materials that are more stable during cycling. Similar research results were reported by Bobet et al. [190]. The authors suggested that during the process of hydrogenation of $\mathrm{Mg}_{2} \mathrm{Ni}$ with a modified graphite compound, two different phenomena occur. One phenomenon is related to increased gas-solid surface contact caused by the destruction of the oxide layer and its partial blockage by graphite.

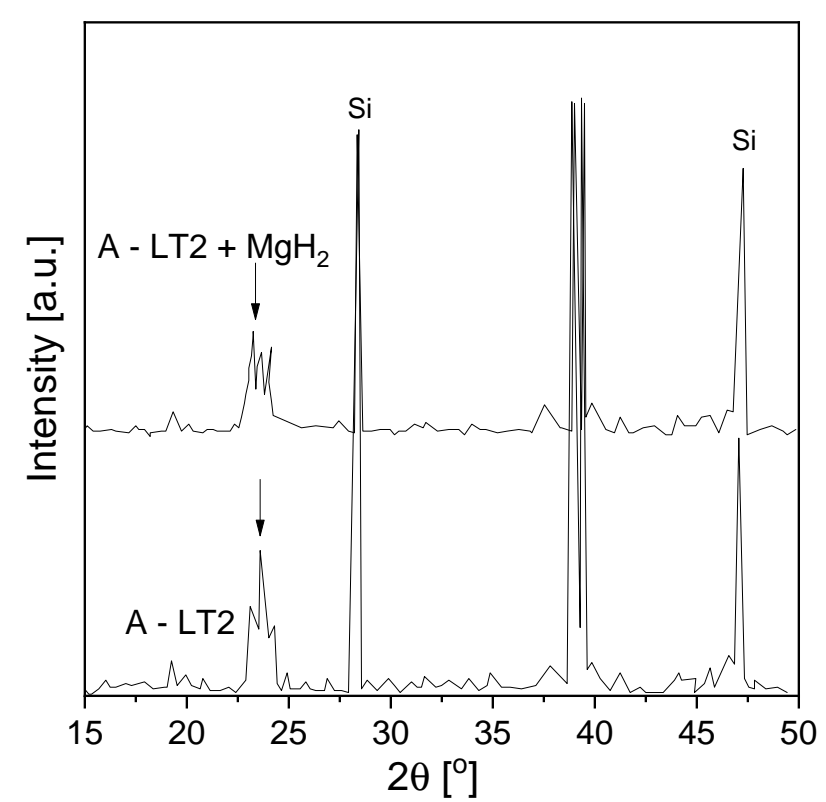

Figure 18. $\mathrm{XRD}$ profiles of ball-milled $\mathrm{Mg}_{2} \mathrm{NiH}_{4}$ with the low-temperature phase visible. The graph is based on [267].

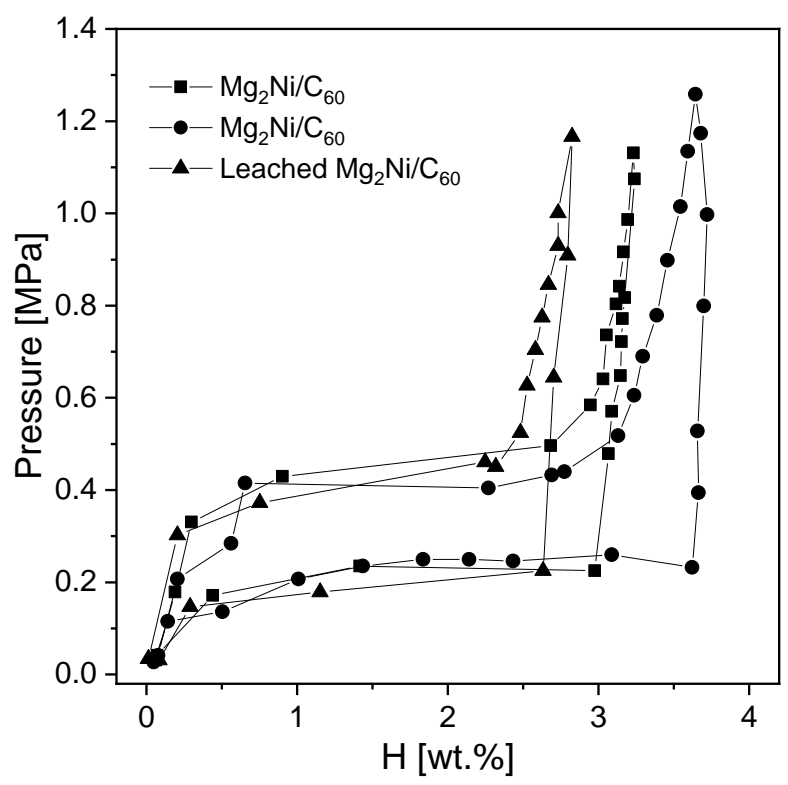

Figure 19. Pressure-composition isotherms at $300{ }^{\circ} \mathrm{C}$ of $\mathrm{Mg}_{2} \mathrm{Ni}$ and $\mathrm{Mg} 2 \mathrm{Ni} / \mathrm{C}_{60}$ compounds before and after leaching. The graph is based on [269]. 


\section{5. $\mathrm{Mg}_{2} \mathrm{CoH}_{5}$}

$\mathrm{Mg}_{2} \mathrm{CoH}_{5}$, a complex hydride, is analogous to the previously mentioned hydrides. However, it is an attractive hydride for several applications and is an interesting compound on its own. Its gravimetric hydrogen capacity is $4.5 \mathrm{wt} . \%$, and theoretically, it can be used as a stationary hydrogen storage and thermal energy storage medium [270]. The main advantages of this hydride are its relatively high gravimetric hydrogen capacity and good kinetics for hydrogen sorption. However, regardless of the cost of the cobalt itself, as in the case of most ternary hydrides, the synthesis of $\mathrm{Mg}_{2} \mathrm{CoH}_{5}$ is a very interesting and not trivial process. There is no $\mathrm{Mg}_{2} \mathrm{Co}$ intermetallic compound in the equilibrium phase diagram of $\mathrm{Mg}-\mathrm{Co}$, but $\mathrm{Mg}_{2} \mathrm{Co}, \mathrm{MgCo}$, and $\mathrm{MgCo}_{2}$ have been proven to exist after the hydride decomposition of ternary hydrides [270]. The Mg-Co-H system is interesting mostly because of the different hydride phases existing as a function of pressure and temperature $\left(\mathrm{Mg}_{2} \mathrm{CoH}_{5}\right.$, $\mathrm{Mg}_{6} \mathrm{Co}_{2} \mathrm{H}_{11}$, and $\mathrm{MgH}_{2}$ ) [271,272]. These hydrides are receiving attention due to their potential kinetic/thermodynamic properties associated with their synthesis techniques. The hydride $\mathrm{Mg}_{2} \mathrm{CoH}_{5}$ can be formed only by energetic techniques: sintering, mechanical milling, and reactive mechanical milling (RMM) under specific temperature and pressure conditions. The Mg-Co-H system allows the formation of two complex hydrides: tetragonal $\beta-\mathrm{Mg}_{2} \mathrm{CoH}_{5}$ and orthorhombic $\gamma-\mathrm{Mg}_{6} \mathrm{Co}_{2} \mathrm{H}_{11}$ [272,273]. However, other phases, namely $\mathrm{MgH}_{2}$ and Co with content percentages dependent on the experimental conditions, are also usually present [271,272]. The absence of stable precursors $\left(\mathrm{Mg}_{2} \mathrm{Co}\right.$ or $\left.\mathrm{Mg}_{3} \mathrm{Co}\right)$ and the simultaneous formation of $\mathrm{MgH}_{2}$ make the synthesis of a complex $\mathrm{Mg}$-Co hydride (as a single-phase) from elemental $\mathrm{Mg}$ and Co theoretically difficult (similar to $\mathrm{Mg}-\mathrm{Fe}$ ).

Pioneering attempts to synthesize $\mathrm{Mg}_{2} \mathrm{CoH}_{5}$ and $\mathrm{Mg}_{6} \mathrm{Co}_{2} \mathrm{H}_{11}$ hydrides were performed by Zolliker et al. and Ivanov et al. [271,272] from 1985-1988, and the formation of $\mathrm{Mg}_{2} \mathrm{CoH}_{5}$ was reported for the first time. A cylindrical $2 \mathrm{Mg}-\mathrm{Co}$ pellet mixture was sintered for several days between $415-445^{\circ} \mathrm{C}$ and 4-6 MPa hydrogen pressure. To avoid the drastic experimental conditions used during sintering, an important improvement in the preparation of hydrides was achieved by RMM. With this technique, the raw materials were ground at a certain hydrogen pressure (up to $1 \mathrm{MPa}$ ) and room temperature to favor a gas-solid reaction during milling, thereby creating structural/surface defects and producing a refined material. The low-temperature hydride from the $\mathrm{Mg}-\mathrm{Co}-\mathrm{H}$ system was initially referred to as $\mathrm{Mg}_{3} \mathrm{CoH}_{5}$ and characterized by a hexagonal structure [272]. Cerny et al. [273] finally found that the structure was orthorhombic, with a stoichiometric composition of $\mathrm{Mg}_{6} \mathrm{Co}_{2} \mathrm{H}_{11}$.

From a technological point of view, the hydrides $\mathrm{Mg}_{6} \mathrm{Co}_{2} \mathrm{H}_{11}$ and $\mathrm{Mg}_{2} \mathrm{CoH}_{5}$ are attractive for storage applications due to their high gravimetric (4.0 wt. $\%$ and $4.5 \mathrm{wt} . \%$ hydrogen, respectively) and volumetric $\left(>90 \mathrm{~kg} \mathrm{~m}^{3}\right)$ hydrogen storage capacities. However, the complexity of the Mg-Co-H system, with different hydride phases and the absence of stable precursors, is the main reason for the lack of knowledge about this system. In addition, the absorption and desorption kinetics, as well as the hydrogen storage reversibility of $\mathrm{Mg}_{6} \mathrm{Co}_{2} \mathrm{H}_{11}$ and $\mathrm{Mg}_{2} \mathrm{CoH}_{5}$, are still poorly understood.

\section{1. $\mathrm{Mg}_{2} \mathrm{CoH}_{5}$ Synthesis/Mechanical Modifications}

Since $\mathrm{Mg}$ and Co do not alloy at all in the $\mathrm{H}$-free solid metallic state, one of the most common ways of preparing the complex metal hydride $\mathrm{Mg}_{2} \mathrm{CoH}_{5}$ is to sinter $\mathrm{Mg}$ and $\mathrm{Co}$ powders at high hydrogen pressures [274]. However, $\mathrm{Mg}_{2} \mathrm{CoH}_{5}$, similar to the hydrides mentioned above, can be synthesized by mechanical milling (RMM in a hydrogen atmosphere or simple mechanical milling in an inert atmosphere). Further sintering is also considered in some approaches (as performed by Huot et al. in [36] and [32,275]), but in most approaches, this step is neglected [33,34,276]. However, the above methods require considerable time (even several days), and the yield is relatively low $(\sim 50 \%)$.

Sintering was used for the first time by Ivanov et al. [272]. Pure magnesium and cobalt powders were ball milled for 2-3 days and then sintered. The hydriding process was retained regardless of the phase diagram. By measuring a series of pressure-composition isotherms, the enthalpy values of the two hydride phases (low- and high-pressure hydrides) were determined to be -70 and $-79 \mathrm{~kJ} \mathrm{~mol}^{-1} \mathrm{H}_{2}$, respectively, for hydrogen desorption. As reported by Zolliker et al. [271], $\mathrm{Mg}_{2} \mathrm{CoH}_{5}$ and its deuteride 
could be prepared by sintering previously ball-milled pure $\mathrm{Mg}$ and Co between 415 and $445{ }^{\circ} \mathrm{C}$ in a 4-6 MPa hydrogen (or deuterium) pressure atmosphere. The $\mathrm{MgH}_{2}$ and pure metallic Co phases, which remained unreacted, were removed. The enthalpy values were calculated to be $86 \mathrm{~kJ} / \mathrm{mol} \mathrm{H}_{2}$ (desorption) and $-60 \mathrm{~kJ} / \mathrm{mol} \mathrm{H}_{2}$ (absorption). These data were in good agreement with the data provided by Ivanov et al. [272]. Furthermore, this result indicated the existence of hysteresis phenomena. The synthesized material was a black crystalline solid with a tetragonally distorted $\mathrm{CaF}_{2}$-type structure that transformed into a disordered cubic phase at $215^{\circ} \mathrm{C}$. However, when implementing the above approach during complex hydride synthesis, a reaction yield of lower than $30 \%$ was obtained.

A breakthrough in hydride technology was achieved by preparing hydrides via mechanical synthesis. To obtain $\mathrm{Mg}_{2} \mathrm{CoH}_{5}$, MA must be implemented: milling $\mathrm{Mg}$ and $\mathrm{Co}$ in an inert atmosphere followed by sintering [271], milling $\mathrm{Mg}$ and $\mathrm{Co}$ in a $\mathrm{H}_{2}$ atmosphere (RMA) [34], or milling $\mathrm{MgH}_{2}$ and $\mathrm{Co}$ in a $\mathrm{H}_{2}$ atmosphere [277]. The sintered material is exposed to drastic experimental conditions that are limited by the moderate hydrogen pressure and room temperature used in the RMA technique. Unfortunately, little research has been devoted to synthesis procedures involving BM designed to obtain $\mathrm{Mg}_{2} \mathrm{CoH}_{5}$ as the only ternary hydride.

A novel method of $\mathrm{Mg}_{2} \mathrm{CoH}_{5}$ synthesis was presented by Norek et al. [276]. A 2:1 $\mathrm{MgH}_{2}-\mathrm{Co}$ powder mixture was ball milled for $1 \mathrm{~h}$ in an argon atmosphere. Later, sintering at a high hydrogen pressure $\left(>8.5 \mathrm{MPa}\right.$ ) and heating from room temperature to $500{ }^{\circ} \mathrm{C}$ was applied. The relatively short milling time and high $\mathrm{H}_{2}$ pressure prevented $\mathrm{MgH}_{2}$ decomposition, which increased the reaction rate and final reaction yield. The authors suggested that the yield of the reaction $(\sim 90 \mathrm{wt} . \%)$ was connected to the amount of synthesized sample due to the heat generated by the reaction itself. The increased yield was also caused by high pressure, which helped to avoid magnesium hydride decomposition. No pure $\mathrm{Mg}$ was observed before the formation of $\mathrm{Mg}_{2} \mathrm{CoH}_{5}$ or any $\mathrm{MgH}_{2}$ phases, which reacted with cobalt during the reaction. The authors noticed that at temperatures above $400{ }^{\circ} \mathrm{C}$, the unreacted residual Co underwent an allotropic phase transformation (from a hexagonal to cubic phase). Two allotropic phases of $\mathrm{Mg}_{2} \mathrm{CoH}_{5}$ (low- and high-temperature phases) were observed, with the change from the low-temperature to high-temperature phase occurring at approximately $200^{\circ} \mathrm{C}$. The authors suggested that no $\mathrm{MgH}_{2}$ phase was needed for $\mathrm{Mg}_{2} \mathrm{CoH}_{5}$ synthesis. According to them, the ternary hydride could be formed directly from pure elements under specific pressure and temperature conditions. Another breakthrough was made by Zepon et al. [277]. Nanocrystalline (particle size below $1 \mu \mathrm{m}$ ) $\mathrm{Mg}_{2} \mathrm{CoH}_{5}$ was synthesized from a $2 \mathrm{Mg}+\mathrm{Co}$ mixture milled at $4 \mathrm{MPa}$ hydrogen pressure for 3-24 $\mathrm{h}$ at room temperature. As a result, a $97 \%$ reaction yield was achieved. The absorption and desorption temperatures were estimated to be 300 and $350{ }^{\circ} \mathrm{C}$, respectively. Increased temperature resulted in an increased hydrogen capacity and improved kinetics. The research also provided a broad description of the reaction mechanism. Similar to $\mathrm{Mg}_{2} \mathrm{FeH}_{6}$, the formation of the complex hydride $\mathrm{Mg}_{2} \mathrm{CoH}_{5}$ during RBM was a two-step reaction. First, $\mathrm{Mg}$ reacted with hydrogen, and a mixture of $\mathrm{MgH}_{2}$ and Co was formed. A further reaction path consisted of $\mathrm{MgH}_{2}$ reacting with $\mathrm{Co}$ and hydrogen and generating $\mathrm{Mg}_{2} \mathrm{CoH}_{5}$ as a result. The time needed to complete $\mathrm{Mg}_{2} \mathrm{CoH}_{5}$ formation was significantly shorter than that required for the $\mathrm{Mg}_{2} \mathrm{FeH}_{6}$ alloy with the same milling parameters [278]. Hydrogen desorption at low temperatures up to $325^{\circ} \mathrm{C}$ was connected with a diffusion mechanism, and no change in the high-temperature crystalline phase of $\mathrm{Mg}_{2} \mathrm{CoH}_{5}$ occurred. Above that temperature, the high-temperature phase of $\mathrm{Mg}_{2} \mathrm{CoH}_{5}$ became unstable, and the ternary hydride decomposed into hydrogen and pure $\mathrm{Mg}$ and $\mathrm{Co}$. Moreover, the DSC onset temperature for desorption of the reactive milled $\mathrm{Mg}_{2} \mathrm{CoH}_{5}$ was $\sim 230^{\circ} \mathrm{C}$, which was approximately $50{ }^{\circ} \mathrm{C}$ lower than that in the $\mathrm{Mg}_{2} \mathrm{FeH}_{6}$ case. Moreover, nanocrystalline $\mathrm{Mg}_{2} \mathrm{CoH}_{5}$ synthesized by reactive milling presented considerably different hydrogen desorption behavior than $\mathrm{Mg}_{2} \mathrm{FeH}_{6}$.

A comparison between $\mathrm{Mg}_{2} \mathrm{CoH}_{5}$ milled in an inert atmosphere and in a hydrogen atmosphere was performed by Veron et al. with $2 \mathrm{Mg}$-Co and $2 \mathrm{Mg}$-Co mixtures [279]. Three hydrides could be formed in the $\mathrm{Mg}$-Co-H system under different conditions, i.e., $\mathrm{Mg}_{6} \mathrm{Co}_{2} \mathrm{H}_{11}, \mathrm{Mg}_{2} \mathrm{CoH}_{5}$, and $\mathrm{MgH}_{2}$, which were observed as three plateaus in the pressure-composition isotherm (PCI) curves. The low-hydrogen-pressure 
plateau corresponded to $\mathrm{Mg}_{6} \mathrm{Co}_{2} \mathrm{H}_{11}$ formation, and the high-pressure plateau corresponded to $\mathrm{Mg}_{2} \mathrm{CoH}_{5}$. The decomposition enthalpy for the $\mathrm{Mg}_{2} \mathrm{CoH}_{5}$ phase was $-84 \mathrm{~kJ} / \mathrm{mol} \mathrm{H}_{2}$, and the hydride was almost unaffected by cycling. The desorption curves of samples milled in argon and hydrogen atmospheres are shown in Figure 20a,b, respectively. Unfortunately, no formation enthalpy data for the sample ball-milled in an argon atmosphere were provided from the information about hydrogen pressure after cycling. In contrast, the enthalpy value for the noncycled sample from BM was in good agreement with the value estimated for the sample synthesized in a hydrogen atmosphere.
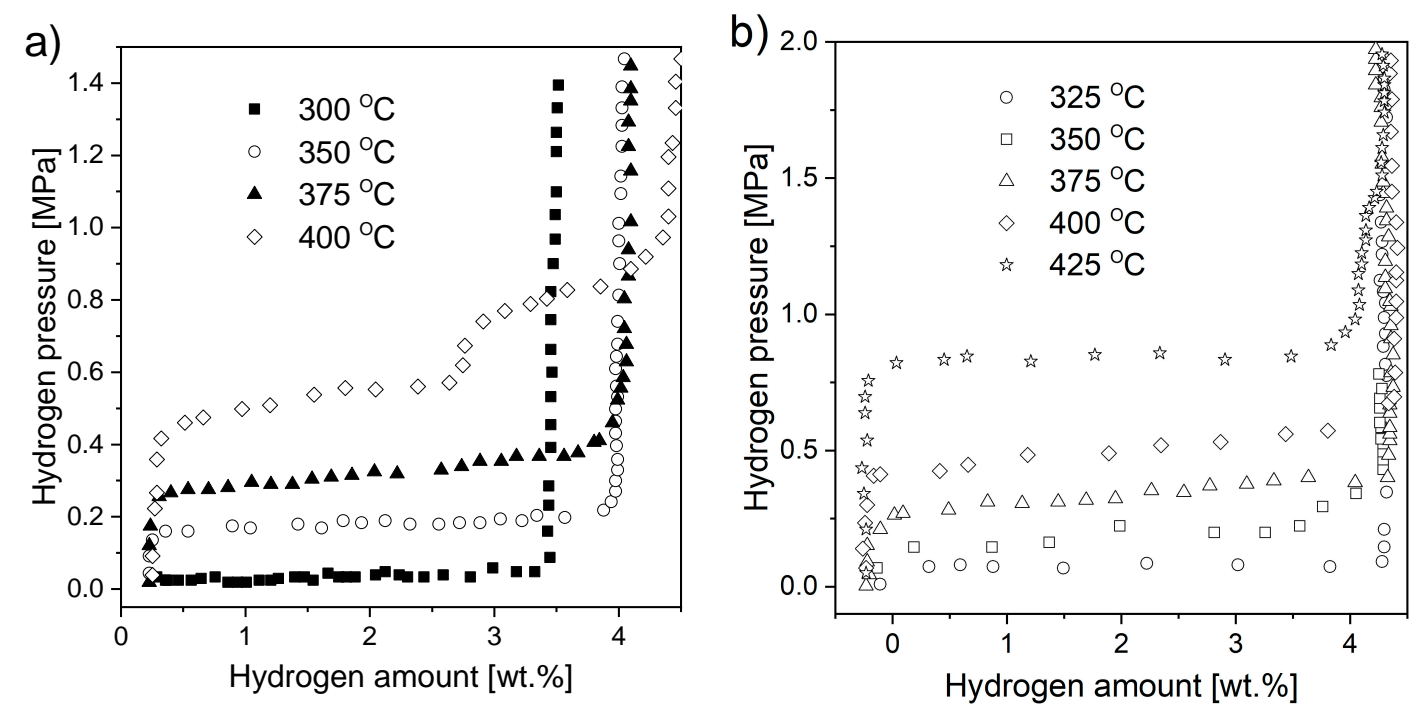

Figure 20. Desorption PCI curves of (a) a 2Mg-Co mixture milled in an argon atmosphere and (b) a $2 \mathrm{Mg}$-Co mixture milled in a hydrogen atmosphere. The graphs are based on [279].

\subsection{Reaction Yield Analysis}

A microstructural analysis of the $\mathrm{Mg}_{2} \mathrm{CoH}_{5}$ alloy produced by $\mathrm{RBM}\left(0.4 \mathrm{MPa} \mathrm{H}_{2}\right)$ of a $2 \mathrm{Mg}$-Co mixture was performed by Gennari et al. [34]. High reactivity (compared with that of $\mathrm{Mg}_{2} \mathrm{FeH}_{6}$ ball milled under the same conditions [38]), i.e., a high yield with short milling times, was achieved due to improved intermixing and contact between the powders. An endothermic peak indicating hydride decomposition was observed at $\sim 300^{\circ} \mathrm{C}$ independent of milling time. From XRD and DSC analysis, the amount of $\mathrm{Mg}_{2} \mathrm{CoH}_{5}$ was estimated as $20 \mathrm{wt} . \%$ after $90 \mathrm{~h}$ of milling. Fernandez et al. [33] combined mechanical milling and MA. A 2Mg-Co mixture was milled $(200 \mathrm{~h})$ in an argon atmosphere and then milled $(90 \mathrm{~h})$ in a hydrogen atmosphere, both at room temperature. As a result, a 50\% synthesis yield was achieved. Premilling caused microstructural refinement and Mg-Co intermixing, which influenced the kinetics of $\mathrm{Mg}_{2} \mathrm{CoH}_{5}$ formation. The elemental Co phase acted as a catalyst for hydrogen dissociation and association. Hence, the sorption kinetics rate increased. Cycling tests revealed that the desorption onset temperature changed due to the nonuniform grain size. Two plateaus were observed, which indicated the presence of two phases, $\mathrm{Mg}_{2} \mathrm{CoH}_{5}$ and $\mathrm{Mg}_{6} \mathrm{Co}_{2} \mathrm{H}_{11}$. The decomposition peak was observed at $205^{\circ} \mathrm{C}$. Kinetics measurements were performed at a constant temperature between 150 and $350{ }^{\circ} \mathrm{C}$ (Figure 21a). The best hydrogen capacity was measured at $350^{\circ} \mathrm{C}(\sim 3.5 \mathrm{wt} . \%)$, which was in good agreement with the results for sintered samples (Figure 21b). A great advantage of the RMA technique over the sintering technique is the fact that the produced complex hydride is characterized by very fast absorption ( $70 \%$ of the overall hydrogen uptake occurred before $100 \mathrm{~s}$ ) because of more uniform grains and their refinement after cycling. On the other hand, a nonuniform grain size was observed for the sintered samples, which influenced the onset desorption temperature. 

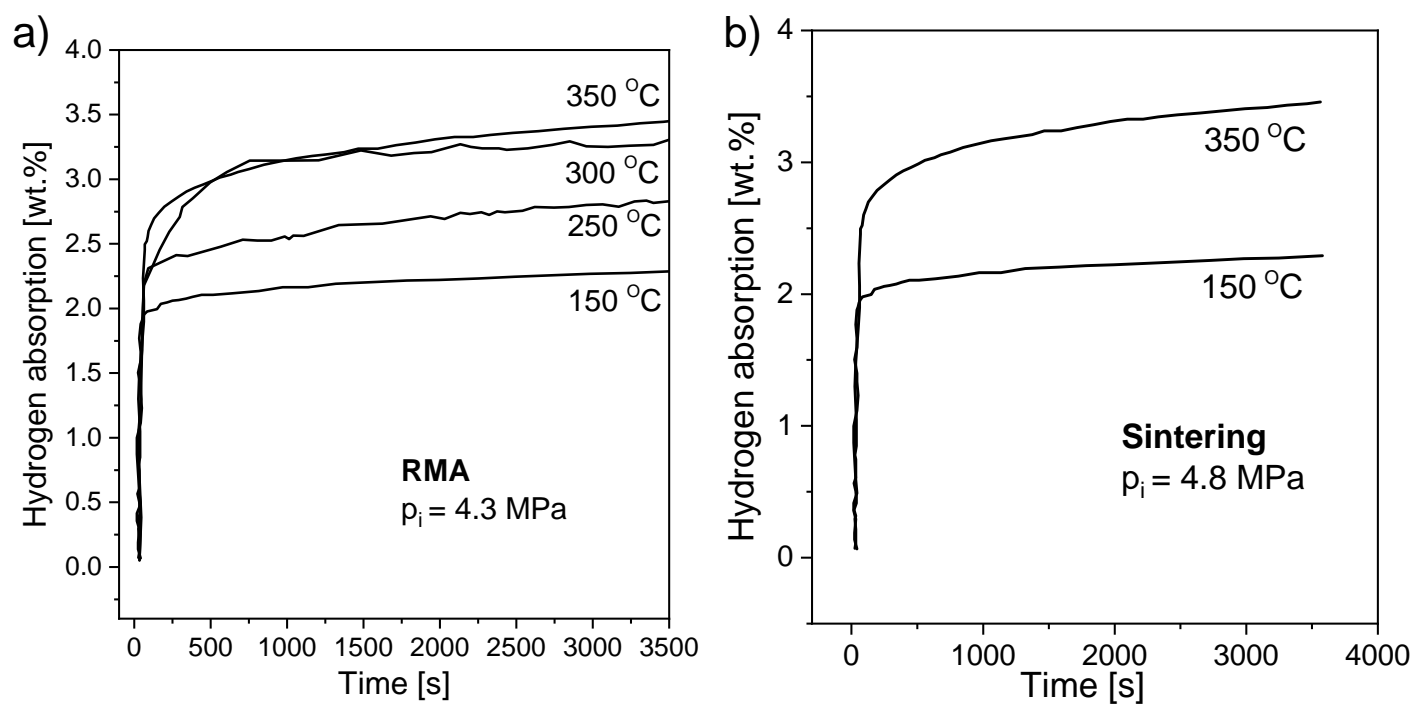

Figure 21. Absorption kinetics of $\mathrm{Mg}_{2} \mathrm{CoH}_{5}$ produced by (a) RMA and (b) sintering at different pressures. The graphs are based on [33].

$\mathrm{Mg}_{2} \mathrm{CoH}_{5}$ was synthesized by single-step $\mathrm{RMM}$ in a hydrogen atmosphere (0.5 MPa) from $2 \mathrm{MgH}_{2}-\mathrm{Co}$ and $3 \mathrm{MgH}_{2}-\mathrm{Co}$ mixtures [280]. With the $2 \mathrm{Mg}$-Co mixture, a yield of $83 \%$ was achieved with an assumed $\Delta \mathrm{H}=82 \mathrm{~kJ} / \mathrm{mol} \mathrm{H}_{2}$. The measured volumetric hydrogen desorption was $3.8 \mathrm{wt} . \%$, which was relatively close to the theoretical value (4.4 wt.\%). No endothermic peak associated with transformation from a tetragonal to cubic structure $\left(\sim 210{ }^{\circ} \mathrm{C}\right)$ was observed, which may be caused by the difficulty of detecting the phase transition due to the nanometric grain size, as noted before $[33,34]$. Even with the $3 \mathrm{MgH}_{2}-\mathrm{Co}$ mixture, $\mathrm{Mg}_{2} \mathrm{CoH}_{5}$ was the dominant phase, with a small amount of $\mathrm{Mg}_{6} \mathrm{Co}_{2} \mathrm{H}_{11}$ as a secondary phase (at high temperature and pressure). Hence, the reaction yield was $\sim 80 \%$. Additionally, $\mathrm{Mg}_{2} \mathrm{CoH}_{5}$ had the highest hydrogen storage capacity ( $3.7 \mathrm{wt} . \%$ ) between 250 and $300{ }^{\circ} \mathrm{C}$. Hydrogen absorption and desorption curves for different $\mathrm{MgH}_{2}$-Co ratios and different temperatures are visible in Figure 22a,b. The formation of $\mathrm{Mg}_{2} \mathrm{CoH}_{5}$ from a $3 \mathrm{MgH}_{2}-\mathrm{Co}$ mixture proceeds by not fully and symmetrical reversible reaction, which is why $\mathrm{Mg}_{2} \mathrm{CoH}_{5}$ is not appropriate for mobile applications.
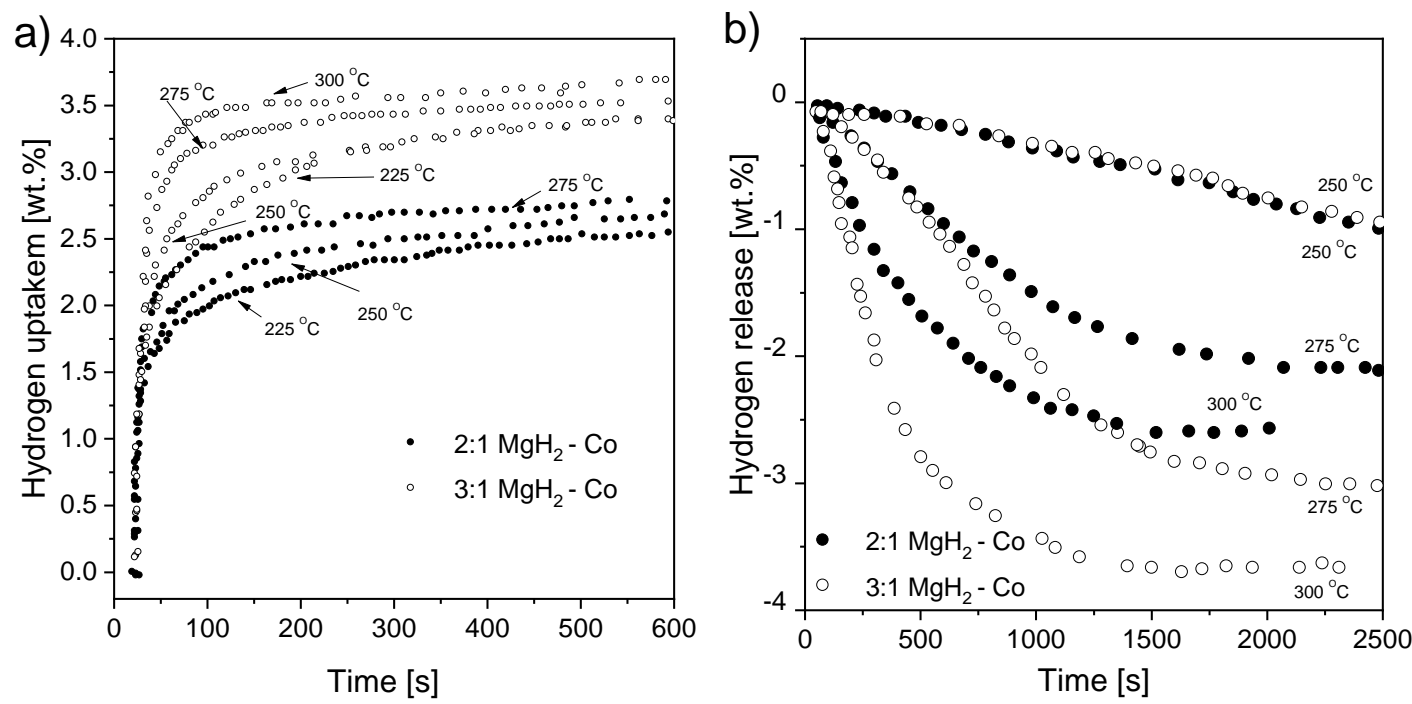

Figure 22. (a) Hydrogen absorption curves at various temperatures after $5 \mathrm{~h}$ of RMM at a $2 \mathrm{MPa}$ initial pressure and (b) hydrogen desorption curves after $5 \mathrm{~h}$ of RMM at a hydrogen desorption pressure of $0.02 \mathrm{MPa}$. The graphs are based on [280]. 
$\mathrm{BM}$ and ball alloying are possible alternatives for synthesizing hydrides with good outcomes. However, as always, the above techniques and processes need to be better understood and optimized. Outstanding performances were reported by Norek et al. [276] and Zepon et al. [277] with reaction yields of $\sim 90 \%$ and $97 \%$, respectively.

\subsection{Cycling Stability}

Much research has shown different estimated enthalpy values of magnesium-cobalt hydride. As mentioned before, the first attempt was performed by Ivanov et al. [272], who obtained -79 and $-70 \mathrm{~kJ} / \mathrm{mol} \mathrm{H} \mathrm{H}_{2}$ for the hydrogen desorption of the $\mathrm{Mg}_{2} \mathrm{CoH}_{5}$ and $\mathrm{Mg}_{3} \mathrm{CoH}_{5}$ phases, respectively. Later, the $\mathrm{Mg}_{2} \mathrm{CoH}_{5}$ enthalpy values were estimated as $-95 \mathrm{~kJ} / \mathrm{mol} \mathrm{H}_{2}$ and $-108 \mathrm{~kJ} / \mathrm{mol} \mathrm{H}_{2}$ for the lower and upper plateau, respectively [281]. Zolliker et al. [271] published different values for the heat of dissociation $\left(86 \mathrm{~kJ} / \mathrm{mol} \mathrm{H}_{2}\right)$ and heat of formation $\left(60 \mathrm{~kJ} / \mathrm{mol} \mathrm{H}_{2}\right)$ of the $\mathrm{Mg}_{2} \mathrm{CoH}_{5}$ phase. The abovementioned works prove that the hydrogen loading and cycling stability of the $\mathrm{Mg}_{2} \mathrm{Co}-\mathrm{H}$ hydride system have been examined broadly. Unfortunately, the results are not in good agreement, and some issues remain unsolved (especially the effect of BM on ternary hydride properties).

The synthesis of $\mathrm{Mg}_{2} \mathrm{CoH}_{5}$, a nanocrystalline complex metal hydride, was performed by $\mathrm{MA}$ for the first time by Chen et al. in 2001 [281]. A mixture of $2 \mathrm{MgH}_{2}+\mathrm{Co}$ was mechanically alloyed in a hydrogen atmosphere. The hydrogenation characteristics were investigated and indicated a noted improvement in the kinetics of hydride formation. As a result of the very fine microstructure obtained by $\mathrm{BM}$ (the powder had a dark gray color), the decomposition temperatures for $\mathrm{MgH}_{2}$ and $\mathrm{Mg}_{2} \mathrm{CoH}_{5}$ shifted to lower values. The $\mathrm{Mg}_{2} \mathrm{CoH}_{5}$ dissociation and formation enthalpy values were -83.2 and $69.5 \mathrm{~kJ} / \mathrm{mol} \mathrm{H}_{2}$, respectively. More rapid hydride formation was possible due to the presence of milled cobalt, which influenced fast hydride formation via a metastable phase. It could be concluded from Figure 23 that with increasing BM time, the hydrogen content of the sample also increased, and the dehydrating reactions shifted to a lower temperature. This result was attributed to the kinetic behavior of the powder, which was a consequence of changes in the surface characteristics of the milled powders. After 20 cycles, a $2 \%$ hydrogen capacity degradation was observed. These results do not compare well with $[279,280]$, where the hydrogen equilibrium pressure and hydrogen storage capacity were stable upon cycling.

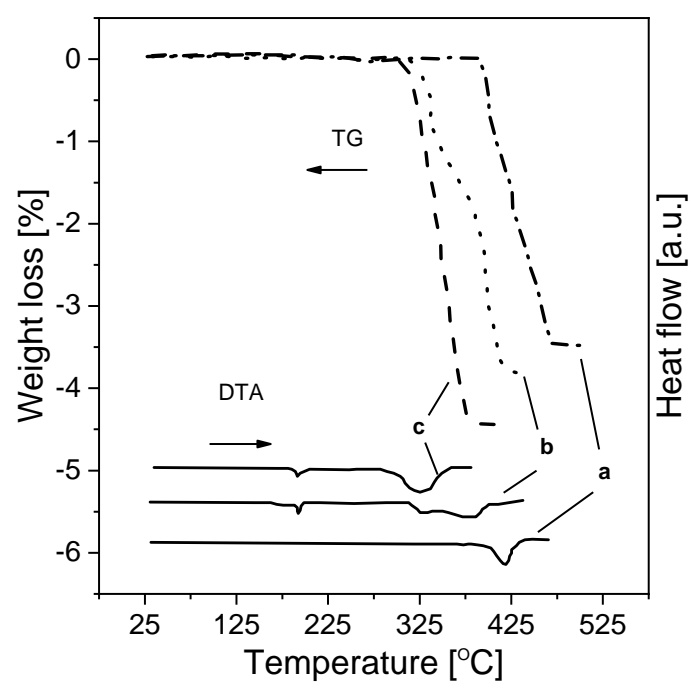

Figure 23. DTA and TG curves of (a) the initial $2 \mathrm{MgH}_{2}+\mathrm{Co}$ mixture and ball-milled sample and after (b) $2 \mathrm{~h}$ and (c) $10 \mathrm{~h}$. The graph is based on [281].

Reiser et al. [204] carried out a broad investigation of the cyclic stability of a Mg-Co-H system for two ternary hydrides: $\mathrm{Mg}_{2} \mathrm{CoH}_{5}$ and $\mathrm{Mg}_{6} \mathrm{Co}_{2} \mathrm{H}_{11}$. The material was still considered as a good heat/energy storage system despite differences in its thermodynamic data. Excellent stability of the 
obtained hydride was observed after more than 1000 cycles. Two plateaus existed in the region between 2.5 and $3.7 \mathrm{wt} . \%$ hydrogen content. The equilibrium pressure for the first region was calculated and corresponded to the heat of desorption, equal to $76 \mathrm{~kJ} / \mathrm{mol} \mathrm{H}_{2}$. For the second region, no reliable value could be calculated. Nevertheless, the relatively high enthalpy of formation made this system sufficient as a heat storage medium. The dissociation pressure for the first plateau was lower than those for the previously discussed $\mathrm{Mg}-\mathrm{Fe}-\mathrm{H}$ and $\mathrm{Mg}-\mathrm{Ni}-\mathrm{H}$ systems.

\section{General Conclusions and Future Prospects}

Despite the likely thousands of extremely interesting papers published in the literature and presented to some extent in this review, magnesium hydride and magnesium-based hydrides will likely not solve the hydrogen storage problem, especially for mobile applications. A relatively high gravimetric capacity of the material itself is likely not enough to overcome the low practical (despite very high theoretical) volumetric capacity and problems related to handling and reactivity. Consequently, other, more "friendly" and easy-to-use materials are likely to be applied in practice. However, the fact that magnesium hydrides and magnesium-based hydrides have been investigated for decades now and are still not fully understood proves that there is still significant potential in this type of material in terms of the basic science and from a theoretical standpoint, as well as for other applications (such as electrodes for batteries). Thus, there is still much to be discovered and confirmed. Despite the fact that we are skeptical about the potential mobile applications and hydrogen storage capability of magnesium hydrides and magnesium-based hydrides, there is significant practical potential in these materials for waste heat storage in the temperature range of $400-550{ }^{\circ} \mathrm{C}$ due to their high enthalpy values of formation and decomposition.

Among all the problems shown in this review, such as synthesis yield issues, kinetics issues, cyclic stability issues, thermodynamic stability, degradation etc., one much less scientific problem is of the greatest importance-surprisingly, the cost issue. Not mentioned too much in the literature, among all those described materials having quite similar properties, only two seem to have a real application potential due to their acceptable price. Figure 24 shows the comparison of the four compounds described in this review in terms of their hydrogen storage effectiveness by volume and price. Each of them is represented by the area on the graph since both the possible yield and the bulk density of the powders were considered. It is more than clear that while having very similar volumetric densities, and also quite similar working temperatures (not shown here), both $\mathrm{Mg}_{2} \mathrm{NiH}_{4}$ and $\mathrm{Mg}_{2} \mathrm{CoH}_{5}$ are definitely too expensive to consider them for practical use while $\mathrm{MgH}_{2}$ and $\mathrm{Mg}_{2} \mathrm{FeH}_{6}$ are available.

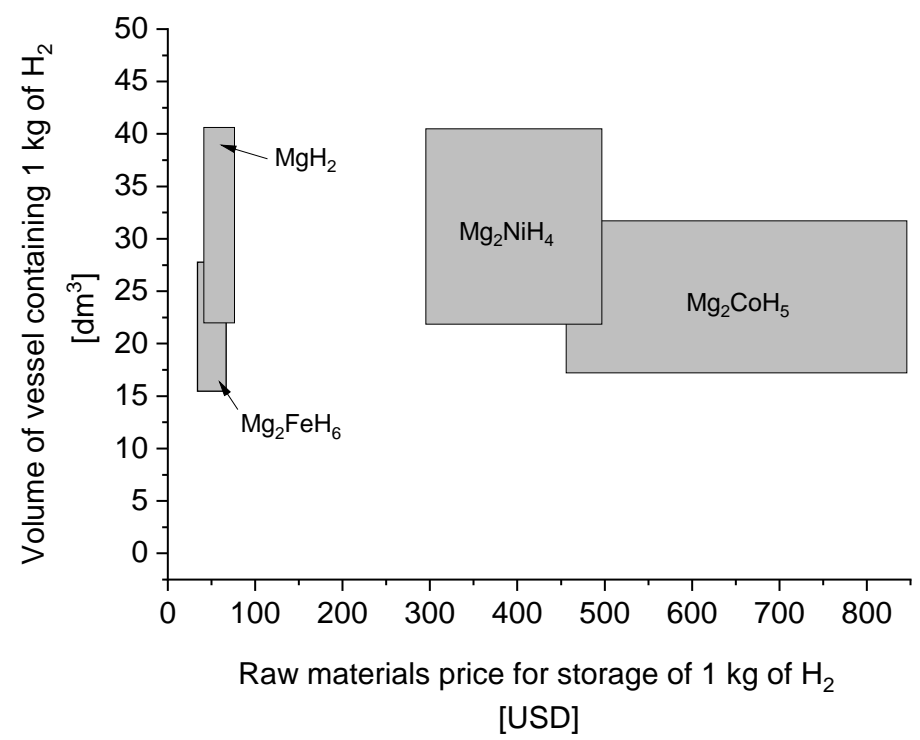

Figure 24. Graph showing the volume of the tank and cost of the powder required to store $1 \mathrm{~kg}$ of hydrogen in the form of the chosen compound. 
There are, however, methods to make the production of such storage systems cheaper. In particular, using scrap materials as substrates to lower the cost of production may be beneficial. However, even if the price will be acceptable if these materials are to be applied for high-volume, high-risk storage, all the unknowns must be solved in advance to avoid technical difficulties or even potential material-related failures and tragedies.

A big problem in describing those materials in the form of a review paper has probably also been spotted by readers of this review, and it lies far from any physical or chemical property. The great number of experiments performed within this topic have not, in our opinion, resulted in obtaining general, systematic knowledge about the behavior of these materials. There are several factors causing this deficiency, but the most important, in our opinion, are the lack of standard conditions and procedures for testing this group of materials, imprecise experimental descriptions, and a lack of standard examination of possible impurities in the investigated systems. For these reasons, the results in most cases can be compared only qualitatively. One of the biggest challenges for the hydrogen storage society is to normalize the measurement conditions to such an extent that newly discovered materials can be easily compared with the old ones.

Author Contributions: Conceptualization, A.B. and M.P.; writing—original draft preparation, A.B.; writing—review and editing, M.P.; visualization, A.B. and M.P.; supervision, M.P. Both authors have read and agreed to the published version of the manuscript.

Funding: This work was financially supported by the National Science Centre (NCN) in Poland, No. UMO-2018/29/B/ST8/01979. Additional support from the statutory research funds of the Department of Functional Materials and Hydrogen Technology is appreciated as well as Ministry of National Defense Republic of Poland Program-Research Grant MUT Project 13-995 (proof checking fee).

Acknowledgments: The authors would like to thank Tomasz Płociński for providing the SEM photo (Figure 3a).

Conflicts of Interest: The authors declare no conflict of interest.

\section{References}

1. Hirscher, M. Handbook of Hydrogen Storage: New Materials for Future Energy Storage; WILEY-VCH: Weinheim, Germany, 2010.

2. Green, C.; Baksi, S.; Dilmaghani, M. Challenges to a climate stabilizing energy future. Energy Policy 2007, 35, 616-626. [CrossRef]

3. Solomon, S.; Plattner, G.-K.; Knutti, R.; Friedlingstein, P. Irreversible climate change due to carbon dioxide emissions. Proc. Natl. Acad. Sci, USA 2009, 106, 1704-1709. [CrossRef] [PubMed]

4. Pearson, P.J.G.; Foxon, T.J. A low carbon industrial revolution? Insights and challenges from past technological and economic transformations. Energy Policy 2012, 50, 117-127. [CrossRef]

5. Hadjixenophontos, E.; Dematteis, E.M.; Berti, N.; Wołczyk, A.R.; Huen, P.; Brighi, M.; Le, T.T.; Santoru, A.; Payandeh, S.; Peru, F. A Review of the MSCA ITN ECOSTORE-Novel Complex Metal Hydrides for Efficient and Compact Storage of Renewable Energy as Hydrogen and Electricity. Inorganics 2020, 8, 17. [CrossRef]

6. Ley, M.B.; Jepsen, L.H.; Lee, Y.-S.; Cho, Y.W.; Von Colbe, J.M.B.; Dornheim, M.; Rokni, M.; Jensen, J.O.; Sloth, M.; Filinchuk, Y. Complex hydrides for hydrogen storage-new perspectives. Mater. Today 2014, 17, 122-128. [CrossRef]

7. Møller, K.T.; Jensen, T.R.; Akiba, E.; Li, H.-w. Hydrogen-A sustainable energy carrier. Prog. Nat. Sci. Mater. Int. 2017, 27, 34-40. [CrossRef]

8. Hirscher, M.; Yartys, V.A.; Baricco, M.; von Colbe, J.B.; Blanchard, D.; Bowman, R.C., Jr.; Broom, D.P.; Buckley, C.E.; Chang, F.; Chen, P. Materials for hydrogen-based energy storage—Past, recent progress and future outlook. J. Alloys Compd. 2020, 827, 153548. [CrossRef]

9. Jain, I.P.; Jain, P.; Jain, A. Novel hydrogen storage materials: A review of lightweight complex hydrides. J. Alloys Compd. 2010, 503, 303-339. [CrossRef]

10. Milanese, C.; Jensen, T.; Hauback, B.; Pistidda, C.; Dornheim, M.; Yang, H.; Lombardo, L.; Zuettel, A.; Filinchuk, Y.; Ngene, P. Complex hydrides for energy storage. Int. J. Hydrogen Energy 2019, 44, 7860-7874. [CrossRef] 
11. Møller, K.T.; Sheppard, D.; Ravnsbæk, D.B.; Buckley, C.E.; Akiba, E.; Li, H.-W.; Jensen, T.R. Complex metal hydrides for hydrogen, thermal and electrochemical energy storage. Energies 2017, 10, 1645. [CrossRef]

12. Züttel, A. Materials for hydrogen storage. Mater. Today 2003, 6, 24-33. [CrossRef]

13. von Colbe, J.B.; Ares, J.-R.; Barale, J.; Baricco, M.; Buckley, C.; Capurso, G.; Gallandat, N.; Grant, D.M.; Guzik, M.N.; Jacob, I. Application of hydrides in hydrogen storage and compression: Achievements, outlook and perspectives. Int. J. Hydrogen Energy 2019, 44, 7780-7808. [CrossRef]

14. de Rango, P.; Marty, P.; Fruchart, D. Hydrogen storage systems based on magnesium hydride: From laboratory tests to fuel cell integration. Appl. Phys. A 2016, 122, 126. [CrossRef]

15. Panas, A.J.; Fikus, B.; Płatek, P.; Kunce, I.; Witek, K.; Kuziora, P.; Olejarczyk, A.; Dyjak, S.; Michalska-Domańska, M.; Jaroszewicz, L.; et al. Pressurised-cell test stand with oscillating heating for investigation heat transfer phenomena in metal hydride beds. Int. J. Hydrogen Energy 2016, 41, 16974-16983. [CrossRef]

16. Yartys, V.; Lototskyy, M.; Akiba, E.; Albert, R.; Antonov, V.; Ares, J.; Baricco, M.; Bourgeois, N.; Buckley, C.; von Colbe, J.B. Magnesium based materials for hydrogen based energy storage: Past, present and future. Int. J. Hydrogen Energy 2019, 44, 7809-7859. [CrossRef]

17. Krishna, R.; Titus, E.; Salimian, M.; Okhay, O.; Rajendran, S.; Rajkumar, A.; Sousa, J.; Ferreira, A.; Gil, J.C.; Gracio, J. Hydrogen storage for energy application. In Hydrogen Storage; Liu, J., Ed.; InTechOpen: Winchester, UK, 2012; pp. 243-266.

18. Huot, J.; Ravnsbæk, D.B.; Zhang, J.; Cuevas, F.; Latroche, M.; Jensen, T.R. Mechanochemical synthesis of hydrogen storage materials. Prog. Mater. Sci. 2013, 58, 30-75. [CrossRef]

19. Yaroshevsky, A.A. Abundances of chemical elements in the Earth's crust. Geochem. Int. 2006, 44, 48-55. [CrossRef]

20. Stampfer, J.F.J.; Holley, C.E.J.; Suttle, J.F. The magnesium-hydrogen system. J. Am. Chem. Soc. 1960, 82, 3504-3508. [CrossRef]

21. Webb, C.J. A review of catalyst-enhanced magnesium hydride as a hydrogen storage material. J. Phys. Chem. Solids 2015, 84, 96-106. [CrossRef]

22. Varin, R.A.; Zbroniec, L.; Polanski, M.; Bystrzycki, J. A Review of Recent Advances on the Effects of Microstructural Refinement and Nano-Catalytic Additives on the Hydrogen Storage Properties of Metal and Complex Hydrides. Energies 2011, 4, 1-25. [CrossRef]

23. Vajo, J.J.; Salguero, T.T.; Gross, A.F.; Skeith, S.L.; Olson, G.L. Thermodynamic destabilization and reaction kinetics in light metal hydride systems. J. Alloys Compd. 2007, 446-447, 409-414. [CrossRef]

24. Bystrzycki, J.; Polanski, M.; Plocinski, T. Nono-engineering approach to Destabilization of Magensium Hydride $\left(\mathrm{MgH}_{2}\right)$ by Solid-State Reaction with Si. J. Nanosci. Nanotechnol. 2008, 8, 1-8. [CrossRef]

25. Bystrzycki, J.; Płociński, T.; Zieliński, W.; Wiśniewski, Z.; Polanski, M.; Mróz, W.; Bojar, Z.; Kurzdłowski, K.J. Nano-engineering of magnesium hydride for hydrogen storage. Microelectron. Eng. 2009, 86, 889-891. [CrossRef]

26. Bösenberg, U.; Ravnsbæk, D.B.; Hagemann, H.; D'Anna, V.; Minella, C.B.; Pistidda, C.; Van Beek, W.; Jensen, T.R.; Bormann, R.d.; Dornheim, M. Pressure and temperature influence on the desorption pathway of the $\mathrm{LiBH}_{4}-\mathrm{MgH}_{2}$ composite system. J. Phys. Chem. C 2010, 114, 15212-15217. [CrossRef]

27. Dornheim, M.; Doppiu, S.; Barkhordarian, G.; Boesenberg, U.; Klassen, T.; Gutfleisch, O.; Bormann, R. Hydrogen storage in magnesium-based hydrides and hydride composites. Scr. Mater. 2007, 56, 841-846. [CrossRef]

28. Zaluska, A.; Zaluski, L.; Strom-Olsen, J.O. Nanocrystalline magnesium for hydrogen storage. J. Alloys Compd. 1999, 288, 217-225. [CrossRef]

29. Huot, J.; Liang, G.; Schulz, R. Mechanically alloyed metal hydride systems. Appl. Phys. A Mater. 2001, 72, 187-195. [CrossRef]

30. Matović, L.; Novaković, N.; Kurko, S.; Šiljegović, M.; Matović, B.; Kačarević Popović, Z.; Romčević, N.; Ivanović, N.; Grbović Novaković, J. Structural destabilisation of $\mathrm{MgH}_{2}$ obtained by heavy ion irradiation. Int. J. Hydrogen Energy 2009, 34, 7275-7282. [CrossRef]

31. Reilly, J.J., Jr.; Wiswall, R.H., Jr. Reaction of hydrogen with alloys of magnesium and nickel and the formation of $\mathrm{Mg}_{2} \mathrm{NiH}_{4}$. Inorg. Chem. 1968, 7, 2254-2256. [CrossRef]

32. Fernández, I.G.; Meyer, G.O.; Gennari, F.C. Reversible hydrogen storage in $\mathrm{Mg}_{2} \mathrm{CoH}_{5}$ prepared by a combined milling-sintering procedure. J. Alloys Compd. 2007, 446-447, 106-109. [CrossRef] 
33. Fernández, I.G.; Meyer, G.O.; Gennari, F.C. Hydriding/dehydriding behavior of $\mathrm{Mg}_{2} \mathrm{CoH}_{5}$ produced by reactive mechanical milling. J. Alloys Compd. 2008, 464, 111-117. [CrossRef]

34. Gennari, F.C.; Castro, F.J. Formation, composition and stability of Mg-Co compounds. J. Alloys Compd. 2005, 396, 182-192. [CrossRef]

35. Didisheim, J.J.; Zolliker, P.; Yvon, K.; Fischer, P.; Schefer, J.; Gubelmann, M.; Williams, A.F. Dimagnesium iron(II) hydride, $\mathrm{Mg}_{2} \mathrm{FeH}_{6}$, containing octahedral $\mathrm{FeH}_{6}{ }^{4-}$ anions. Inorg. Chem. 1984, 23, 1953-1957. [CrossRef]

36. Huot, J.; Hayakawa, H.; Akiba, E. Preparation of the hydrides $\mathrm{Mg}_{2} \mathrm{FeH}_{6}$, and $\mathrm{Mg}_{2} \mathrm{CoH}_{5}$, by mechanical alloying followed by sintering. J. Alloys Compd. 1997, 248, 164-167. [CrossRef]

37. Bogdanovic, B.; Reiser, A.; Schlichte, K.; Spliethoff, B.; Tesche, B. Thermodynamics and dynamics of the $\mathrm{Mg}-\mathrm{Fe}-\mathrm{H}$ system and its potential for thermochemical thermal energy storage. J. Alloys Compd. 2002, 345, 77-89. [CrossRef]

38. Gennari, F.C.; Castro, F.J.; Andrade Gamboa, J.J. Synthesis of $\mathrm{Mg}_{2} \mathrm{FeH}_{6}$ by reactive mechanical alloying: Formation and decomposition properties. J. Alloys Compd. 2002, 339, 261-267. [CrossRef]

39. Castro, F.J.; Gennari, F.C. Effect of the nature of the starting materials on the formation of $\mathrm{Mg}_{2} \mathrm{FeH}_{6}$. J. Alloys Compd. 2004, 375, 292-296. [CrossRef]

40. Herrich, M.; Ismail, N.; Handstein, A.; Pratt, A.; Gutfleisch, O. Synthesis and decomposition of $\mathrm{Mg}_{2} \mathrm{FeH}_{6}$ prepared by reactive milling. Mater. Sci. Eng. B Solid State Mater. Adv. Technol. 2004, 108, 28-32. [CrossRef]

41. Douglass, D.L. The Formation and Dissociation of Magnesium Alloy Hydrides and Their Use for Fuel Storage in the Hydrogen Car. Metall. Trans. A 1975, 6, 2179. [CrossRef]

42. Orimo, S.; Fujii, H. Materials science of Mg-Ni-based new hydrides. Appl. Phys. A Mater. 2001, 72, $167-186$. [CrossRef]

43. Blomqvist, H.; Ronnebro, E.; Noreus, D.; Kuji, T. Competing stabilisation mechanisms in $\mathrm{Mg}_{2} \mathrm{NiH}_{4}$. J. Alloys Compd. 2002, 330, 268-270. [CrossRef]

44. Haussermann, U.; Blomqvist, H.; Noreus, D. Bonding and stability of the hydrogen storage material $\mathrm{Mg}_{2} \mathrm{NiH}_{4}$. Inorg. Chem. 2002, 41, 3684-3692. [CrossRef] [PubMed]

45. Varin, R.A.; Czujko, T.; Mizera, J. Microstructural evolution during controlled ball milling of $\left(\mathrm{Mg}_{2} \mathrm{Ni}+\mathrm{MgNi}_{2}\right)$ intermetallic alloy. J. Alloys Compd. 2003, 350, 332-339. [CrossRef]

46. Manickam, K.; Mistry, P.; Walker, G.; Grant, D.; Buckley, C.E.; Humphries, T.D.; Paskevicius, M.; Jensen, T.; Albert, R.; Peinecke, K. Future perspectives of thermal energy storage with metal hydrides. Int. J. Hydrogen Energy 2019, 44, 7738-7745. [CrossRef]

47. Hardian, R.; Pistidda, C.; Chaudhary, A.L.; Capurso, G.; Gizer, G.; Cao, H.; Milanese, C.; Girella, A.; Santoru, A.; Yigit, D.; et al. Waste Mg-Al based alloys for hydrogen storage. Int. J. Hydrogen Energy 2018, 43, 16738-16748. [CrossRef]

48. Pistidda, C.; Bergemann, N.; Wurr, J.; Rzeszutek, A.; Møller, K.T.; Hansen, B.R.; Garroni, S.; Horstmann, C.; Milanese, C.; Girella, A. Hydrogen storage systems from waste Mg alloys. J. Power Sources 2014, 270, 554-563. [CrossRef]

49. Polanski, M.; Nawra, D.; Zasada, D. $\mathrm{Mg}_{2} \mathrm{FeH}_{6}$ synthesized from plain steel and magnesium hydride. J. Alloys Compd. 2019, 776, 1029-1040. [CrossRef]

50. Rzeszotarska, M.; Czujko, T.; Polański, M. $\mathrm{Mg}_{2}(\mathrm{Fe}, \mathrm{Cr}, \mathrm{Ni}) \mathrm{H}_{\mathrm{X}}$ complex hydride synthesis from austenitic stainless steel and magnesium hydride. Int. J. Hydrogen Energy 2020. [CrossRef]

51. Wiberg, E.; Goeltzer, H.; Bauer, R. Synthese von Magnesiumhydrid aus den Elementen. Z. fur Nat. Sect. B J. Chem. Sci. 1951, 6, 394-395. [CrossRef]

52. Jain, I.P.; Lal, C.; Jain, A. Hydrogen storage in Mg: A most promising material. Int. J. Hydrogen Energy 2010, 35, 5133-5144. [CrossRef]

53. Crivello, J.-C.; Dam, B.; Denys, R.; Dornheim, M.; Grant, D.; Huot, J.; Jensen, T.R.; De Jongh, P.; Latroche, M.; Milanese, C. Review of magnesium hydride-based materials: Development and optimisation. Appl. Phys. A 2016, 122, 97. [CrossRef]

54. Crivello, J.-C.; Denys, R.; Dornheim, M.; Felderhoff, M.; Grant, D.; Huot, J.; Jensen, T.R.; De Jongh, P.; Latroche, M.; Walker, G. Mg-based compounds for hydrogen and energy storage. Appl. Phys. A 2016, 122, 85. [CrossRef]

55. Wang, Y.; Wang, Y. Recent advances in additive-enhanced magnesium hydride for hydrogen storage. Prog. Nat. Sci. Mater. Int. 2017, 27, 41-49. [CrossRef] 
56. Zhang, J.; Yan, S.; Qu, H. Recent progress in magnesium hydride modified through catalysis and nanoconfinement. Int. J. Hydrogen Energy 2018, 43, 1545-1565. [CrossRef]

57. Puszkiel, J.A.; Andrade-Gamboa, J.J.; Gennari, F.C. Recent Progress in Mg-Co-H and Mg-Fe-H Systems for Hydrogen Energy Storage Applications. In Emerging Materials for Energy Conversion and Storage, 1st ed.; Cheong, K.Y., Impellizzeri, G., Fraga, M., Eds.; Elvevier: Cambridge, UK, 2018; pp. 393-428.

58. Chen, X.; Zou, J.; Huang, S.; He, G.; Zhao, N.; Zeng, X.; Ding, W. Hydrogen storage in Mg2Ni(Fe)H4 nano particles synthesized from coarse-grained $\mathrm{Mg}$ and nano sized $\mathrm{Ni}(\mathrm{Fe})$ precursor. RSC Adv. 2018, 8, 18959-18965. [CrossRef]

59. Bastide, J.P.; Bonnetot, B.; Letoffe, J.M.; Claudy, P. Polymorphism of Magnesium Hydride under high-pressure. Mater. Res. Bull. 1980, 15, 1215-1224. [CrossRef]

60. Moser, D.; Baldissin, G.; Bull, D.J.; Riley, D.J.; Morrison, I.; Ross, D.K.; Oates, W.A.; Noreus, D. The pressure-temperature phase diagram of $\mathrm{MgH}(2)$ and isotopic substitution. J. Phys. Condens. Matter 2011, 23, 305403. [CrossRef]

61. Ellinger, F.H.; Holley, C.E., Jr.; McInteer, B.B.; Pavone, D.; Potter, R.M.; Staritzky, E.; Zachariasen, W.H. The preparation and some properties of magnesium hydride. J. Am. Chem. Soc. 1955, 77, 2647-2648. [CrossRef]

62. Varin, R.A.; Czujko, T.; Wronski, Z. Particle size, grain size and gamma-MgH $\mathrm{M}_{2}$ effects on the desorption properties of nanocrystalline commercial magnesium hydride processed by controlled mechanical milling. Nanotechnology 2006, 17, 3856-3865. [CrossRef]

63. Montone, A.; Aurora, A.; Mirabile Gattia, D.; Vittori Antisari, M. On the barriers limiting the reaction kinetics between catalysed Mg and hydrogen. Scr. Mater. 2010, 63, 456-459. [CrossRef]

64. Vigeholm, B.; Jensen, K.; Larsen, B.; Pedersen, A.S. Elements of hydride formation mechanisms in nearly spherical magnesium powder particles. J. Less Common Met. 1987, 131, 133-141. [CrossRef]

65. Vigeholm, B.; Kjøller, J.; Larsen, B.; Pedersen, A.S. Formation and decomposition of magnesium hydride. J. Less Common Met. 1983, 89, 135-144. [CrossRef]

66. Huhn, P.-A.; Dornheim, M.; Klassen, T.; Bormann, R. Thermal stability of nanocrystalline magnesium for hydrogen storage. J. Alloys Compd. 2005, 404, 499-502. [CrossRef]

67. Nielsen, T.K.; Manickam, K.; Hirscher, M.; Besenbacher, F.; Jensen, T.R. Confinement of $\mathrm{MgH}_{2}$ nanoclusters within nanoporous aerogel scaffold materials. ACS Nano 2009, 3, 3521-3528. [CrossRef]

68. Nielsen, T.K.; Besenbacher, F.; Jensen, T.R. Nanoconfined hydrides for energy storage. Nanoscale 2011, 3, 2086-2098. [CrossRef]

69. Kim, K.C.; Dai, B.; Johnson, J.K.; Sholl, D.S. Assessing nanoparticle size effects on metal hydride thermodynamics using the Wulff construction. Nanotechnology 2009, 20, 204001. [CrossRef]

70. Paskevicius, M.; Sheppard, D.A.; Buckley, C.E. Thermodynamic changes in mechanochemically synthesized magnesium hydride nanoparticles. J. Am. Chem. Soc. 2010, 132, 5077-5083. [CrossRef] [PubMed]

71. Zhao-Karger, Z.; Hu, J.; Roth, A.; Wang, D.; Kübel, C.; Lohstroh, W.; Fichtner, M. Altered thermodynamic and kinetic properties of $\mathrm{MgH}_{2}$ infiltrated in microporous scaffold. Chem. Commun. 2010, 46, 8353-8355. [CrossRef] [PubMed]

72. Wagemans, R.W.; van Lenthe, J.H.; de Jongh, P.E.; van Dillen, A.J.; de Jong, K.P. Hydrogen storage in magnesium clusters: Quantum chemical study. J. Am. Chem. Soc. 2005, 127, 16675-16680. [CrossRef]

73. Wu, Z.; Allendorf, M.D.; Grossman, J.C. Quantum Monte Carlo simulation of nanoscale $\mathrm{MgH}_{2}$ cluster thermodynamics. J. Am. Chem. Soc. 2009, 131, 13918-13919. [CrossRef]

74. Asano, K.; Westerwaal, R.J.; Anastasopol, A.; Mooij, L.P.A.; Boelsma, C.; Ngene, P.; Schreuders, H.; Eijt, S.W.H.; Dam, B. Destabilization of Mg Hydride by Self-Organized Nanoclusters in the Immiscible Mg-Ti System. J. Phys. Chem. C 2015, 119, 12157-12164. [CrossRef]

75. Huang, Y.; Xia, G.; Chen, J.; Zhang, B.; Li, Q.; Yu, X. One-step uniform growth of magnesium hydride nanoparticles on graphene. Prog. Nat. Sci. Mater. Int. 2017, 27, 81-87. [CrossRef]

76. Huot, J.; Cuevas, F.; Deledda, S.; Edalati, K.; Filinchuk, Y.; Grosdidier, T.; Hauback, B.C.; Heere, M.; Jensen, T.R.; Latroche, M. Mechanochemistry of metal hydrides: Recent advances. Materials 2019, 12, 2778. [CrossRef]

77. Kuziora, P.; Wyszyńska, M.; Polanski, M.; Bystrzycki, J. Why the ball to powder ratio (BPR) is insufficient for describing the mechanical ball milling process. Int. J. Hydrogen Energy 2014, 39, 9883-9887. [CrossRef]

78. Kitagawa, Y.; Tanabe, K. Development of a kinetic model of hydrogen absorption and desorption in magnesium and analysis of the rate-determining step. Chem. Phys. Lett. 2018, 699, 132-138. [CrossRef] 
79. Friedlmeier, G.; Groll, M. Experimental analysis and modelling of the hydriding kinetics of Ni-doped and pure Mg. J. Alloys Compd. 1997, 253, 550-555. [CrossRef]

80. Huot, J.; Liang, G.; Boily, S.; Van Neste, A.; Schulz, R. Structural study and hydrogen sorption kinetics of ball-milled magnesium hydride. J. Alloys Compd. 1999, 293, 495-500. [CrossRef]

81. Zaluska, A.; Zaluski, L.; Ström-Olsen, J. Synergy of hydrogen sorption in ball-milled hydrides of Mg and $\mathrm{Mg}_{2}$ Ni. J. Alloys Compd. 1999, 289, 197-206. [CrossRef]

82. Huot, J.; Akiba, E.; Takada, T. Mechanical alloying of MgNi compounds under hydrogen and inert atmosphere. J. Alloys Compd. 1995, 231, 815-819. [CrossRef]

83. Chen, Y.; Williams, J. Formation of metal hydrides by mechanical alloying. J. Alloys Compd. 1995, 217, 181-184. [CrossRef]

84. Tessier, P.; Enoki, H.; Bououdina, M.; Akiba, E. Ball-milling of $\mathrm{Mg}_{2} \mathrm{Ni}$ under hydrogen. J. Alloys Compd. 1998, 268, 285-289. [CrossRef]

85. Liang, G.; Huot, J.; Boily, S.; Van Neste, A.; Schulz, R. Catalytic effect of transition metals on hydrogen sorption in nanocrystalline ball milled $\mathrm{MgH}_{2}-\mathrm{Tm}(\mathrm{Tm}=\mathrm{Ti}, \mathrm{V}, \mathrm{Mn}, \mathrm{Fe}$ and $\mathrm{Ni}$ ) systems. J. Alloys Compd. 1999, 292, 247-252. [CrossRef]

86. Jung, K.; Lee, E.; Lee, K. Catalytic effects of metal oxide on hydrogen absorption of magnesium metal hydride. J. Alloys Compd. 2006, 421, 179-184. [CrossRef]

87. Li, Q.; Xu, K.; Chou, K.; Lin, Q.; Zhang, J.; Lu, X. Investigation of the hydriding kinetic mechanism in the $\mathrm{MgH}_{2} / \mathrm{Cr}_{2} \mathrm{O}_{3}$-nanocomposite. Intermetallics 2005, 13, 1190-1194. [CrossRef]

88. Barkhordarian, G.; Klassen, T.; Bormann, R. Effect of $\mathrm{Nb}_{2} \mathrm{O}_{5}$ content on hydrogen reaction kinetics of $\mathrm{Mg}$. J. Alloys Compd. 2004, 364, 242-246. [CrossRef]

89. Hanada, N.; Ichikawa, T.; Hino, S.; Fujii, H. Remarkable improvement of hydrogen sorption kinetics in magnesium catalyzed with $\mathrm{Nb}_{2} \mathrm{O}_{5}$. J. Alloys Compd. 2006, 420, 46-49. [CrossRef]

90. Gupta, R.; Agresti, F.; Russo, S.L.; Maddalena, A.; Palade, P.; Principi, G. Structure and hydrogen storage properties of $\mathrm{MgH}_{2}$ catalysed with $\mathrm{La}_{2} \mathrm{O}_{3}$. J. Alloys Compd. 2008, 450, 310-313. [CrossRef]

91. Schulz, R.; Huot, J.; Liang, G.; Boily, S.; Lalande, G.; Denis, M.; Dodelet, J. Recent developments in the applications of nanocrystalline materials to hydrogen technologies. Mater. Sci. Eng. A 1999, 267, 240-245. [CrossRef]

92. Polanski, M.; Bystrzycki, J.; Plocinski, T. The effect of milling conditions on microstructure and hydrogen absorption/desorption properties of magnesium hydride $\left(\mathrm{MgH}_{2}\right)$ without and with $\mathrm{Cr}_{2} \mathrm{O}_{3}$ nanoparticles. Int. J. Hydrogen Energy 2008, 33, 1859-1867. [CrossRef]

93. Antisari, M.V.; Aurora, A.; Gattia, D.M.; Montone, A. On the nucleation step in the $\mathrm{Mg}-\mathrm{MgH}_{2} \mathrm{phase}$ transformation. Scr. Mater. 2009, 61, 1064-1067. [CrossRef]

94. Kral, L.; Cermak, J. Improvement of hydrogen storage properties of Mg by catalytic effect of Al-containing phases in Mg-Al-Ti-Zr-C powders. Int. J. Hydrogen Energy 2019, 44, 13561-13568. [CrossRef]

95. Bhatnagar, A.; Johnson, J.K.; Shaz, M.; Srivastava, O. $\mathrm{TiH}_{2}$ as a dynamic additive for improving the de/rehydrogenation properties of $\mathrm{MgH}_{2}$ : A combined experimental and theoretical mechanistic investigation. J. Phys. Chem. C 2018, 122, 21248-21261. [CrossRef]

96. Zhou, C.; Li, C.; Li, Y.; Zhang, Q. Enhanced hydrogen storage kinetics of an Mg-Pr-Al composite by in situ formed $\mathrm{Pr}_{3} \mathrm{Al}_{11}$ nanoparticles. Dalton Trans. 2019, 48, 7735-7742. [CrossRef] [PubMed]

97. Korablov, D.; Besenbacher, F.; Jensen, T.R. Kinetics and thermodynamics of hydrogenation-dehydrogenation for $\mathrm{Mg}-25 \% \mathrm{TM}(\mathrm{TM}=\mathrm{Ti}, \mathrm{Nb}$ or $\mathrm{V})$ composites synthesized by reactive ball milling in hydrogen. Int. J. Hydrogen Energy 2018, 43, 16804-16814. [CrossRef]

98. Khan, D.; Zou, J.; Zeng, X.; Ding, W. Hydrogen storage properties of nanocrystalline $\mathrm{Mg}_{2} \mathrm{Ni}$ prepared from compressed $2 \mathrm{MgH}_{2} \mathrm{Ni}$ powder. Int. J. Hydrogen Energy 2018, 43, 22391-22400. [CrossRef]

99. Calizzi, M.; Chericoni, D.; Jepsen, L.H.; Jensen, T.R.; Pasquini, L. Mg-Ti nanoparticles with superior kinetics for hydrogen storage. Int. J. Hydrogen Energy 2016, 41, 14447-14454. [CrossRef]

100. Pasquini, L.; Callini, E.; Brighi, M.; Boscherini, F.; Montone, A.; Jensen, T.R.; Maurizio, C.; Vittori Antisari, M.; Bonetti, E. Magnesium nanoparticles with transition metal decoration for hydrogen storage. J. Nanoparticle Res. 2011, 13, 5727-5737. [CrossRef]

101. Callini, E.; Pasquini, L.; Rude, L.H.; Nielsen, T.K.; Jensen, T.R.; Bonetti, E. Hydrogen storage and phase transformations in Mg-Pd nanoparticles. J. Appl. Phys. 2010, 108. [CrossRef] 
102. Jensen, T.R.; Andreasen, A.; Vegge, T.; Andreasen, J.W.; Ståhl, K.; Pedersen, A.S.; Nielsen, M.M.; Molenbroek, A.M.; Besenbacher, F. Dehydrogenation kinetics of pure and nickel-doped magnesium hydride investigated by in situ time-resolved powder X-ray diffraction. Int. J. Hydrogen Energy 2006, 31, 2052-2062. [CrossRef]

103. Andreasen, A.; Sørensen, M.; Burkarl, R.; Møller, B.; Molenbroek, A.; Pedersen, A.; Vegge, T.; Jensen, T.R. Dehydrogenation kinetics of air-exposed $\mathrm{MgH}_{2} / \mathrm{Mg}_{2} \mathrm{Cu}$ and $\mathrm{MgH}_{2} / \mathrm{MgCu}_{2}$ studied with in situ X-ray powder diffraction. Appl. Phys. A 2006, 82, 515-521. [CrossRef]

104. Andreasen, A.; Sørensen, M.; Burkarl, R.; Møller, B.; Molenbroek, A.; Pedersen, A.S.; Andreasen, J.W.; Nielsen, M.M.; Jensen, T.R. Interaction of hydrogen with an Mg-Al alloy. J. Alloys Compd. 2005, 404, 323-326. [CrossRef]

105. Pęska, M.; Czujko, T.; Polański, M. Hydrogenation Ability of Mg-Li Alloys. Energies 2020, 13, 2080. [CrossRef]

106. Park, H.R.; Kwon, S.N.; Song, M.Y. Effects of milling time on the hydrogen storage properties of Mg-based transition metals-added alloys. Mater. Sci. 2018, 24, 166-171. [CrossRef]

107. Liang, G.; Huot, J.; Boily, S.; Van Neste, A.; Schulz, R. Hydrogen storage properties of the mechanically milled $\mathrm{MgH}_{2}-\mathrm{V}$ nanocomposite. J. Alloys Compd. 1999, 291, 295-299. [CrossRef]

108. Pelletier, J.; Huot, J.; Sutton, M.; Schulz, R.; Sandy, A.; Lurio, L.; Mochrie, S. Hydrogen desorption mechanism in $\mathrm{MgH}_{2}-\mathrm{Nb}$ nanocomposites. Phys. Rev. B 2001, 63, 052103. [CrossRef]

109. Pang, Y.; Yuan, T.; Yang, J.; Gao, M.; Pan, H.; Liu, Y.; Zheng, S. In situ formation of $\mathrm{Al}_{3} \mathrm{Ti}, \mathrm{MgF}_{2}$ and $\mathrm{Al}$ and their superior synergetic effects on reversible hydrogen storage of $\mathrm{MgH}_{2}$. Catal. Today 2018, 318, 107-112. [CrossRef]

110. Pighin, S.; Capurso, G.; Russo, S.L.; Peretti, H. Hydrogen sorption kinetics of magnesium hydride enhanced by the addition of $\mathrm{Zr}_{8} \mathrm{Ni}_{21}$ alloy. J. Alloys Compd. 2012, 530, 111-115. [CrossRef]

111. El-Eskandarany, M.S.; Al-Ajmi, F.; Banyan, M. Mechanically-Induced Catalyzation of $\mathrm{MgH}_{2}$ Powders with $\mathrm{Zr}_{2} \mathrm{Ni}$-Ball Milling Media. Catalysts 2019, 9, 382. [CrossRef]

112. Zhang, L.; Cai, Z.; Yao, Z.; Ji, L.; Sun, Z.; Yan, N.; Zhang, B.; Xiao, B.; Du, J.; Zhu, X. A striking catalytic effect of facile synthesized $\mathrm{ZrMn}_{2}$ nanoparticles on the de/rehydrogenation properties of $\mathrm{MgH}_{2}$. J. Mater. Chem. A 2019, 7, 5626-5634. [CrossRef]

113. Makihara, Y.; Umeda, K.; Shoji, F.; Kato, K.; Miyairi, Y. Cooperative dehydriding mechanism in a mechanically milled Mg-50 mass\% ZrMn 2 composite. J. Alloys Compd. 2008, 455, 385-391. [CrossRef]

114. Santos, S.; Ishikawa, T.; Botta, W.; Huot, J. $\mathrm{MgH}_{2}+$ FeNb nanocomposites for hydrogen storage. Mater. Chem. Phys. 2014, 147, 557-562. [CrossRef]

115. Zhou, C.; Fang, Z.Z.; Ren, C.; Li, J.; Lu, J. Effect of Ti intermetallic catalysts on hydrogen storage properties of magnesium hydride. J. Phys. Chem. C 2013, 117, 12973-12980. [CrossRef]

116. Ren, C.; Fang, Z.Z.; Zhou, C.; Lu, J.; Ren, Y.; Zhang, X. Hydrogen storage properties of magnesium hydride with V-based additives. J. Phys. Chem. C 2014, 118, 21778-21784. [CrossRef]

117. Liang, G.; Boily, S.; Huot, J.; Van Neste, A.; Schulz, R. Hydrogen absorption properties of a mechanically milled Mg-50 wt.\% LaNi ${ }_{5}$ composite. J. Alloys Compd. 1998, 268, 302-307. [CrossRef]

118. Liang, G.; Huot, J.; Boily, S.; Van Neste, A.; Schulz, R. Hydrogen storage in mechanically milled Mg-LaNi and $\mathrm{MgH}_{2}-\mathrm{LaNi}_{5}$ composites. J. Alloys Compd. 2000, 297, 261-265. [CrossRef]

119. Gross, K.J.; Spatz, P.; Züttel, A.; Schlapbach, L. Mechanically milled Mg composites for hydrogen storage the transition to a steady state composition. J. Alloys Compd. 1996, 240, 206-213. [CrossRef]

120. Varin, R.A.; Zaranski, Z.; Czujko, T.; Polanski, M.; Wronski, Z.S. The composites of magnesium hydride and iron-titanium intermetallic. Int. J. Hydrogen Energy 2011, 36, 1177-1183. [CrossRef]

121. Liu, P.; Chen, H.; Yu, H.; Liu, X.; Jiang, R.; Li, X.; Zhou, S. Oxygen vacancy in magnesium/cerium composite from ball milling for hydrogen storage improvement. Int. J. Hydrogen Energy 2019, 44, 13606-13612. [CrossRef]

122. El-Eskandarany, M.S.; Al-Nasrallah, E.; Banyan, M.; Al-Ajmi, F. Bulk nanocomposite $\mathrm{MgH}_{2} / 10 \mathrm{wt}^{\mathrm{O}} \%$ $\left(8 \mathrm{Nb}_{2} \mathrm{O}_{5} / 2 \mathrm{Ni}\right)$ solid-hydrogen storage system for fuel cell applications. Int. J. Hydrogen Energy 2018, 43, 23382-23396. [CrossRef]

123. Aguey-Zinsou, K.-F.; Fernandez, J.A.; Klassen, T.; Bormann, R. Effect of $\mathrm{Nb}_{2} \mathrm{O}_{5}$ on $\mathrm{MgH}_{2}$ properties during mechanical milling. Int. J. Hydrogen Energy 2007, 32, 2400-2407. [CrossRef]

124. Bhat, V.; Rougier, A.; Aymard, L.; Darok, X.; Nazri, G.; Tarascon, J. Catalytic activity of oxides and halides on hydrogen storage of $\mathrm{MgH}_{2}$. J. Power Sources 2006, 159, 107-110. [CrossRef] 
125. Dehouche, Z.; Djaozandry, R.; Huot, J.; Boily, S.; Goyette, J.; Bose, T.; Schulz, R. Influence of cycling on the thermodynamic and structure properties of nanocrystalline magnesium based hydride. J. Alloys Compd. 2000, 305, 264-271. [CrossRef]

126. Dehouche, Z.; Klassen, T.; Oelerich, W.; Goyette, J.; Bose, T.; Schulz, R. Cycling and thermal stability of nanostructured $\mathrm{MgH}_{2}-\mathrm{Cr}_{2} \mathrm{O}_{3}$ composite for hydrogen storage. J. Alloys Compd. 2002, 347, 319-323. [CrossRef]

127. Oelerich, W.; Klassen, T.; Bormann, R. Hydrogen sorption of nanocrystalline Mg at reduced temperatures by metal-oxide catalysts. Adv. Eng. Mater. 2001, 3, 487-490. [CrossRef]

128. Sadhasivam, T.; Sterlin Leo Hudson, M.; Pandey, S.K.; Bhatnagar, A.; Singh, M.K.; Gurunathan, K.; Srivastava, O.N. Effects of nano size mischmetal and its oxide on improving the hydrogen sorption behaviour of $\mathrm{MgH}_{2}$. Int. J. Hydrogen Energy 2013, 38, 7353-7362. [CrossRef]

129. Ivanov, E.; Konstanchuk, I.; Bokhonov, B.; Boldyrev, V. Hydrogen interaction with mechanically alloyed magnesium-salt composite materials. J. Alloys Compd. 2003, 359, 320-325. [CrossRef]

130. Jin, S.-A.; Shim, J.-H.; Cho, Y.W.; Yi, K.-W. Dehydrogenation and hydrogenation characteristics of $\mathrm{MgH}_{2}$ with transition metal fluorides. J. Power Sources 2007, 172, 859-862. [CrossRef]

131. Malka, I.E.; Czujko, T.; Bystrzycki, J. Catalytic effect of halide additives ball milled with magnesium hydride. Int. J. Hydrogen Energy 2010, 35, 1706-1712. [CrossRef]

132. Luo, Y.; Wang, P.; Ma, L.-P.; Cheng, H.-M. Hydrogen sorption kinetics of $\mathrm{MgH}_{2}$ catalyzed with $\mathrm{NbF}_{5}$. J. Alloys Compd. 2008, 453, 138-142. [CrossRef]

133. Kim, J.W.; Ahn, J.-P.; Jin, S.-A.; Lee, S.H.; Chung, H.-S.; Shim, J.-H.; Cho, Y.W.; Oh, K.H. Microstructural evolution of $\mathrm{NbF}_{5}$-doped $\mathrm{MgH}_{2}$ exhibiting fast hydrogen sorption kinetics. J. Power Sources 2008, 178, 373-378. [CrossRef]

134. Jin, S.-A.; Shim, J.-H.; Ahn, J.-P.; Cho, Y.W.; Yi, K.-W. Improvement in hydrogen sorption kinetics of $\mathrm{MgH}_{2}$ with $\mathrm{Nb}$ hydride catalyst. Acta Mater. 2007, 55, 5073-5079. [CrossRef]

135. Barkhordarian, G.; Klassen, T.; Bormann, R. Fast hydrogen sorption kinetics of nanocrystalline Mg using $\mathrm{Nb}_{2} \mathrm{O}_{5}$ as catalyst. Scr. Mater. 2003, 49, 213-217. [CrossRef]

136. Nielsen, T.K.; Jensen, T.R. $\mathrm{MgH}_{2}-\mathrm{Nb}_{2} \mathrm{O}_{5}$ investigated by in situ synchrotron X-ray diffraction. Int. J. Hydrogen Energy 2012, 37, 13409-13416. [CrossRef]

137. Friedrichs, O.; Aguey-Zinsou, F.; Fernandez, J.A.; Sanchez-Lopez, J.; Justo, A.; Klassen, T.; Bormann, R.; Fernandez, A. $\mathrm{MgH}_{2}$ with $\mathrm{Nb}_{2} \mathrm{O}_{5}$ as additive, for hydrogen storage: Chemical, structural and kinetic behavior with heating. Acta Mater. 2006, 54, 105-110. [CrossRef]

138. Friedrichs, O.; Klassen, T.; Sánchez-López, J.; Bormann, R.; Fernández, A. Hydrogen sorption improvement of nanocrystalline $\mathrm{MgH}_{2}$ by $\mathrm{Nb}_{2} \mathrm{O}_{5}$ nanoparticles. Scr. Mater. 2006, 54, 1293-1297. [CrossRef]

139. Zaluska, A.; Zaluski, L.; Ström-Olsen, J.O. Structure, catalysis and atomic reactions on the nano-scale- a systematic approach to metal hydrides for hydrogen storage. Appl. Phys. A Mater. Sci. Process. 2001, 72 , 157-165. [CrossRef]

140. Vajo, J.J.; Mertens, F.; Ahn, C.C.; Bowman, R.C.; Fultz, B. Altering hydrogen storage properties by hydride destabilization through alloy formation: $\mathrm{LiH}$ and $\mathrm{MgH}_{2}$ destabilized with Si. J. Phys. Chem. B 2004, 108, 13977-13983. [CrossRef]

141. Pedersen, A.S.; Kjøller, J.; Larsen, B.; Vigeholm, B.; Jensen, J.A. Long-term cycling of the magnesium hydrogen system. Int. J. Hydrogen Energy 1984, 9, 799-802. [CrossRef]

142. Bogdanović, B.; Spliethoff, B. Active $\mathrm{MgH}_{2}-\mathrm{Mg}$-systems for hydrogen storage. Int. J. Hydrogen Energy 1987, 12, 863-873. [CrossRef]

143. Bogdanović, B.; Hartwig, T.; Spliethoff, B. The development, testing and optimization of energy storage materials based on the $\mathrm{MgH}_{2}-\mathrm{Mg}$ system. Int. J. Hydrogen Energy 1993, 18, 575-589. [CrossRef]

144. Friedlmeier, G.; Manthey, A.; Wanner, M.; Groll, M. Cyclic stability of various application-relevant metal hydrides. J. Alloys Compd. 1995, 231, 880-887. [CrossRef]

145. Polanski, M.; Bystrzycki, J.; Varin, R.A.; Plocinski, T.; Pisarek, M. The effect of chromium (III) oxide $\left(\mathrm{Cr}_{2} \mathrm{O}_{3}\right)$ nanopowder on the microstructure and cyclic hydrogen storage behavior of magnesium hydride $\left(\mathrm{MgH}_{2}\right)$. J. Alloys Compd. 2011, 509, 2386-2391. [CrossRef]

146. Imamura, H.; Sakasai, N. Hydriding characteristics of Mg-based composites prepared using a ball mill. J. Alloys Compd. 1995, 231, 810-814. [CrossRef]

147. Imamura, H.; Sakasai, N.; Kajii, Y. Hydrogen absorption of Mg-Based composites prepared by mechanical milling: Factors affecting its characteristics. J. Alloys Compd. 1996, 232, 218-223. [CrossRef] 
148. Klyamkin, S.; Tarasov, B.; Straz, E.; Lukashev, R.; Gabis, I.; Evard, E.; Voyt, A. Ball milling synthesis and properties of hydrogen sorbents in magnesium hydride-graphite system. Международный научный журналАльтернативная энергетика и экология 2005, 1, 27-29.

149. Shang, C.; Guo, Z. Effect of carbon on hydrogen desorption and absorption of mechanically milled $\mathrm{MgH}_{2}$. J. Power Sources 2004, 129, 73-80. [CrossRef]

150. Wu, C.; Wang, P.; Yao, X.; Liu, C.; Chen, D.; Lu, G.; Cheng, H. Effect of carbon/noncarbon addition on hydrogen storage behaviors of magnesium hydride. J. Alloys Compd. 2006, 414, 259-264. [CrossRef]

151. Lillo-Ródenas, M.; Guo, Z.; Aguey-Zinsou, K.; Cazorla-Amorós, D.; Linares-Solano, A. Effects of different carbon materials on $\mathrm{MgH}_{2}$ decomposition. Carbon 2008, 46, 126-137. [CrossRef]

152. Rud, A.; Lakhnik, A.; Ivanchenko, V.; Uvarov, V.; Shkola, A.; Dekhtyarenko, V.; Ivaschuk, L.; Kuskova, N. Hydrogen storage of the Mg-C composites. Int. J. Hydrogen Energy 2008, 33, 1310-1316. [CrossRef]

153. Skripnyuk, V.M.; Rabkin, E.; Bendersky, L.; Magrez, A.; Carreño-Morelli, E.; Estrin, Y. Hydrogen storage properties of as-synthesized and severely deformed magnesium-multiwall carbon nanotubes composite. Int. J. Hydrogen Energy 2010, 35, 5471-5478. [CrossRef]

154. Chen, D.; Chen, L.; Liu, S.; Ma, C.; Chen, D.; Wang, L. Microstructure and hydrogen storage property of $\mathrm{Mg} / \mathrm{MWNTs}$ composites. J. Alloys Compd. 2004, 372, 231-237. [CrossRef]

155. Amirkhiz, B.S.; Danaie, M.; Mitlin, D. The influence of SWCNT-metallic nanoparticle mixtures on the desorption properties of milled $\mathrm{MgH}_{2}$ powders. Nanotechnology 2009, 20, 204016. [CrossRef] [PubMed]

156. Spassov, T.; Zlatanova, Z.; Spassova, M.; Todorova, S. Hydrogen sorption properties of ball-milled Mg-C nanocomposites. Int. J. Hydrogen Energy 2010, 35, 10396-10403. [CrossRef]

157. Huang, Z.; Guo, Z.; Calka, A.; Wexler, D.; Liu, H.-K. Effects of carbon black, graphite and carbon nanotube additives on hydrogen storage properties of magnesium. J. Alloys Compd. 2007, 427, 94-100. [CrossRef]

158. Rud, A.; Lakhnik, A. Effect of carbon allotropes on the structure and hydrogen sorption during reactive ball-milling of Mg-C powder mixtures. Int. J. Hydrogen Energy 2012, 37, 4179-4187. [CrossRef]

159. Balde, C.P.; Hereijgers, B.P.; Bitter, J.H.; Jong, K.P.d. Sodium alanate nanoparticles—Linking size to hydrogen storage properties. J. Am. Chem. Soc. 2008, 130, 6761-6765. [CrossRef] [PubMed]

160. Adelhelm, P.; De Jongh, P.E. The impact of carbon materials on the hydrogen storage properties of light metal hydrides. J. Mater. Chem. 2011, 21, 2417-2427. [CrossRef]

161. Sun, Z.; Lu, X.; Nyahuma, F.M.; Yan, N.; Xiao, J.; Su, S.; Zhang, L. Enhancing hydrogen storage properties of $\mathrm{MgH}_{2}$ by transition metals and carbon materials: A brief review. Front. Chem. 2020, 8, 552. [CrossRef]

162. Sakintuna, B.; Lamari-Darkrim, F.; Hirscher, M. Metal hydride materials for solid hydrogen storage: A review. Int. J. Hydrogen Energy 2007, 32, 1121-1140. [CrossRef]

163. Wu, C.; Cheng, H.-M. Effects of carbon on hydrogen storage performances of hydrides. J. Mater. Chem. 2010, 20, 5390-5400. [CrossRef]

164. Zhang, J.; Zhu, Y.; Yao, L.; Xu, C.; Liu, Y.; Li, L. State of the art multi-strategy improvement of Mg-based hydrides for hydrogen storage. J. Alloys Compd. 2019, 782, 796-823. [CrossRef]

165. Imamura, H.; Sakasai, N.; Fujinaga, T. Characterization and hydriding properties of Mg-graphite composites prepared by mechanical grinding as new hydrogen storage materials. J. Alloys Compd. 1997, 253, 34-37. [CrossRef]

166. Imamura, H.; Takesue, Y.; Akimoto, T.; Tabata, S. Hydrogen-absorbing magnesium composites prepared by mechanical grinding with graphite: Effects of additives on composite structures and hydriding properties. J. Alloys Compd. 1999, 293, 564-568. [CrossRef]

167. Imamura, H.; Kusuhara, M.; Minami, S.; Matsumoto, M.; Masanari, K.; Sakata, Y.; Itoh, K.; Fukunaga, T. Carbon nanocomposites synthesized by high-energy mechanical milling of graphite and magnesium for hydrogen storage. Acta Mater. 2003, 51, 6407-6414. [CrossRef]

168. Imamura, H.; Tabata, S.; Takesue, Y.; Sakata, Y.; Kamazaki, S. Hydriding-dehydriding behavior of magnesium composites obtained by mechanical grinding with graphite carbon. Int. J. Hydrogen Energy 2000, 25, 837-843. [CrossRef]

169. Imamura, H.; Tabata, S.; Shigetomi, N.; Takesue, Y.; Sakata, Y. Composites for hydrogen storage by mechanical grinding of graphite carbon and magnesium. J. Alloys Compd. 2002, 330, 579-583. [CrossRef]

170. Rashad, M.; Pan, F.; Zhang, J.; Asif, M. Use of high energy ball milling to study the role of graphene nanoplatelets and carbon nanotubes reinforced magnesium alloy. J. Alloys Compd. 2015, 646, $223-232$. [CrossRef] 
171. Xu, H.; Zou, N.; Li, Q. Effect of ball milling time on microstructure and hardness of porous magnesium/carbon nanofiber composites. JOM 2017, 69, 1236-1243. [CrossRef]

172. De Piccoli, C.; Dal Toè, S.; Lo Russo, S.; Maddalena, A.; Plade, P.; Saber, A.; Sartori, S.; Principi, G. Hydrogen storage in magnesium hydride doped with niobium pentaoxide and graphite. Chem. Eng. Trans. 2004, 4, 343-347.

173. Luo, Y.-C.; Meng, C.; Xu, S.-H.; FENG, C.; Kang, L. Microstructure and hydrogen storage performance of alloys Mg_xTi_(100-x) prepared by high-energy ball milling. J. Lanzhou Univ. Technol. 2011, 5, 4.

174. Tkacz, M.; Baranowski, B. Heats of formation and decomposition of nickel and $\mathrm{Ni}_{0.8} \mathrm{Cu}_{0.2}$ hydrides measured in high pressures of gaseous hydrogen. J. Less Common Met. 1985, 113, 83-87. [CrossRef]

175. De Castro, J.; Santos, S.; Costa, A.; Yavari, A.; Ishikawa, T. Structural characterization and dehydrogenation behavior of $\mathrm{Mg}-5$ at.\% $\mathrm{Nb}$ nano-composite processed by reactive milling. J. Alloys Compd. 2004, 376, 251-256. [CrossRef]

176. Gutfleisch, O.; Dal Toe, S.; Herrich, M.; Handstein, A.; Pratt, A. Hydrogen sorption properties of Mg-1 wt.\% $\mathrm{Ni}-0.2$ wt.\% Pd prepared by reactive milling. J. Alloys Compd. 2005, 404, 413-416. [CrossRef]

177. Lee, D.; Kwon, I.; Bobet, J.-L.; Song, M.Y. Effects on the $\mathrm{H}_{2}$-sorption properties of $\mathrm{Mg}$ of $\mathrm{Co}$ (with various sizes) and $\mathrm{CoO}$ addition by reactive grinding. J. Alloys Compd. 2004, 366, 279-288. [CrossRef]

178. Hanada, N.; Ichikawa, T.; Fujii, H. Catalytic effect of nanoparticle 3D-transition metals on hydrogen storage properties in magnesium hydride $\mathrm{MgH}_{2}$ prepared by mechanical milling. J. Phys. Chem. B 2005, 109, 7188-7194. [CrossRef] [PubMed]

179. Gennari, F.; Castro, F.; Urretavizcaya, G.; Meyer, G. Catalytic effect of Ge on hydrogen desorption from $\mathrm{MgH}_{2}$. J. Alloys Compd. 2002, 334, 277-284. [CrossRef]

180. Shahi, R.R.; Tiwari, A.P.; Shaz, M.A.; Srivastava, O.N. Studies on de/rehydrogenation characteristics of nanocrystalline $\mathrm{MgH}_{2}$ co-catalyzed with Ti, Fe and Ni. Int. J. Hydrogen Energy 2013, 38, 2778-2784. [CrossRef]

181. Wang, P.; Wang, A.; Zhang, H.; Ding, B.; Hu, Z. Hydrogenation characteristics of Mg-TiO 2 (rutile) composite. J. Alloys Compd. 2000, 313, 218-223. [CrossRef]

182. Song, M.Y.; Bobet, J.L.; Darriet, B. Improvement in hydrogen sorption properties of $\mathrm{Mg}$ by reactive mechanical grinding with $\mathrm{Cr}_{2} \mathrm{O}_{3}, \mathrm{Al}_{2} \mathrm{O}_{3}$ and $\mathrm{CeO}_{2}$. J. Alloys Compd. 2002, 340, 256-262. [CrossRef]

183. Song, M.; Kwon, I.; Kwon, S.; Park, C.; Park, H.; Bae, J.-S. Preparation of hydrogen-storage alloy Mg-10 wt $\%$ $\mathrm{Fe}_{2} \mathrm{O}_{3}$ under various milling conditions. Int. J. Hydrogen Energy 2006, 31, 43-47. [CrossRef]

184. Gennari, F.C.; Castro, F.J.; Urretavizcaya, G. Hydrogen desorption behavior from magnesium hydrides synthesized by reactive mechanical alloying. J. Alloys Compd. 2001, 321, 46-53. [CrossRef]

185. El-Eskandarany, M.S.; Shaban, E.; Al-Halaili, B. Nanocrystalline $\beta-\gamma-\beta$ cyclic phase transformation in reacted ball milled $\mathrm{MgH}_{2}$ powders. Int. J. Hydrogen Energy 2014, 39, 12727-12740. [CrossRef]

186. Wang, P.; Zhang, H.; Ding, B.; Hu, Z. Direct hydrogenation of Mg and decomposition behavior of the hydride formed. J. Alloys Compd. 2000, 313, 209-213. [CrossRef]

187. Huot, J.; Tremblay, M.-L.; Schulz, R. Synthesis of nanocrystalline hydrogen storage materials. J. Alloys Compd. 2003, 356, 603-607. [CrossRef]

188. Huang, Z.; Guo, Z.; Calka, A.; Wexler, D.; Liu, H.-K. Improvement in hydrogen cycling properties of magnesium through added graphite. Mater. Lett. 2007, 61, 3163-3166. [CrossRef]

189. Fuster, V.; Urretavizcaya, G.; Castro, F. Characterization of MgH2 formation by low-energy ball-milling of $\mathrm{Mg}$ and $\mathrm{Mg}+\mathrm{C}$ (graphite) mixtures under $\mathrm{H}_{2}$ atmosphere. J. Alloys Compd. 2009, 481, 673-680. [CrossRef]

190. Bobet, J.-L.; Grigorova, E.; Khrussanova, M.; Khristov, M.; Stefanov, P.; Peshev, P.; Radev, D. Hydrogen sorption properties of graphite-modified magnesium nanocomposites prepared by ball-milling. J. Alloys Compd. 2004, 366, 298-302. [CrossRef]

191. Huang, Z.; Guo, Z.; Calka, A.; Wexler, D.; Wu, J.; Notten, P.; Liu, H. Noticeable improvement in the desorption temperature from graphite in rehydrogenated $\mathrm{MgH}_{2}$ /graphite composite. Mater. Sci. Eng. A 2007, 447, 180-185. [CrossRef]

192. Hwang, S.-J.; Chuang, Y.-S. Enhanced hydrogen storage properties of $\mathrm{MgH}_{2}$ co-catalyzed with zirconium oxide and single-walled carbon nanotubes. J. Alloys Compd. 2016, 664, 284-290. [CrossRef]

193. An, G.-H.; Ahn, H.-J. Carbon nanofiber/cobalt oxide nanopyramid core-shell nanowires for high-performance lithium-ion batteries. J. Power Sources 2014, 272, 828-836. [CrossRef] 
194. Wang, Y.; Li, L.; An, C.; Wang, Y.; Chen, C.; Jiao, L.; Yuan, H. Facile synthesis of TiN decorated graphene and its enhanced catalytic effects on dehydrogenation performance of magnesium hydride. Nanoscale 2014, 6, 6684-6691. [CrossRef]

195. Ranjbar, A.; Ismail, M.; Guo, Z.; Yu, X.; Liu, H.-K. Effects of CNTs on the hydrogen storage properties of $\mathrm{MgH}_{2}$ and $\mathrm{MgH}_{2}-\mathrm{BCC}$ composite. Int. J. Hydrogen Energy 2010, 35, 7821-7826. [CrossRef]

196. Ismail, M.; Juahir, N.; Mustafa, N. Improved hydrogen storage properties of $\mathrm{MgH}_{2}$ co-doped with $\mathrm{FeCl}_{3}$ and carbon nanotubes. J. Phys. Chem. C 2014, 118, 18878-18883. [CrossRef]

197. Shahi, R.R.; Bhatnagar, A.; Pandey, S.K.; Dixit, V.; Srivastava, O. Effects of Ti-based catalysts and synergistic effect of SWCNTs-TiF 3 on hydrogen uptake and release from $\mathrm{MgH}_{2}$. Int. J. Hydrogen Energy 2014, 39, 14255-14261. [CrossRef]

198. Chuang, Y.-S.; Hwang, S.-J. Synthesis and hydrogen absorption/desorption properties of $\mathrm{Mg}-\mathrm{Nb}_{2} \mathrm{O}_{5}-\mathrm{SWCNT/MWCNT}$ nanocomposite prepared by reactive milling. J. Alloys Compd. 2016, 656, 835-842. [CrossRef]

199. An, C.; Liu, G.; Li, L.; Wang, Y.; Chen, C.; Wang, Y.; Jiao, L.; Yuan, H. In situ synthesized one-dimensional porous Ni@ C nanorods as catalysts for hydrogen storage properties of $\mathrm{MgH}_{2}$. Nanoscale 2014, 6, 3223-3230. [CrossRef]

200. Hudson, M.S.L.; Takahashi, K.; Ramesh, A.; Awasthi, S.; Ghosh, A.K.; Ravindran, P.; Srivastava, O.N. Graphene decorated with Fe nanoclusters for improving the hydrogen sorption kinetics of $\mathrm{MgH}_{2}$-experimental and theoretical evidence. Catal. Sci. Technol. 2016, 6, 261-268. [CrossRef]

201. Gross, A.F.; Ahn, C.C.; Van Atta, S.L.; Liu, P.; Vajo, J.J. Fabrication and hydrogen sorption behaviour of nanoparticulate $\mathrm{MgH}_{2}$ incorporated in a porous carbon host. Nanotechnology 2009, 20, 204005. [CrossRef]

202. Zhang, S.; Gross, A.F.; Van Atta, S.L.; Lopez, M.; Liu, P.; Ahn, C.C.; Vajo, J.J.; Jensen, C.M. The synthesis and hydrogen storage properties of a $\mathrm{MgH}_{2}$ incorporated carbon aerogel scaffold. Nanotechnology 2009, 20, 204027. [CrossRef]

203. Gibbins, S.G. Formation of a complex magnesium iron hydride. Abstr. Pap. Am. Chem. Soc. 1971, 155.

204. Reiser, A.; Bogdanović, B.; Schlichte, K. The application of Mg-based metal-hydrides as heat energy storage systems. Int. J. Hydrogen Energy 2000, 25, 425-430. [CrossRef]

205. Wang, Y.; Cheng, F.; Li, C.; Tao, Z.; Chen, J. Preparation and characterization of nanocrystalline $\mathrm{Mg}_{2} \mathrm{FeH}_{6}$. J. Alloys Compd. 2010, 508, 554-558. [CrossRef]

206. Nayeb-Hashemi, A.A.; Clark, J.B. The Fe-Mg (iron-magnesium) System. Bull. Alloy. Phase Diagr. 1985, 6, 236-238. [CrossRef]

207. Polanski, M.; Płociński, T.; Kunce, I.; Bystrzycki, J. Dynamic synthesis of ternary $\mathrm{Mg}_{2} \mathrm{FeH}_{6}$. Int. J. Hydrogen Energy 2010, 35, 1257-1266. [CrossRef]

208. Polanski, M.; Bystrzycki, J.; Varin, R.A.; Plocinski, T. Rapid hydrogenation at $30{ }^{\circ} \mathrm{C}$ of magnesium $(\mathrm{Mg})$ and iron $(\mathrm{Fe})$ nanocomposite obtained through a decomposition of $\mathrm{Mg}_{2} \mathrm{FeH}_{6}$ precursor. Int. J. Hydrogen Energy 2011, 36, 1059-1065. [CrossRef]

209. Polanski, M.; Witek, K.; Nielsen, T.K.; Jaroszewicz, L.; Bystrzycki, J. The influence of the milling time on the yield of $\mathrm{Mg}_{2} \mathrm{FeH}_{6}$ from a two-step synthesis conducted in a custom-made reactor. Int. J. Hydrogen Energy 2013, 38, 2785-2789. [CrossRef]

210. Witek, K.; Karczewski, K.; Karpowicz, M.; Polanski, M. $\mathrm{Mg}_{2} \mathrm{FeH}_{6}$ Synthesis Efficiency Map. Crystals 2018, 8, 94. [CrossRef]

211. Polanski, M.; Nielsen, T.K.; Cerenius, Y.; Bystrzycki, J.; Jensen, T.R. Synthesis and decomposition mechanisms of $\mathrm{Mg}_{2} \mathrm{FeH}_{6}$ studied by in-situ synchrotron X-ray diffraction and high-pressure DSC. Int. J. Hydrogen Energy 2010, 35, 3578-3582. [CrossRef]

212. Puszkiel, J.A.; Larochette, P.A.; Gennari, F.C. Thermodynamic and kinetic studies of Mg-Fe-H after mechanical milling followed by sintering. J. Alloys Compd. 2008, 463, 134-142. [CrossRef]

213. Puszkiel, J.A.; Larochette, R.A.; Gennari, F.C. Hydrogen storage properties of $\mathrm{Mg}(\mathrm{x}) \mathrm{Fe}$ (x: 2, 3 and 15) compounds produced by reactive ball milling. J. Power Sources 2009, 186, 185-193. [CrossRef]

214. Puszkiel, J.; Gennari, F.; Larochette, P.A.; Karimi, F.; Pistidda, C.; Gosalawit-Utke, R.; Jepsen, J.; Jensen, T.R.; Gundlach, C.; von Colbe, J.B.; et al. Sorption behavior of the $\mathrm{MgH}_{2}-\mathrm{Mg}_{2} \mathrm{FeH}_{6}$ hydride storage system synthesized by mechanical milling followed by sintering. Int. J. Hydrogen Energy 2013, 38, 14618-14630. [CrossRef] 
215. Farina, L.; Brutti, S.; Trequattrini, F.; Palumbo, O.; Gatto, S.; Reale, P.; Silvestri, L.; Panero, S.; Paolone, A. An extensive study of the $\mathrm{Mg}-\mathrm{Fe}-\mathrm{H}$ material obtained by reactive ball milling of $\mathrm{MgH}_{2}$ and $\mathrm{Fe}$ in a molar ratio 3:1. Int. J. Hydrogen Energy 2017, 42, 22333-22341. [CrossRef]

216. Selvam, P.; Yvon, K. Synthesis of $\mathrm{Mg}_{2} \mathrm{FeH}_{6}, \mathrm{Mg}_{2} \mathrm{CoH}_{5}$ and $\mathrm{Mg}_{2} \mathrm{NiH}_{4}$ by high-pressure sintering of the elements. Int. J. Hydrogen Energy 1991, 16, 615-617. [CrossRef]

217. Zhou, D.; Li, S.; Varin, R.; Peng, P.; Liu, J.; Yang, F. Mechanical alloying and electronic simulations of $2 \mathrm{Mg}-\mathrm{Fe}$ mixture powders for hydrogen storage. Mater. Sci. Eng. A 2006, 427, 306-315. [CrossRef]

218. Puszkiel, J.A.; Larochette, P.A.; Baruj, A.; Meyer, G.; Gennari, F.C. Hydrogen cycling properties of xMg-Fe materials (x: 2, 3 and 15) produced by reactive ball milling. Int. J. Hydrogen Energy 2016, 41, 1688-1698. [CrossRef]

219. Urbanczyk, R.; Peinecke, K.; Peil, S.; Felderhoff, M. Development of a heat storage demonstration unit on the basis of $\mathrm{Mg}_{2} \mathrm{FeH}_{6}$ as heat storage material and molten salt as heat transfer media. Int. J. Hydrogen Energy 2017, 42, 13818-13826. [CrossRef]

220. Zaïdi, W.; Bonnet, J.P.; Zhang, J.; Cuevas, F.; Latroche, M.; Couillaud, S.; Bobet, J.L.; Sougrati, M.T.; Jumas, J.C.; Aymard, L. Reactivity of complex hydrides $\mathrm{Mg}_{2} \mathrm{FeH}_{6}, \mathrm{Mg}_{2} \mathrm{CoH}_{5}$ and $\mathrm{Mg}_{2} \mathrm{NiH}_{4}$ with lithium ion: Far from equilibrium electrochemically driven conversion reactions. Int. J. Hydrogen Energy 2013, 38, 4798-4808. [CrossRef]

221. Hightower, A.; Fultz, B.; Bowman, R.C. Mechanical alloying of Fe and Mg. J. Alloys Compd. 1997, 252, 238-244. [CrossRef]

222. Huot, J.; Boily, S.; Akiba, E.; Schulz, R. Direct synthesis of $\mathrm{Mg}_{2} \mathrm{FeH}_{6}$ by mechanical alloying. J. Alloys Compd. 1998, 280, 306-309. [CrossRef]

223. Nyallang Nyamsi, S.; Yartys, V.; Lototskyy, M. Synthesis of $\mathrm{Mg}_{2} \mathrm{FeH}_{6}$ assisted by heat treatment of starting materials. Mater. Today: Proc. 2018, 5, 10533-10541. [CrossRef]

224. Puszkiel, J.; Castro Riglos, M.; Ramallo-López, J.; Mizrahi, M.; Gemming, T.; Pistidda, C.; Arneodo Larochette, P.; Bellosta von Colbe, J.; Klassen, T.; Dornheim, M.; et al. New Insight on the Hydrogen Absorption Evolution of the Mg-Fe-H System under Equilibrium Conditions. Metals 2018, 8, 967. [CrossRef]

225. Deledda, S.; Hauback, B. The formation mechanism and structural characterization of the mixed transition-metal complex hydride $\mathrm{Mg}_{2}\left(\mathrm{FeH}_{6}\right)_{0.5}\left(\mathrm{CoH}_{5}\right)_{0.5}$ obtained by reactive milling. Nanotechnology 2009, 20, 204010. [CrossRef] [PubMed]

226. Konstanchuk, I.; Ivanov, E.Y.; Pezat, M.; Darriet, B.; Boldyrev, V.; Hagenmuller, P. The hydriding properties of a mechanical alloy with composition Mg-25\% Fe. J. Less Common Met. 1987, 131, 181-189. [CrossRef]

227. Puszkiel, J.; Gennari, F. Reversible hydrogen storage in metal-doped Mg-LiBH 4 composites. Scr. Mater. 2009, 60, 667-670. [CrossRef]

228. Orimo, S.-I.; Nakamori, Y.; Kitahara, G.; Miwa, K.; Ohba, N.; Towata, S.-I.; Züttel, A. Dehydriding and rehydriding reactions of $\mathrm{LiBH}_{4}$. J. Alloys Compd. 2005, 404, 427-430. [CrossRef]

229. Luo, W. $\left(\mathrm{LiNH}_{2}-\mathrm{MgH}_{2}\right)$ : A viable hydrogen storage system. J. Alloys Compd. 2004, 381, 284-287. [CrossRef]

230. Vajo, J.J.; Skeith, S.L.; Mertens, F. Reversible storage of hydrogen in destabilized $\mathrm{LiBH}_{4}$. J. Phys. Chem. $B$ 2005, 109, 3719-3722. [CrossRef]

231. Gosselin, C.; Deledda, S.; Hauback, B.C.; Huot, J. Effect of synthesis route on the hydrogen storage properties of $2 \mathrm{MgH}_{2}-\mathrm{Fe}$ compound doped with $\mathrm{LiBH}_{4}$. J. Alloys Compd. 2015, 645, S304-S307. [CrossRef]

232. Deng, S.; Xiao, X.; Han, L.; Li, Y.; Li, S.; Ge, H.; Wang, Q.; Chen, L. Hydrogen storage performance of $5 \mathrm{LiBH}_{4}+$ $\mathrm{Mg}_{2} \mathrm{FeH}_{6}$ composite system. Int. J. Hydrogen Energy 2012, 37, 6733-6740. [CrossRef]

233. Li, G.; Matsuo, M.; Deledda, S.; Sato, R.; Hauback, B.C.; Orimo, S.I. Dehydriding Property of $\mathrm{LiBH}_{4} \mathrm{Combined}$ with $\mathrm{Mg}_{2} \mathrm{FeH}_{6}$. Mater. Trans. 2013, 54, 1532-1534. [CrossRef]

234. Asselli, A.A.C.; Huot, J. Investigation of effect of milling atmosphere and starting composition on $\mathrm{Mg}_{2} \mathrm{FeH}_{6}$ formation. Metals 2014, 4, 388-400. [CrossRef]

235. Li, S.L.; Varin, R.A.; Morozova, O.; Khomenko, T. Controlled mechano-chemical synthesis of nanostructured ternary complex hydride $\mathrm{Mg}_{2} \mathrm{FeH}_{6}$ under low-energy impact mode with and without pre-milling. J. Alloys Compd. 2004, 384, 231-248. [CrossRef]

236. Huen, P.; Ravnsbæk, D.B. All-solid-state lithium batteries-The $\mathrm{Mg}_{2} \mathrm{FeH}_{6}$-electrode $\mathrm{LiBH}_{4}$-electrolyte system. Electrochem. Commun. 2018, 87, 81-85. [CrossRef] 
237. Varin, R.A.; Li, S.; Wronski, Z.; Morozova, O.; Khomenko, T. The effect of sequential and continuous high-energy impact mode on the mechano-chemical synthesis of nanostructured complex hydride $\mathrm{Mg}_{2} \mathrm{FeH}_{6}$. J. Alloys Compd. 2005, 390, 282-296. [CrossRef]

238. Asselli, A.A.C.; Leiva, D.R.; Jorge, A.M.; Ishikawa, T.T.; Botta, W.J. Synthesis and hydrogen sorption properties of $\mathrm{Mg}_{2} \mathrm{FeH}_{6}-\mathrm{MgH}_{2}$ nanocomposite prepared by reactive milling. J. Alloys Compd. 2012, 536, S250-S254. [CrossRef]

239. Brutti, S.; Farina, L.; Trequattrini, F.; Palumbo, O.; Reale, P.; Silvestri, L.; Panero, S.; Paolone, A. Extremely Pure $\mathrm{Mg}_{2} \mathrm{FeH}_{6}$ as a Negative Electrode for Lithium Batteries. Energies 2018, 11, 1952. [CrossRef]

240. Varin, R.A.; Li, S.; Calka, A.; Wexler, D. Formation and environmental stability of nanocrystalline and amorphous hydrides in the $2 \mathrm{Mg}$-Fe mixture processed by controlled reactive mechanical alloying (CRMA). J. Alloys Compd. 2004, 373, 270-286. [CrossRef]

241. Herbst, J.; Hector, L., Jr. Structural discrimination via density functional theory and lattice dynamics: Monoclinic $\mathrm{Mg}_{2} \mathrm{NiH}_{4}$. Phys. Rev. B 2009, 79, 155113. [CrossRef]

242. Fadonougbo, J.O.; Kim, H.-J.; Suh, B.-C.; Suh, J.-Y.; Lee, Y.-S.; Shim, J.-H.; Yim, C.D.; Cho, Y.W. Kinetics and thermodynamics of near eutectic $\mathrm{Mg}-\mathrm{Mg}_{2} \mathrm{Ni}$ composites produced by casting process. Int. J. Hydrogen Energy 2020. [CrossRef]

243. Darnaudery, J.; Darriet, B.; Pezat, M. The $\mathrm{Mg}_{2} \mathrm{Ni}_{0.75} \mathrm{M}_{0.25}$ alloys ( $\mathrm{M}=3 \mathrm{D}$ element): Their application to hydrogen storage. Int. J. Hydrogen Energy 1983, 8, 705-708. [CrossRef]

244. Zadorozhnyy, V.; Klyamkin, S.; Zadorozhnyy, M.; Bermesheva, O.; Kaloshkin, S. Hydrogen storage nanocrystalline TiFe intermetallic compound: Synthesis by mechanical alloying and compacting. Int. J. Hydrogen Energy 2012, 37, 17131-17136. [CrossRef]

245. Singh, A.K.; Singh, A.K.; Srivastava, O. On the synthesis of the $\mathrm{Mg}_{2} \mathrm{Ni}$ alloy by mechanical alloying. J. Alloys Compd. 1995, 227, 63-68. [CrossRef]

246. Zaluski, L.; Zaluska, A.; Ström-Olsen, J. Hydrogen absorption in nanocrystalline $\mathrm{Mg}_{2} \mathrm{Ni}$ formed by mechanical alloying. J. Alloys Compd. 1995, 217, 245-249. [CrossRef]

247. Rönnebro, E.; Noréus, D. Surface sensitivity of $\mathrm{Mg}_{2} \mathrm{NiH}_{4}$ leading to a profound color change. Appl. Surf. Sci. 2004, 228, 115-119. [CrossRef]

248. Javadian, P.; Zlotea, C.; Ghimbeu, C.M.; Latroche, M.; Jensen, T.R. Hydrogen storage properties of nanoconfined LiBH4-Mg2NiH4 reactive hydride composites. J. Phys. Chem. C 2015, 119, 5819-5826. [CrossRef]

249. Vajo, J.J.; Li, W.; Liu, P. Thermodynamic and kinetic destabilization in $\mathrm{LiBH}_{4} / \mathrm{Mg}_{2} \mathrm{NiH}_{4}$ : Promise for borohydride-based hydrogen storage. Chem. Commun. 2010, 46, 6687-6689. [CrossRef]

250. Gavra, Z.; Mintz, M.; Kimmel, G.; Hadari, Z. Allotropic transitions of magnesium nickel hydride $\left(\mathrm{Mg}_{2} \mathrm{NiH}_{4}\right)$. Inorg. Chem. 1979, 18, 3595-3597. [CrossRef]

251. Lelis, M.; Milcius, D.; Wirth, E.; Hålenius, U.; Eriksson, L.; Jansson, K.; Kadir, K.; Ruan, J.; Sato, T.; Yokosawa, T. A mechanically switchable metal-insulator transition in $\mathrm{Mg}_{2} \mathrm{NiH}_{4}$ discovers a strain sensitive, nanoscale modulated resistivity connected to a stacking fault. J. Alloys Compd. 2010, 496, 81-86. [CrossRef]

252. Post, M.; Murray, J. $\mathrm{Mg}_{2} \mathrm{Ni}$ hydride: In situ heat conduction calorimetry of the phase transition near $510 \mathrm{~K}$. J. Less Common Met. 1987, 134, 15-26. [CrossRef]

253. Zolliker, P.; Yvon, K.; Jorgensen, J.; Rotella, F. Structural studies of the hydrogen storage material magnesium nickel hydride $\left(\mathrm{Mg}_{2} \mathrm{NiH}_{4}\right)$. 2. Monoclinic low-temperature structure. Inorg. Chem. 1986, 25, 3590-3593. [CrossRef]

254. Polanski, M.; Nielsen, T.K.; Kunce, I.; Norek, M.; Płociński, T.; Jaroszewicz, L.R.; Gundlach, C.; Jensen, T.R.; Bystrzycki, J. $\mathrm{Mg}_{2} \mathrm{NiH}_{4}$ synthesis and decomposition reactions. Int. J. Hydrogen Energy 2013, 38, 4003-4010. [CrossRef]

255. Noréus, D.; Kihlborg, L. Twinning at the unit cell level in the low temperature phase of $\mathrm{Mg}_{2} \mathrm{NiH}_{4}$ studied by electron microscopy. J. Less Common Met. 1986, 123, 233-239. [CrossRef]

256. Hayakawa, H.; Ishido, Y.; Nomura, K.; Uruno, H.; Ono, S. Phase transformations among three polymorphs of $\mathrm{Mg}_{2} \mathrm{NiH}_{4}$. J. Less Common Met. 1984, 103, 277-283. [CrossRef]

257. Li, L.; Akiyama, T.; Yagi, J.-I. Activity and capacity of hydrogen storage alloy $\mathrm{Mg}_{2} \mathrm{NiH}_{4}$ produced by hydriding combustion synthesis. J. Alloys Compd. 2001, 316, 118-123. [CrossRef]

258. Saita, I.; Li, L.; Saito, K.; Akiyama, T. Hydriding combustion synthesis of $\mathrm{Mg}_{2} \mathrm{NiH}_{4}$. J. Alloys Compd. 2003, 356, 490-493. [CrossRef] 
259. Li, L.; Akiyama, T.; Yagi, J.-i. Reaction mechanism of hydriding combustion synthesis of $\mathrm{Mg}_{2} \mathrm{NiH}_{4}$. Intermetallics 1999, 7, 671-677. [CrossRef]

260. Saita, I.; Li, L.; Saito, K.; Akiyama, T. Pressure-Composition-Temperature properties of hydriding combustion-synthesized $\mathrm{Mg}_{2} \mathrm{NiH}_{4}$. Mater. Trans. 2002, 43, 1100-1104. [CrossRef]

261. Bowman, R.C.; Fultz, B. Metallic hydrides I: Hydrogen storage and other gas-phase applications. Mrs Bull. 2002, 27, 688-693. [CrossRef]

262. Baum, L.A.; Meyer, M.; Mendoza-Zélis, L. Complex Mg-based hydrides obtained by mechanosynthesis: Characterization and formation kinetics. Int. J. Hydrogen Energy 2008, 33, 3442-3446. [CrossRef]

263. Liu, X.; Zhu, Y.; Li, L. Hydriding characteristics of $\mathrm{Mg}_{2} \mathrm{Ni}$ prepared by mechanical milling of the product of hydriding combustion synthesis. Int. J. Hydrogen Energy 2007, 32, 2450-2454. [CrossRef]

264. Aoyagi, H.; Aoki, K.; Masumoto, T. Effect of ball milling on hydrogen absorption properties of FeTi, $\mathrm{Mg}_{2} \mathrm{Ni}$ and $\mathrm{LaNi}_{5}$. J. Alloys Compd. 1995, 231, 804-809. [CrossRef]

265. Martinez-Coronado, R.; Retuerto, M.; Alonso, J. Simplified mechano-synthesis procedure of $\mathrm{Mg}_{2} \mathrm{NiH}_{4}$. Int. J. Hydrogen Energy 2012, 37, 4188-4193. [CrossRef]

266. Orimo, S.; Fujii, H.; Ikeda, K. Notable hydriding properties of a nanostructured composite material of the $\mathrm{Mg}_{2} \mathrm{Ni}-\mathrm{H}$ system synthesized by reactive mechanical grinding. Acta Mater. 1997, 45, 331-341. [CrossRef]

267. Blomqvist, H.; Noreus, D. Mechanically reversible conductor-insulator transition in $\mathrm{Mg}_{2} \mathrm{NiH}_{4}$. J. Appl. Phys. 2002, 91, 5141-5148. [CrossRef]

268. Nohara, S.; Inoue, H.; Fukumoto, Y.; Iwakura, C. Effect of surface modification of an MgNi alloy with graphite by ball-milling on the rate of hydrogen absorption. J. Alloys Compd. 1997, 252, L16-L18. [CrossRef]

269. Bouaricha, S.; Dodelet, J.; Guay, D.; Huot, J.; Boily, S.; Schulz, R. Effect of carbon-containing compounds on the hydriding behavior of nanocrystalline $\mathrm{Mg}_{2} \mathrm{Ni}$. J. Alloys Compd. 2000, 307, 226-233. [CrossRef]

270. Zhang, J.; Zhou, D.-W.; Liu, J.-S. First-principles investigation of $\mathrm{Mg}_{2} \mathrm{CoH}_{5}$ complex hydride. Trans. Nonferrous Met. Soc. China 2009, 19, 205-209. [CrossRef]

271. Zolliker, P.; Yvon, K.; Fischer, P.; Schefer, J. Dimagnesium cobalt(I) pentahydride, $\mathrm{Mg}_{2} \mathrm{CoH}_{5}$, containing square-pyramidal pentahydrocobaltate $\mathrm{CoH}_{5}{ }^{4-}$ anions. Inorg. Chem. 1985, 24, 4177-4180. [CrossRef]

272. Ivanov, E.Y.; Konstanchuk, I.; Stepanov, A.; Jie, Y.; Pezat, M.; Darriet, B. The ternary system magnesium-cobalt-hydrogen. Inorg. Chem. 1989, 28, 613-615. [CrossRef]

273. Černý, R.; Bonhomme, F.; Yvon, K.; Fischer, P.; Zolliker, P.; Cox, D.; Hewat, A. Hexamagnesium dicobalt undecadeuteride $\mathrm{Mg}_{6} \mathrm{Co}_{2} \mathrm{D}_{11}$ : Containing $\left[\mathrm{CoD}_{4}\right]^{5-}$ and $\left[\mathrm{CoD}_{5}\right]^{4-}$ complex anions conforming to the 18-electron rule. J. Alloys Compd. 1992, 187, 233-241. [CrossRef]

274. Shao, H.; Xu, H.; Wang, Y.; Li, X. Synthesis and hydrogen storage behavior of Mg-Co-H system at nanometer scale. J. Solid State Chem. 2004, 177, 3626-3632. [CrossRef]

275. González Fernández, I.; Gennari, F.C.; Meyer, G.O. Influence of sintering parameters on formation of Mg-Co hydrides based on their thermodynamic characterization. J. Alloys Compd. 2008, 462, 119-124. [CrossRef]

276. Norek, M.; Nielsen, T.K.; Polanski, M.; Kunce, I.; Płociński, T.; Jaroszewicz, L.R.; Cerenius, Y.; Jensen, T.R.; Bystrzycki, J. Synthesis and decomposition mechanisms of ternary $\mathrm{Mg}_{2} \mathrm{CoH}_{5}$ studied using in situ synchrotron X-ray diffraction. Int. J. Hydrogen Energy 2011, 36, 10760-10770. [CrossRef]

277. Zepon, G.; Leiva, D.; Kaufman, M.; Figueroa, S.J.A.; Floriano, R.; Lamas, D.G.; Asselli, A.; Botta, W. Controlled mechanochemical synthesis and hydrogen desorption mechanisms of nanostructured $\mathrm{Mg}_{2} \mathrm{CoH}_{5}$. Int. J. Hydrogen Energy 2015, 40, 1504-1515. [CrossRef]

278. Leiva, D.R.; Zepon, G.; Asselli, A.A.; Fruchart, D.; Miraglia, S.; Ishikawa, T.T.; Botta, W.J. Mechanochemistry and $\mathrm{H}$-sorption properties of $\mathrm{Mg}_{2} \mathrm{FeH}_{6}$-based nanocomposites. Int. J. Mater. Res. 2012, 103, 1147-1154. [CrossRef]

279. Verón, M.G.; Gennari, F.C. Thermodynamic behavior of the Mg-Co-H system: The effect of hydrogen cycling. J. Alloys Compd. 2014, 614, 317-322. [CrossRef]

280. Verón, M.G.; Condó, A.M.; Gennari, F.C. Effective synthesis of $\mathrm{Mg}_{2} \mathrm{CoH}_{5}$ by reactive mechanical milling and its hydrogen sorption behavior after cycling. Int. J. Hydrogen Energy 2013, 38, 973-981. [CrossRef]

281. Chen, J.; Takeshita, H.; Chartouni, D.; Kuriyama, N.; Sakai, T. Synthesis and characterization of nanocrystalline $\mathrm{Mg}_{2} \mathrm{CoH}_{5}$ obtained by mechanical alloying. J. Mater. Sci. 2001, 36, 5829-5834. [CrossRef]

(C) 2020 by the authors. Licensee MDPI, Basel, Switzerland. This article is an open access article distributed under the terms and conditions of the Creative Commons Attribution (CC BY) license (http://creativecommons.org/licenses/by/4.0/). 